\title{
Computational Fluid Dynamics
} Modeling to Simulate a Combined Reforming Process for Syngas and Hydrogen Production

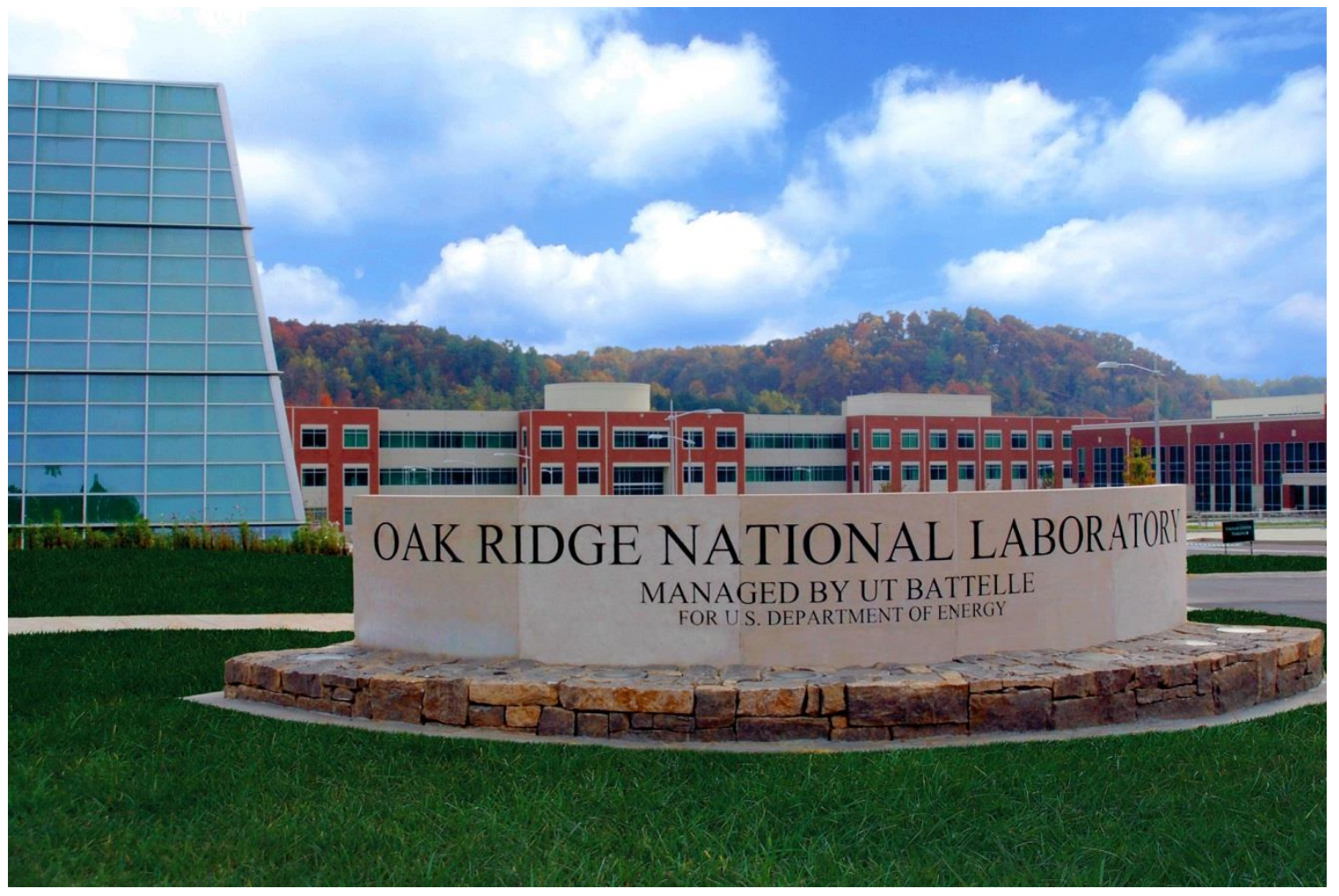

Prashant K. Jain Min-Tsung Kao

Vivek M. Rao Emilian L. Popov Duy Thien Nguyen Jamie Wilson Vittorio Badalassi Approved for public release. W. David Pointer

November 2021 


\title{
DOCUMENT AVAILABILITY
}

Reports produced after January 1, 1996, are generally available free via OSTI.GOV.

Website www.osti.gov

Reports produced before January 1, 1996, may be purchased by members of the public from the following source:

National Technical Information Service

5285 Port Royal Road

Springfield, VA 22161

Telephone 703-605-6000 (1-800-553-6847)

TDD 703-487-4639

Fax 703-605-6900

E-mail info@ntis.gov

Website http://classic.ntis.gov/

Reports are available to DOE employees, DOE contractors, Energy Technology Data Exchange representatives, and International Nuclear Information System representatives from the following source:

Office of Scientific and Technical Information

PO Box 62

Oak Ridge, TN 37831

Telephone 865-576-8401

Fax 865-576-5728

E-mail reports@osti.gov

Website https://www.osti.gov/

\begin{abstract}
This report was prepared as an account of work sponsored by an agency of the United States Government. Neither the United States Government nor any agency thereof, nor any of their employees, makes any warranty, express or implied, or assumes any legal liability or responsibility for the accuracy, completeness, or usefulness of any information, apparatus, product, or process disclosed, or represents that its use would not infringe privately owned rights. Reference herein to any specific commercial product, process, or service by trade name, trademark, manufacturer, or otherwise, does not necessarily constitute or imply its endorsement, recommendation, or favoring by the United States Government or any agency thereof. The views and opinions of authors expressed herein do not necessarily state or reflect those of the United States Government or any agency thereof.
\end{abstract}


ORNL/TM-2021/2313

CRADA/ NFE-20-08198

Nuclear Energy and Fuel Cycle Division

\title{
COMPUTATIONAL FLUID DYNAMICS MODELING TO SIMULATE A COMBINED REFORMING PROCESS FOR SYNGAS AND HYDROGEN PRODUCTION
}

\author{
Prashant K. Jain* \\ Min-Tsung Kao* \\ Vivek M. Rao* \\ Emilian L. Popov* \\ Duy Thien Nguyen* \\ Jamie Wilson $\dagger$ \\ Vittorio Badalassi* \\ W. David Pointer*
}

* Oak Ridge National Laboratory

$\uparrow$ Linde Corporation

November 2021

\author{
Prepared by \\ OAK RIDGE NATIONAL LABORATORY \\ Oak Ridge, TN 37831 \\ managed by \\ UT-BATTELLE LLC \\ for the \\ US DEPARTMENT OF ENERGY \\ under contract DE-AC05-00OR22725
}





\section{CONTENTS}

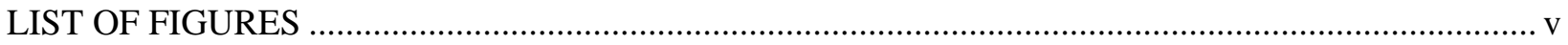

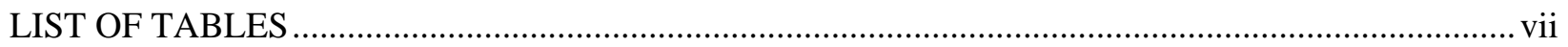

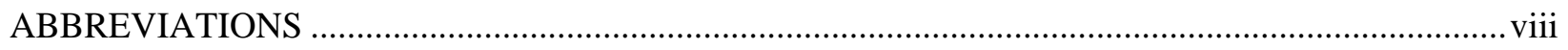

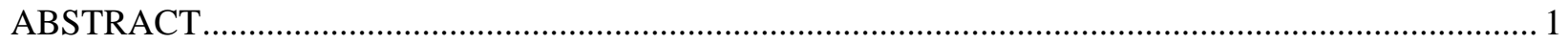

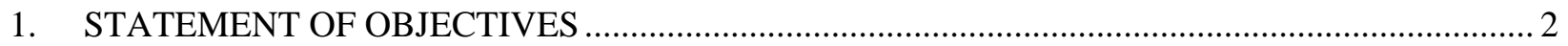

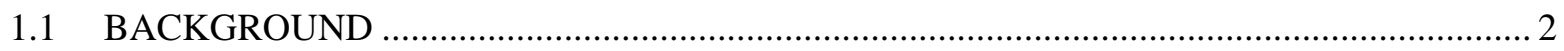

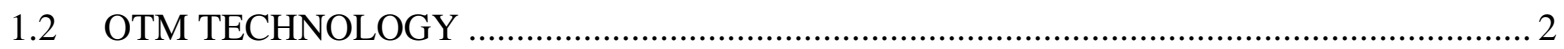

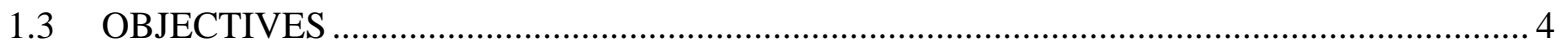

2. BENEFITS TO THE DOE FUNDING OFFICE'S MISSION …................................................ 5

3. TECHNICAL DISCUSSION OF WORK PERFORMED BY ALL PARTIES ................................. 6

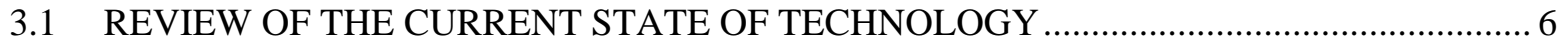

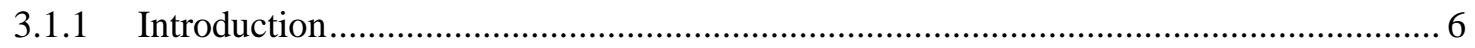

3.1.2 Hydrogen Production from Fossil Fuels .................................................................. 7

3.1.3 Hydrogen Production from Renewable Sources ........................................................ 15

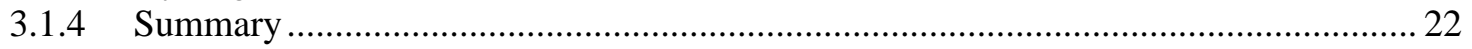

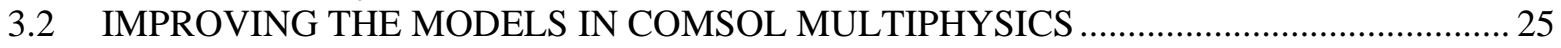

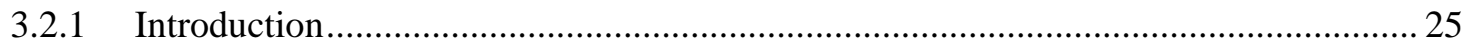

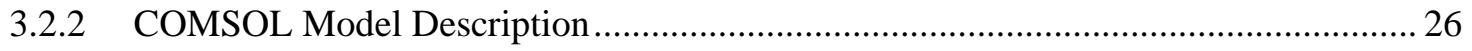

3.2.3 Material Properties, Boundary Conditions, and Physics Models ................................ 29

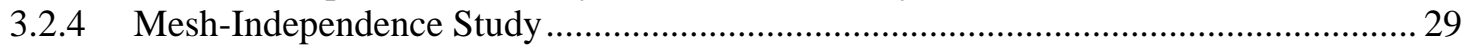

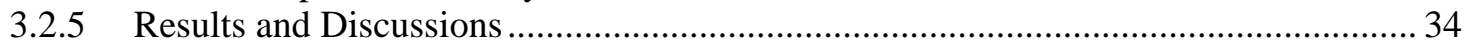

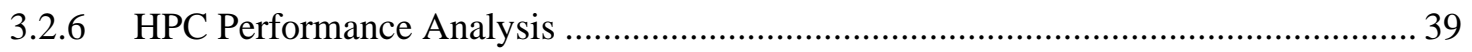

3.3 DEVELOPING A HIGH-FIDELITY CFD MODEL IN STAR-CCM+ .......................... 41

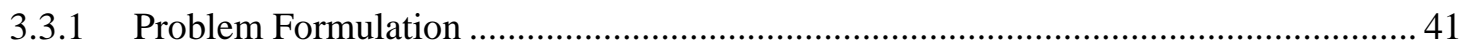

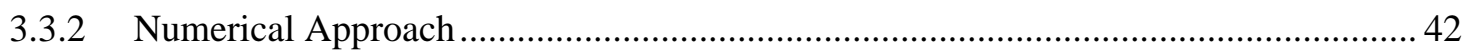

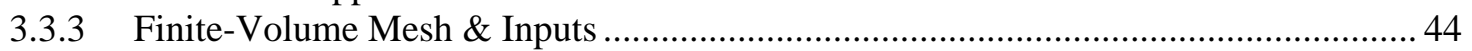

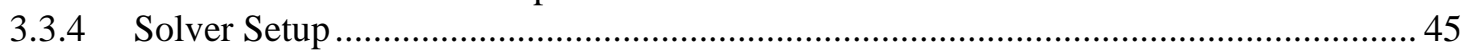

3.3.5 StarCCM+ Results: Simple Reacting Flow in the OTM Tube .................................. 45

3.3.6 StarCCM+ Results: Modeling Oxygen Influx for the Reforming Reaction ................ 46

3.3.7 StarCCM+ Results: Simulation of Reforming and Combustion Reactions ................... 47

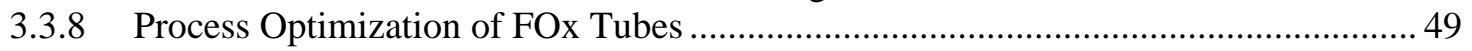

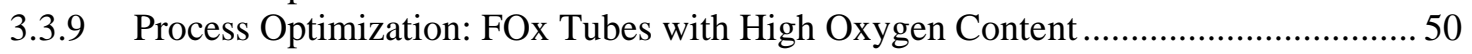

3.3.10 Process Optimization: FOx Tubes with Low Oxygen Content.................................. 51

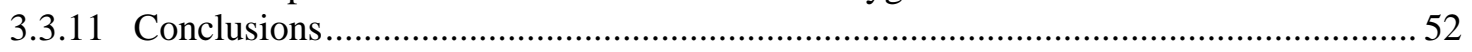

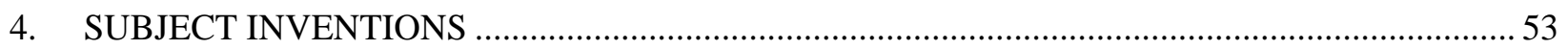

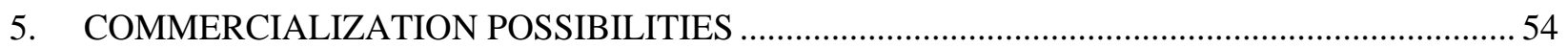

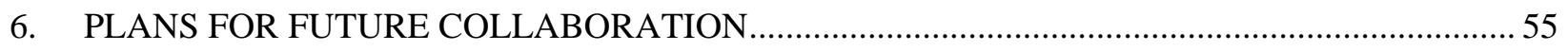

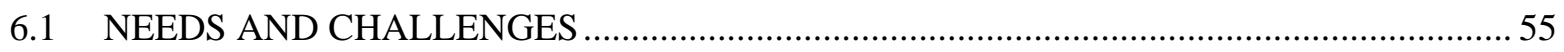

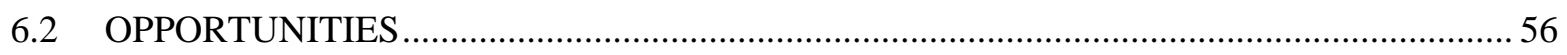

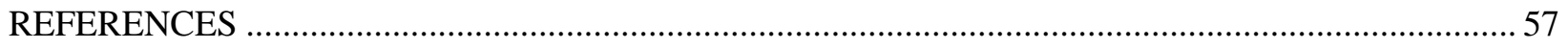





\section{LIST OF FIGURES}

Figure 1. OTM technology—integrated combined reformer panel array (Li 2015).............................. 3

Figure 2. Combined reforming in a single integrated, efficient package (Li 2018)................................. 4

Figure 3.H2@Scale vision showing that hydrogen can be produced from fossil fuels and renewable sources. Hydrogen is also a central input to many important end uses in the industrial, chemical, and transportation sectors (www.energy.gov/eere/fuelcells/h2scale). .......... 7

Figure 4. Hydrogen production processes from fossil fuels (adapted from Nikolaidis and

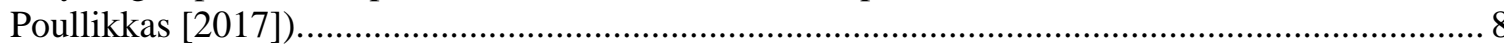

Figure 5. Hydrogen production processes from renewable sources (adapted from Nikolaidis and

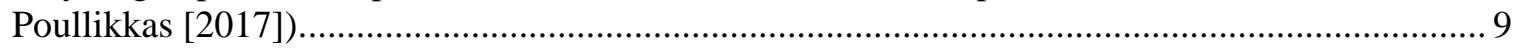

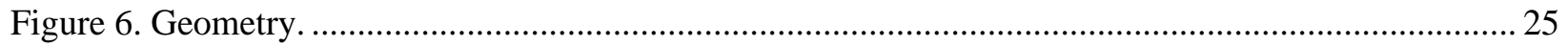

Figure 7. Chemical reactions in the oxygen transport membrane (OTM) tubes................................... 26

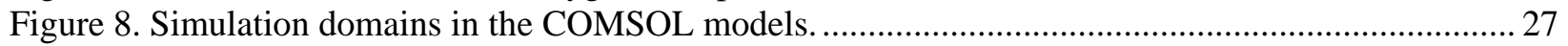

Figure 9. Reaction coefficients from gPROMS® (The $\mathrm{x}$ axis label is molar fraction for (a) and (c)

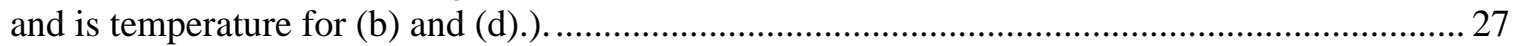

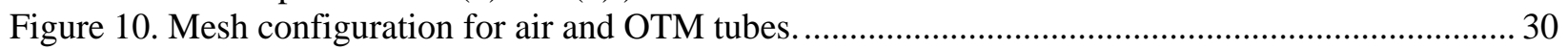

Figure 11. Different mesh configurations for the mesh-independence study ....................................... 30

Figure 12. Temperature distributions for different mesh configurations (color scale is redacted)............. 31

Figure 13. Mass fraction of $\mathrm{CO}(\%)$ for different mesh configurations (color scale is redacted)............... 31

Figure 14. Mass fraction of $\mathrm{CO}_{2}(\%)$ for different mesh configurations (color scale is redacted). ............ 32

Figure 15. Mass fraction of $\mathrm{H}_{2} \mathrm{O}(\%)$ for different mesh configurations (color scale is redacted). ............ 32

Figure 16. Mass fraction of $\mathrm{H}_{2}(\%)$ for different mesh configurations (color scale is redacted)............... 33

Figure 17. Mass fraction of $\mathrm{CH}_{4}(\%)$ for different mesh configurations (color scale is redacted). ............ 33

Figure 18. Temperature distribution for air and OTM tubes (color scale and values are redacted). .......... 34

Figure 19. Velocity distribution in the OTM tubes (color scale is redacted) ............................................ 35

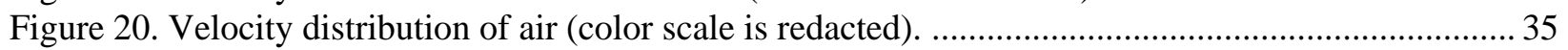

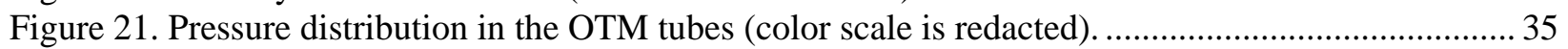

Figure 22. The molar concentration of $\mathrm{O}_{2}\left(\mathrm{~mol} / \mathrm{m}^{3}\right)$ (color scale is redacted) ........................................ 36

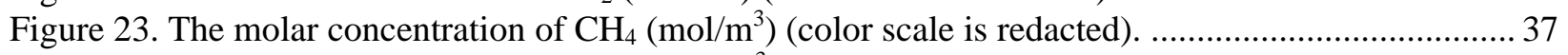

Figure 24. The molar concentration of $\mathrm{H}_{2} \mathrm{O}\left(\mathrm{mol} / \mathrm{m}^{3}\right)$ (color scale is redacted). .................................. 37

Figure 25. The molar concentration of $\mathrm{H}_{2}\left(\mathrm{~mol} / \mathrm{m}^{3}\right)$ (color scale is redacted) ....................................... 38

Figure 26. The molar concentration of $\mathrm{CO}\left(\mathrm{mol} / \mathrm{m}^{3}\right)$ (color scale is redacted)..................................... 38

Figure 27. The molar concentration of $\mathrm{CO}_{2}\left(\mathrm{~mol} / \mathrm{m}^{3}\right)$ (color scale is redacted). ................................... 39

Figure 28. HPC strong scaling speedup for Mesh_2 and Mesh_3 .................................................... 40

Figure 29. An array of OTM tubes: physical model (top) and computational model (bottom)................. 41

Figure 30. A sectional view of fluid streams and solid volumes within a single OTM tube..................... 42

Figure 31. Detailed representation of flow streams and electrochemical reactions in the porous

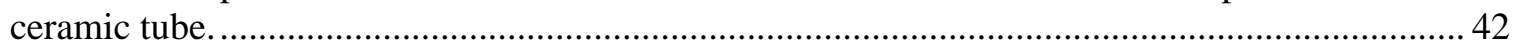

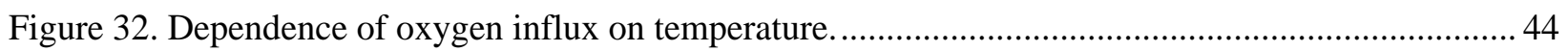

Figure 33. A representative cross-section of the finite-volume mesh on the OTM tube array.................. 45

Figure 34. Axial distribution of temperature in FOx tubes and air (color scale is redacted).................... 46

Figure 35. Reforming reaction: axial distribution of temperature in FOx tubes and air (color scale

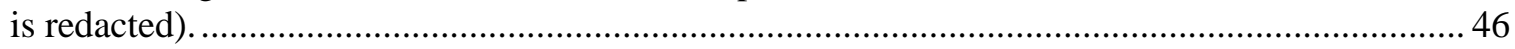

Figure 36. Reforming reaction: axial distribution of gas species (top - carbon dioxide, middle methane, bottom - hydrogen) in FOx tubes (color scale is redacted) ....................................... 47

Figure 37. Reforming and combustion reactions: axial distribution of temperature in the FOx tubes and air (color scale is redacted). 
Figure 38. Reforming and combustion reactions: axial distribution of species (top - carbon dioxide, middle - methane, bottom - hydrogen) in the FOx tubes (color scale is redacted)

Figure 39. Reforming and combustion reactions: axial distribution of oxidation species (top carbon dioxide, middle - methane, bottom - hydrogen) in the FOx tubes.....

Figure 40. High-oxygen sweep: yields of species sorted by decreasing yield of hydrogen....................... 50

Figure 41. High-oxygen sweep: trends of yield dependency on species. ............................................ 51

Figure 42. Low-oxygen sweep: yields of species sorted by decreasing yield of hydrogen. ...................... 51

Figure 43. Low-oxygen sweep: trends of yield dependency on species. ............................................ 52

Figure 44. A summary of yield by species for all parametric designs................................................... 52 


\section{LIST OF TABLES}

Table 1. Summary of hydrogen production processes, adapted from Nikolaidis and Poullikkas

$$
\text { (2017) }
$$

Table 2. HPC strong scaling speedup for Mesh_2

Table 3. HPC strong scaling speedup for Mesh_3 


\section{ABBREVIATIONS}

AMO

ASU

ATR

CCUS

CMC

CSO-SFMO

DOE

fp

HER

HPC

HTGR

HTM

HTSE

ITM

JAEA

LSCN

NG

OCRM

OER

OTM

PAH

PEM

POX

PSA

SI

SLPM

SMR

SOEC

STP

WGS

WSP
Advanced Manufacturing Office

air separation unit

autothermal reforming

carbon capture, utilization, and storage

carboxymethylcellulose

$\mathrm{Ce}_{0.8} \mathrm{Sm}_{0.2} \mathrm{O}_{2-\delta-40} \mathrm{Sr}_{2} \mathrm{Fe}_{1.5} \mathrm{Mo}_{0.5} \mathrm{O}_{5+\delta}$

US Department of Energy

free and porous media flow

hydrogen evolution reaction

high-performance computing

high-temperature gas-cooled reactor

hydrogen transport membrane

high-temperature steam electrolysis

ion transport membrane

Japan Atomic Energy Agency

$\mathrm{La}_{0.6} \mathrm{Sr}_{0.4} \mathrm{Co}_{0.8} \mathrm{Ni}_{0.2} \mathrm{O}_{3-\delta}$

natural gas

oxy- $\mathrm{CO}_{2}$ reforming methane

oxygen evolution reaction

oxygen transport membrane

polycyclic aromatic hydrocarbon

proton exchange membrane

partial oxidation

pressure swing adsorption

sulfur-iodine

standard liter per minute

steam methane reforming

solid oxide electrolysis cell

standard conditions for temperature and pressure

water-gas shift

Westinghouse hybrid sulfur process 



\begin{abstract}
An Oxygen Transport Membrane (OTM) combined reforming technology for producing syngas and hydrogen integrates the advantages of multiple processes - steam methane reforming (SMR), autothermal reforming (ATR), an air separation unit (ASU) — into a single integrated technology. The OTM consists of a primary reforming tube, in which desulfurized natural gas is partially reformed by steam at high pressure in the presence of a metal catalyst. This process is followed in series by a ceramic OTM with a secondary reformer, in which residual methane reforms and $\mathrm{O}^{2-}$ ions react with a portion of the $\mathrm{CO}$ and $\mathrm{H}_{2}$ fuel to provide the heat to support both primary and secondary reforming.
\end{abstract}

Although the OTM combined reformer technology for syngas and $\mathrm{H}_{2}$ production has been substantially developed in the last decade, several challenges that affect the overall production efficiency and reliability are yet to be fully understood, addressed, and resolved. Therefore, developing Computational Fluid Dynamics (CFD) models that incorporate fluid dynamics, mass transport, kinetics, heat transport, and structural mechanics is critical to understanding and minimizing the probability of tube failures during the startup and operation.

In this report, an exhaustive literature review was performed to survey the current state of technology for producing syngas and $\mathrm{H}_{2}$ using either conventional or renewable energy sources. The feedstocks reviewed include natural gas and coal for the conventional technologies, whereas biomass, solar, wind, and nuclear energy for the renewable technologies.

The existing industry-grade COMSOL multiphysics models of OTM were upgraded for the latest software release. In addition, they were improved to help achieve grid and solver independence and were successfully ported on the ORNL high-performance computing clusters to speed up their run times. A $42 \%$ reduction in the simulation run time was achieved.

A new higher-fidelity CFD model of an OTM tube was developed in the StarCCM+ simulation platform. This new model was designed to simulate various physics using first principles, e.g., turbulent flow, heat transfer, and chemical reactions while avoiding unnecessary simplifications. The resulting predictions were qualitatively assessed and provided useful insights into the multiphysics complexity of an OTM tube. 


\section{STATEMENT OF OBJECTIVES}

\subsection{BACKGROUND}

Synthesis gas, or syngas, is a fuel mixture composed of carbon monoxide, and hydrogen. It is primarily produced via gasification of a carbon-containing fuel such as natural gas, coal, biomass, or another hydrocarbon feedstock. Syngas is a crucial intermediate resource for many refineries, metallurgical facilities, and chemical industries when producing hydrogen, carbon monoxide, ammonia, methanol, and synthetic gasoline and diesel fuels.

Steam-methane reforming (SMR) is a widely adopted process for production of syngas, wherein methane in natural gas partially reacts with steam at high temperature $\left(700-1000^{\circ} \mathrm{C}\right)$, in the presence of a catalyst. Sometimes, high purity $\mathrm{O}_{2}$ is added in a secondary autothermal reforming (ATR) step to increase the methane conversion and modify the $\mathrm{H}_{2} / \mathrm{CO}$ ratio of the syngas product. Traditionally, the oxygen is supplied by a cryogenic air separation unit (ASU), which accounts for a significant portion of the capital costs and imposes a significant energy requirement on the combined reforming process (SMR and ATR). In addition, these processes are known for high rates of carbon dioxide emissions.

Oxygen Transport Membrane (OTM), a relatively new technology, has undergone significant research and development to convert methane to syngas, a reaction that consumes oxygen. Most OTM materials are permeable to only oxygen at temperatures higher than $700^{\circ} \mathrm{C}$. However, the thermal energy required to heat OTMs is found to be significantly less than that for other forms of oxygen production. Integrating OTMs into the energy production process can reduce energy consumption and production cost by $35 \%$ compared to the conventional oxygen separation technology (Gupta et al., 2015).

The heat required for the ceramic based OTMs can be acquired from heat exchange with boiler and flue gas circulation. Despite many advantages, OTMs have not been widely applied in the industry because of their low chemical stability (Yang et al. 2005) and the need for high temperature sealing technology.

Recently, industries such as Praxair (Bonaquist et al. 2004) and AZEP (Sundkvist et al. 2007) performed numerous studies to improve these aspects and applied OTMs into their industrial processes that required an oxygen stream.

An integrated OTM and hydrogen transport membrane (HTM) with a porous ceramic substrate and a palladium film coating was developed and tested by Praxair (Schwartz et al. 2010). The OTM-HTM membranes integrated the syngas generation, shift reaction, and hydrogen separation into a single membrane-reactor separator. These membranes were based on ceramic mixed with conducting materials and could operate at $800-1,000^{\circ} \mathrm{C}$. The OTM-HTM membranes showed excellent performance, thus enabling the integrated water gas shift membrane reactor to perform better than conventional WGS and PSA.

\subsection{OTM TECHNOLOGY}

Linde's OTM syngas technology (previously Praxair's) was developed by combining primary SMR, secondary ATR, and air separation unit (ASU) features into a single package to improve syngas production efficiency (Praxair 2014, Li 2018).

An OTM-combined reformer system consists of (1) a primary reforming tube in which desulfurized natural gas is partially reformed by steam at a high pressure in the presence of a metal catalyst, followed in series by (2) a ceramic OTM with a secondary reformer in which residual methane reforms and $\mathrm{O}^{2-}$ ions react with a portion of the $\mathrm{CO}$ and $\mathrm{H}_{2}$ fuel to provide the heat to support both primary and secondary reforming. This novel syngas production technique integrates the advantages of multiple processes in a 
single integrated package. The OTM technology can be integrated with an integrated gasification combined cycle (IGCC) system to increase the carbon capture rate and improve syngas production quality (Praxair 2014, Li 2018).

A schematic diagram of the OTM technology is shown in Figure 1 (Li 2015) and Figure 2 (Li 2018). This technology is built around high-density ceramic membranes that can effectively separate $\mathrm{O}_{2}$ from atmospheric air at high temperatures. These membranes are made of solid-state electrolyte materials that can conduct oxygen ions and electrons and are permeable only to oxygen (and not other gases) at high temperatures.

OTMs consist of an inert, porous support coated with electrochemically active layers which are oxygenselective at operation temperatures of $900-1,000^{\circ} \mathrm{C}$. Oxygen molecules in the air adsorb onto the membrane surface (active layers), dissociate to oxygen atoms, and then combine with electrons that migrate from the other side of the membrane to form oxygen anions $\left(\mathrm{O}^{2-}\right)$, which are transported across the OTM. The rate of oxygen transport across the membrane is referred to as oxygen flux. Fuel species $\left(\mathrm{H}_{2}, \mathrm{CO}\right)$ diffuse through the porous support and combust with oxygen anions at the membrane surface to form oxidation products $\left(\mathrm{H}_{2} \mathrm{O}, \mathrm{CO}_{2}\right)$. Because the driving force is provided by high temperatures and partial pressure of oxygen differentials, an OTM can function without an external circuit. Additionally, a secondary reforming catalyst is deposited onto the fuel-side of the OTM to reform residual methane.

As shown in Figure 1 ( $\mathrm{Li} 2015$ ) and Figure 2 ( $\mathrm{Li} 2018$ ), a mixture of natural gas and steam is fed into the primary reformers and partially reformed syngas $\left(\mathrm{H}_{2}, \mathrm{CO}, \mathrm{CO}_{2}, \mathrm{CH}_{4}, \mathrm{H}_{2} \mathrm{O}\right)$. The mixture then enters the OTM secondary reformers. Syngas and natural gas $\left(\mathrm{CO}, \mathrm{H}_{2}, \mathrm{CH}_{4}\right)$ diffuse through the porous support layer and then combust with oxygen anions $\left(\mathrm{O}^{2-}\right)$ at the active anode. The heat released from the combustions at the active anode radiates to the neighboring tubes (Figure 2) to support the endothermic reforming reactions in the primary and secondary reformers.

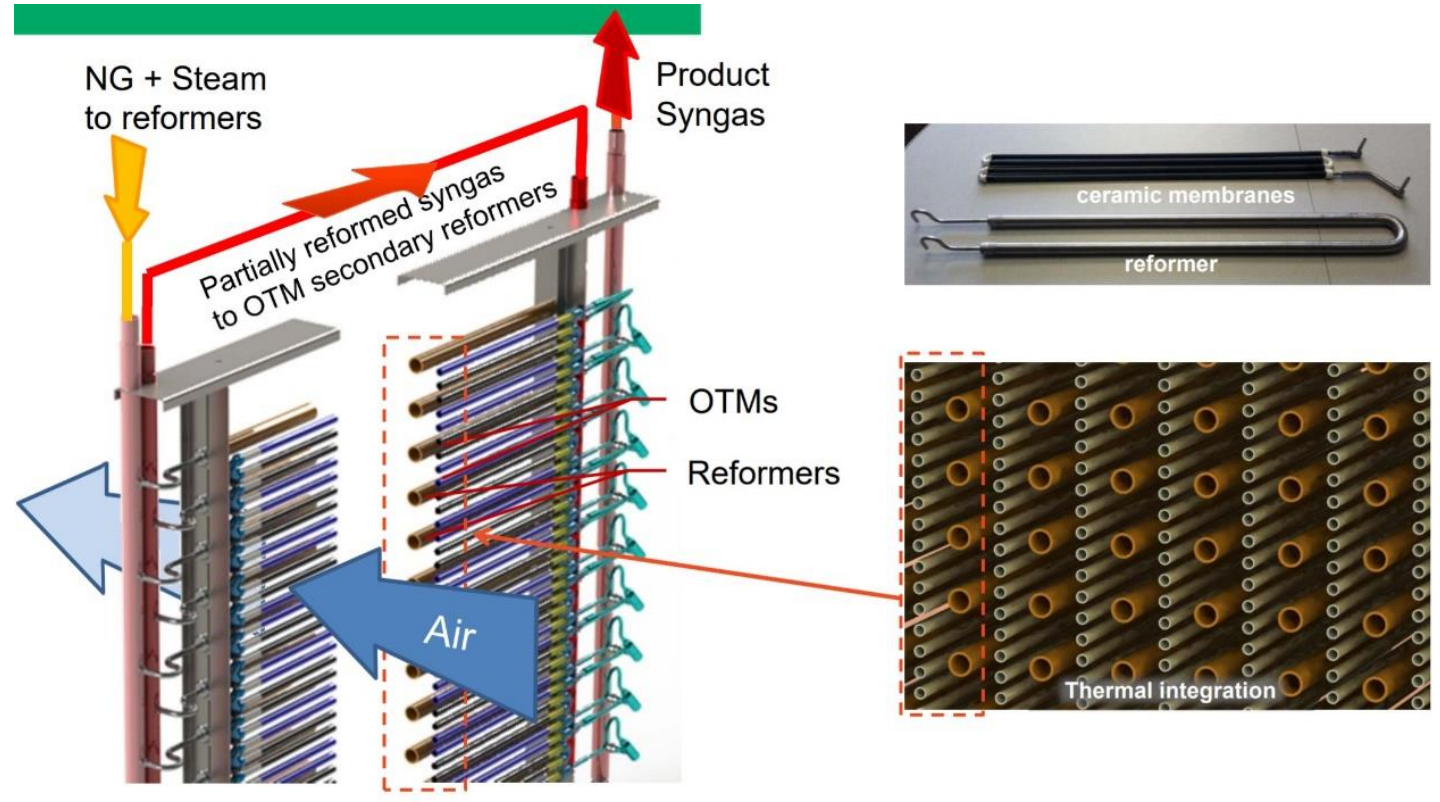

Figure 1. OTM technology—integrated combined reformer panel array (Li 2015). 


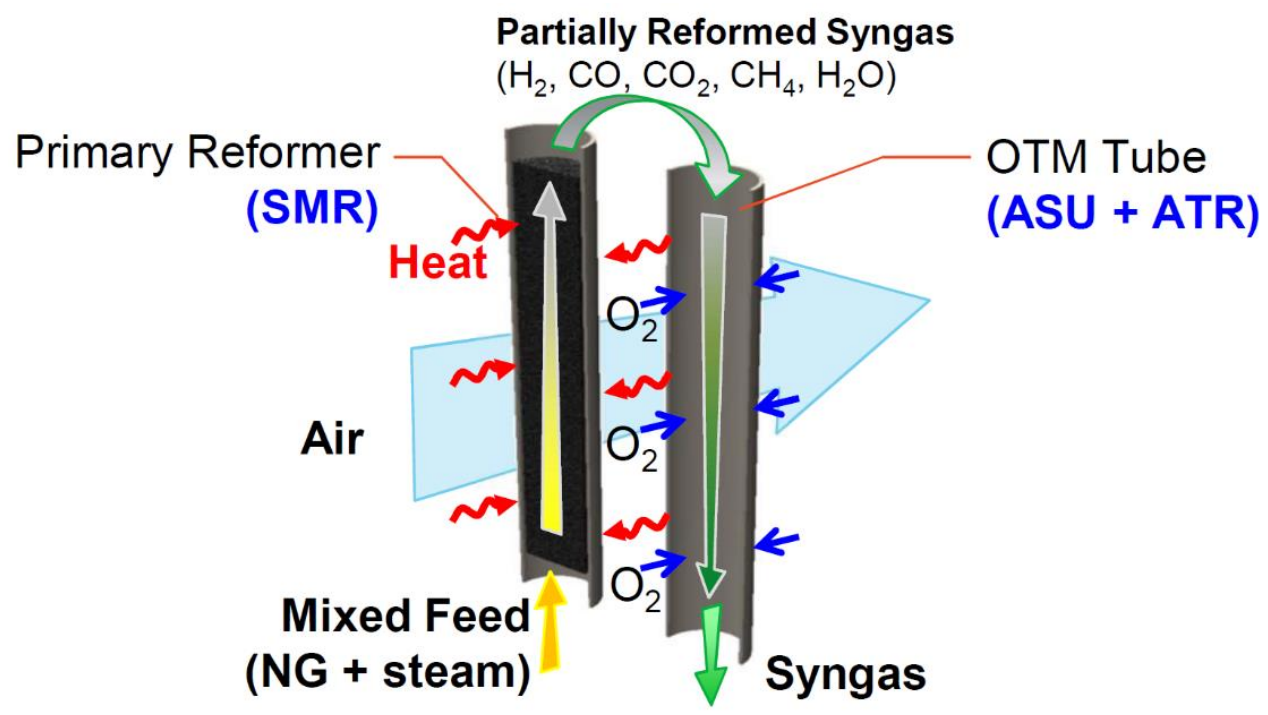

Figure 2. Combined reforming in a single integrated, efficient package (Li 2018).

\subsection{OBJECTIVES}

Although the OTM combined reformer technology for syngas and hydrogen production has been substantially developed in the last decade, several challenges that affect the overall production efficiency and reliability are yet to be fully understood, addressed, and resolved. For example, successful operation of OTMs has been demonstrated consistently on a small scale of <50 OTMs. However, during several intermediate-scale tests ( 250 OTMs), tube failures have occurred during reactor start-up. These failures have been attributed to thermal gradients arising in the system due to complex heat transfer interactions involving coupled convection and radiation physics. Therefore, development of highly accurate computational models, which incorporate fluid dynamics, mass transport, kinetics, heat transport and structural mechanics, is critical for understanding the startup failures and identifying pathways to a successful scaleup and operation.

The following project objectives were addressed and documented in this report:

- Review the state-of-the-art of technology for syngas and hydrogen production using the conventional and renewable energy sources;

- Improve the numerical stability, solver performance, and scalability of the existing COMSOL multiphysics models on high-performance computing systems;

- Develop a higher fidelity CFD model of an OTM tube bundle using appropriate physics models such as chemical reaction kinetics, transport phenomena (heat, mass, and momentum), electrochemistry, and their multiphysics couplings; and

- Evaluate the role of high-performance computing and advanced modeling and simulation to help achieve decarbonization objectives across the syngas and hydrogen economy. 


\section{BENEFITS TO THE DOE FUNDING OFFICE'S MISSION}

This project was in support of the HPC4Mfg Program, sponsored by the DOE's Advanced Manufacturing Office (AMO) within the Office of Energy Efficiency and Renewable Energy. This program is focused on making U.S. manufacturing more efficient and productive while reducing carbon emissions.

In addition to conducting cost-shared research, development, and activities related to next-generation technologies and processes, AMO provides funding for initiatives that will significantly reduce energyrelated emissions, industrial waste, and the energy consumption of manufactured goods throughout their lifecycles. In collaboration with private and public stakeholders, AMO works to decarbonize industry and boost the competitiveness of the U.S. manufacturing sector and clean energy sector through process innovations, research and development, and training and technical assistance.

The OTM technology has the potential to significantly improve syngas production efficiency, with applicability to numerous applications, including gas-to-liquid (GTL) and methanol production. More energy efficient processes will improve profitability and sustainability of natural gas conversion technologies. For example, the OTM technology is estimated to yield the following benefits per unit of methanol produced for small modular methanol production relative to conventional SMR technology: (1) a $23 \%$ reduction in syngas cost of production, (2) a further $19 \%$ reduction in syngas island capital cost, (3) a $22 \%$ reduction in fuel consumption and a $61 \%$ reduction in power consumption for syngas production, and (4) an $80 \%$ reduction in the $\mathrm{CO}_{2}$ footprint for the syngas island.

In summary, this project will help realize the following key benefit to the funding office's mission:

- Improvements in syngas and hydrogen production processes that results in significant reductions in lifecycle energy consumption and carbon emissions. 


\section{TECHNICAL DISCUSSION OF WORK PERFORMED BY ALL PARTIES}

\subsection{REVIEW OF THE CURRENT STATE OF TECHNOLOGY}

This section reviews the current state-of-the-art technology for hydrogen production using traditional resources (fossil fuels) and renewable resources (biomass and water).

\subsubsection{Introduction}

Because of the consequences of climate change resulting from the release of carbon dioxide and greenhouse gases, as well as fossil fuel depletion, it is essential for human beings to approach future energy sources that are sustainable and free from carbon (Conte et al. 2001, Lior 2002, Blok 2005, Lund 2007, Nikolaidis and Poullikkas 2017). Hydrogen is the only carbon-free energy carrier and an abundant element on Earth; however, it usually occurs with other elements. Hydrogen has been widely considered an environmentally benign secondary form of renewable energy (Momirlan and Veziroglu 2002, 2005, Nikolaidis and Poullikkas 2017).

Hydrogen can play an essential role in a transition to a low-carbon economy. Currently, hydrogen is primarily used in several applications:

- As a chemical component in ammonia $\left(\mathrm{NH}_{3}\right)$ production (fertilizers)

- As a chemical feedstock and catalyst

- As a hydrogenating component for food and drug production

- As a chemical component in petrochemical and refinery processing

- As a low-carbon fuel for transportation, electricity generation, and manufacturing

Hydrogen can be produced from many processes that can be categorized as either conventional or renewable technologies. The feedstocks used include natural gas and coal for the conventional technologies, whereas biomass, solar, and wind are used for the renewable technologies. Hydrogen produced through these processes can be stored, transported, and delivered, and it can also be used to produce electricity if necessary (see Figure 3). It is also critical to point out the vital contribution of the energy storage system (Dell and Rand 2001, Hall and Bain 2008, Hadjipaschalis et al. 2009), which must be flexible enough to (i) maintain the energy stored for the desired duration and (ii) to supply energy for use when needed.

The conventional method of hydrogen production using traditional resources or fossil fuels can be accomplished through hydrocarbon reforming and pyrolysis (See Figure 4). The hydrocarbon reforming process includes chemical techniques such as steam reforming, partial oxidation, and autothermal steam reforming. Hydrogen can also be produced using renewable resources such as biomass and water (See Figure 5). Thermochemical and biological processes are applied to process the biomass materials. Each method includes several different technologies. Thermochemical methods use pyrolysis, gasification, combustion, liquefaction technologies, and bio-photolysis and biological fermentation methods. As a renewable resource, water can be used to produce hydrogen through water-splitting processes such as electrolysis, thermolysis, and photo-electrolysis. Several processes in the traditional and renewable categories of hydrogen production use and generate carbon dioxide. For example, in the traditional category, steam methane reforming occurs in the hydrocarbon process of fossil fuels, and pyrolysis and gasification of biomass and plastic waste result from thermochemical processing of renewable sources. 


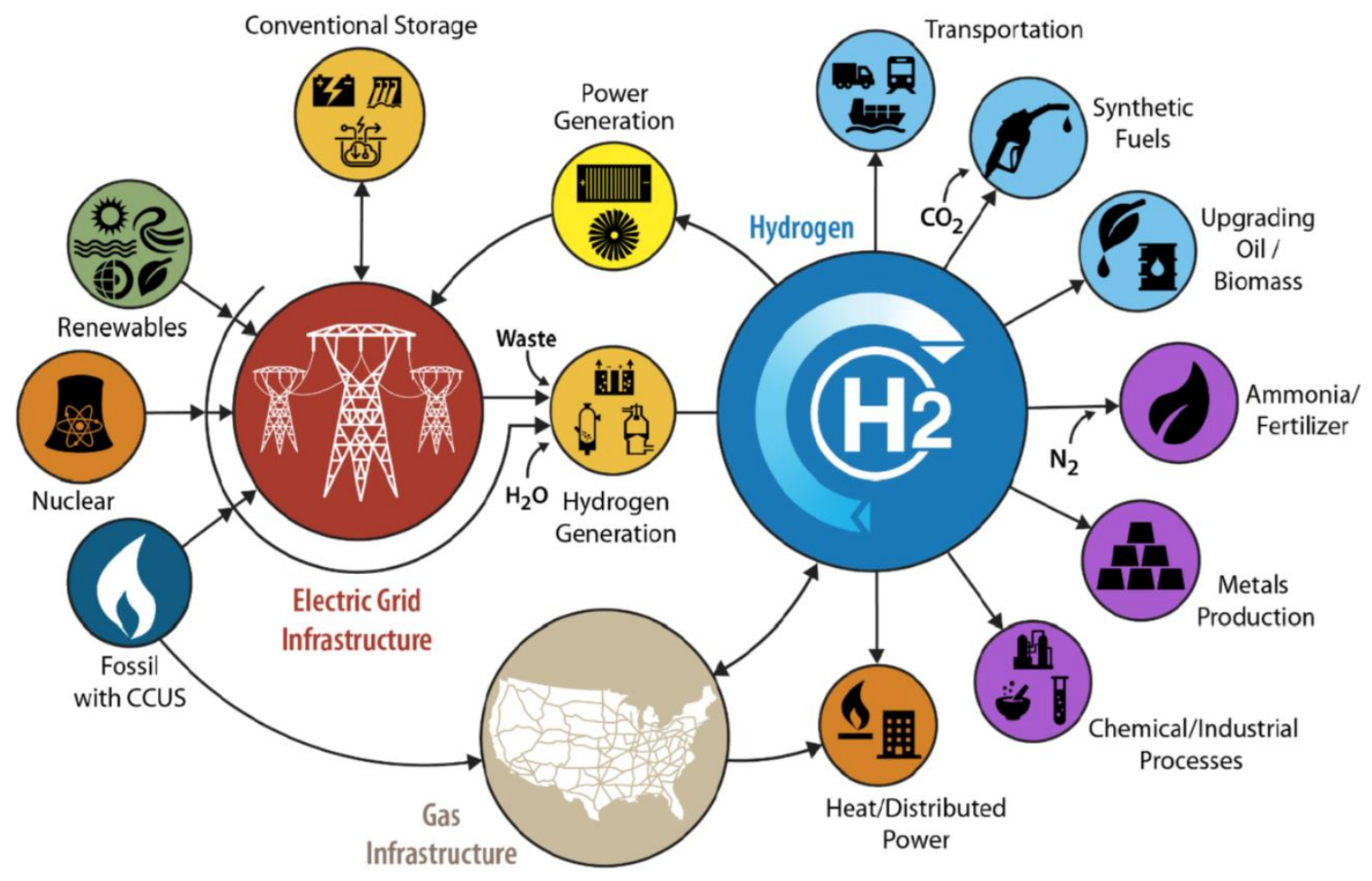

Figure 3. H2@ Scale vision showing that hydrogen can be produced from fossil fuels and renewable sources. Hydrogen is also a central input to many important end uses in the industrial, chemical, and transportation sectors (www.energy.gov/eere/fuelcells/h2scale). These processes and available technologies could provide the lowest cost for producing zero-carbon hydrogen when combined with carbon capture, utilization, and storage (CCUS) technologies (DOE 2020).

\subsubsection{Hydrogen Production from Fossil Fuels}

\subsubsection{Hydrocarbon reforming process}

Technologies such as hydrocarbon reforming and pyrolysis have been successfully developed and applied to fossil fuels for producing hydrogen. Up to this point, hydrogen has been produced $48 \%$ from natural gas (NG), 30\% from the heavy oil and naphtha reforming in refinery/chemical industrial off-gases, $18 \%$ from coal gasification, 3.9\% from water electrolysis, and $0.1 \%$ from other sources (Kothari et al. 2008, Balat and Kirtay 2010, Nikolaidis and Poullikkas 2017, Muradov and Veziroglu 2005, Iulianelli et al. 2016). In the United States, hydrogen production is $99 \%$ sourced from fossil fuels, with $95 \%$ coming from natural gas by steam methane reforming, and $4 \%$ from partial oxidation of natural gas via coal gasification (DOE 2020).

\section{Steam Methane Reforming (SMR) Method}

Steam methane reforming (SMR), or steam reforming of natural gas, the main component of which is methane, is the most common process and is used predominantly in industry for hydrogen generation. However, SMR results in the emission of carbon dioxide and other greenhouse gases, which have a significant negative impact on the Earth's climate (Balat and Balat 2009, Iulianelli et al. 2016). The SMR process mainly involves a nickel-based catalytic conversion of hydrocarbon (methane) in the presence of steam to hydrogen $\left(\mathrm{H}_{2}\right)$ and carbon monoxide $(\mathrm{CO})$ gases, which is called synthetic gas, or syngas. 


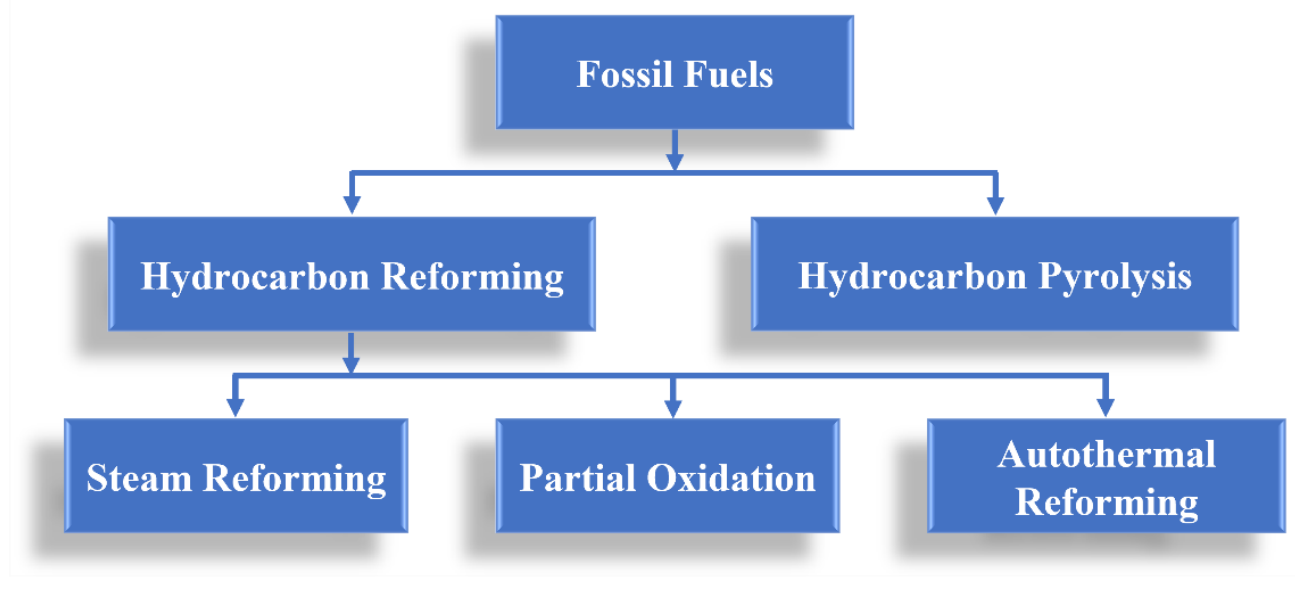

Figure 4. Hydrogen production processes from fossil fuels (adapted from Nikolaidis and Poullikkas [2017]).

The produced syngas is then shifted through water-gas shift (WGS) reactors to increase the amount of $\mathrm{H}_{2}$ in the gas product as much as possible and to convert carbon monoxide to carbon dioxide $\left(\mathrm{CO}_{2}\right)$.

Hydrogen is subsequently separated from the produced gas stream using the pressure swing adsorption (PSA) technique. After the PSA separation, the residual gas, which contains mainly $\mathrm{CO}_{2}$ and a minimal amount of hydrogen, can be recycled or combusted to generate the thermal energy for the reforming and WGS processes. Although the SMR process has been applied in hydrogen production for several decades, further improvement is needed. The SMR process is typically carried out at $800-900^{\circ} \mathrm{C}$, and $15-30 \times 105$ $\mathrm{Pa}$ with the presence of nickel on alumina support, requiring a significant amount of energy. In addition, the SMR process requires the use of high-cost reformer tubes made of expensive alloy, as well as a typical industrial-scale reformer containing an array of catalyst-filled tubes within a large furnace to supply the thermal energy required for the endothermic reforming process.

One of the most serious issues of methane conversion is the limitation of thermodynamic equilibrium to crack the methane formulas: reversible reactions that must be within the range of $800-900^{\circ} \mathrm{C}$. Carbon formation can occur at such a high-temperature range and could form blockages on reformer tubes that would increase total pressure drops and lead to catalyst deactivation (Trimm 1997, Barelli et al. 2008). To avoid catalyst deactivation during the SMR process, temperature, pressure, and gas compositions must be carefully controlled. More research is needed to develop new concepts to improve the SMR process in hydrogen production to reduce the capital cost and further contribute to natural gas's decarbonization pathways.

\section{Advanced Catalyst}

First, the SMR process can be improved by enhancing the catalyst's performance to acquire as much hydrogen as possible while minimizing the negative effect of carbon formation and sulfur poisoning (Iulianelli et al., 2016). Numerous studies have contributed to developing advanced catalysts to mitigate the sintering and coke formation, which, if happens, will cause an increased pressure drop and deactivation of catalyst, thereby enhancing hydrogen production efficiency and system stability and reducing the required energy input.

For example, Homsi et al. (2014) tested the synthesis of a ruthenium-based catalyst on cobalt, magnesium, and mixed aluminum oxides support in the SMR process. They found that the $\mathrm{Ru} / \mathrm{Co}_{6} \mathrm{Al}_{2}$ catalyst performed better than the $\mathrm{Ru} / \mathrm{Al}_{2} \mathrm{O}_{3}$ that is commonly used in industry. The hydrogen production 
was highest, accompanied by the lowest $\mathrm{CO}$ production over the $\mathrm{Ru} / \mathrm{Co}_{6} \mathrm{Al}_{2}$ solid. Although Homsi et al. (2014) noticed the formation of carbon and coke deposits resulting from methane decomposition, the $\mathrm{Ru} / \mathrm{Co}_{6} \mathrm{Al}_{2}$ catalyst was stable for 100 hours on stream under the extreme SMR process conditions.

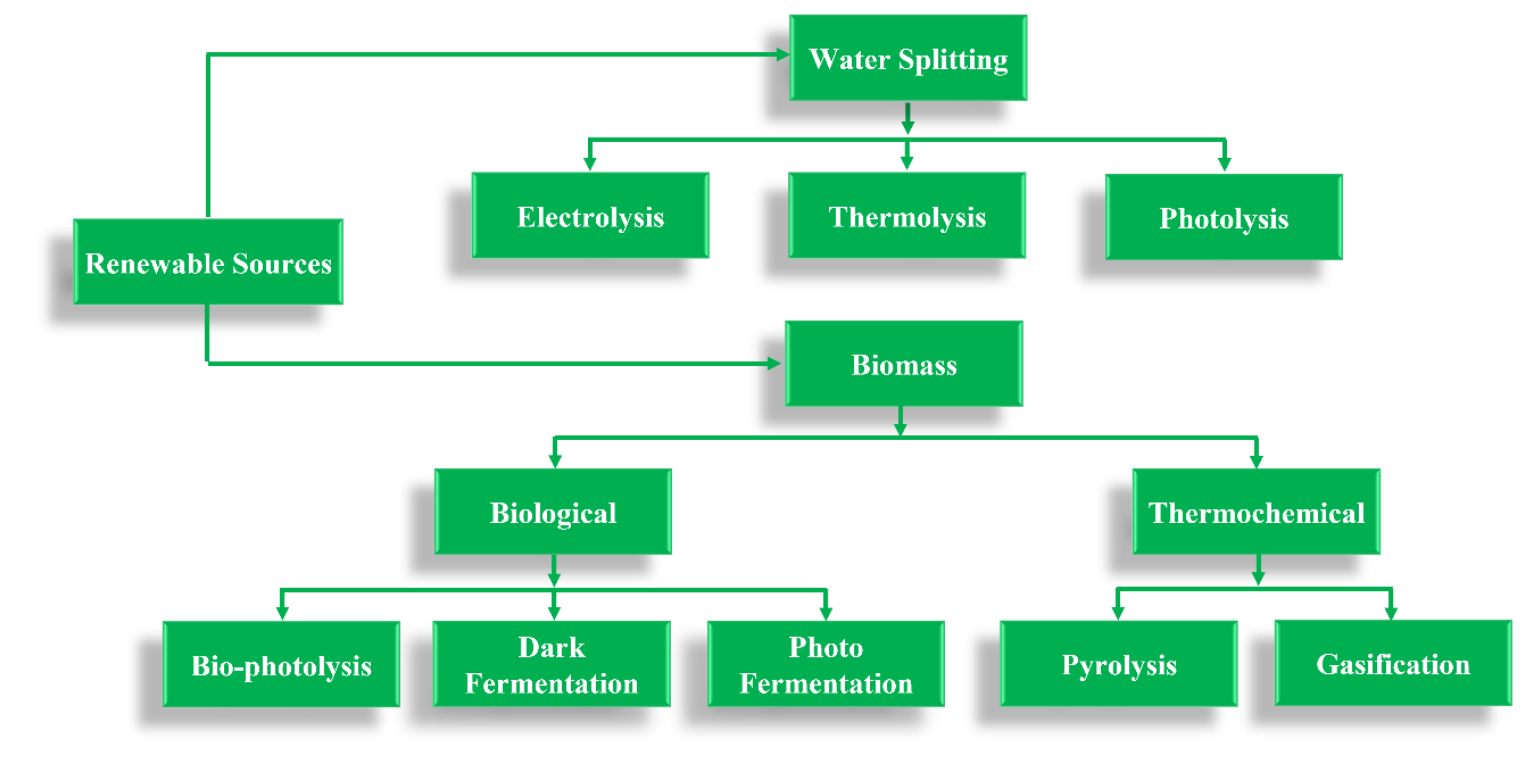

Figure 5. Hydrogen production processes from renewable sources (adapted from Nikolaidis and Poullikkas [2017]).

Roy et al. (2014) studied the $\mathrm{Pd}-\mathrm{Rh} /$ metal foam catalyst for the SMR process. Methane conversion and hydrogen yield were better than the industrial-type alumina-supported catalysts. Moreover, it was found that the $\mathrm{Pd}-\mathrm{Rh} / \mathrm{metal}$ foam catalyst exhibited good stability in the harsh conditions of the SMR environment. However, a small amount of coke deposition was found on the catalyst after 200 hours.

Mei et al. (2014) experimentally and theoretically investigated $\mathrm{MgAl}_{2} \mathrm{O}_{4}$-supported $\mathrm{Rh}$ and $\mathrm{Ir}$ catalysts for the SMR process. They reported that the $\mathrm{MgAl}_{2} \mathrm{O}_{4}$ spinel-supported $\mathrm{Ir}_{50}$ particles had the highest methane steam reforming reactivity, high stability, and resistance to coke formation.

Among all investigated catalysts with high catalytic activity and less coke formation, Ni-based catalysts received the most attention and are commonly used in the SMR process because of their low cost.

Chihaia et al. (2012) performed the SMR process at low temperatures for hydrogen production on two versions of alumina-supported $\mathrm{Ni}$ catalysts with added gold and silver. $\mathrm{Ni}-\mathrm{Au} / \mathrm{Al}$ and $\mathrm{Ni} / \mathrm{Ce}-\mathrm{Al}$ were active and stable catalysts for the $\mathrm{SMR}$ process at $450-550^{\circ} \mathrm{C}$. In addition, $\mathrm{Ni}-\mathrm{Au} / \mathrm{Al}$ had higher $\mathrm{CO}_{2}$ selectivity and slightly higher methane conversion, whereas $\mathrm{Ni} / \mathrm{Ce}-\mathrm{Al}$ had better performances at $700^{\circ} \mathrm{C}$ because of its better stability in time.

Nieva et al. (2014) reported the SMR process on four nickel-based catalysts: $\mathrm{Ni} / \alpha-\mathrm{Al}_{2} \mathrm{O}_{3}, \mathrm{Ni} / \mathrm{SiO}_{2}, \mathrm{Ni}-$ $\mathrm{Zn}-\mathrm{Al}$, and $\mathrm{Ni}-\mathrm{Mg}-\mathrm{Al}$. Their results show that the $\mathrm{Ni}-\mathrm{Zn}-\mathrm{Al}$ catalyst had the highest activity, with the lowest production of carbonaceous deposits in the range of $500-600^{\circ} \mathrm{C}$. Furthermore, the sintering effect was not observed under SMR reaction conditions, indicating that this type of catalyst is suitable for industrial applications. 


\section{Membrane Reactors}

Numerous research efforts have been dedicated to improving the SMR reaction by employing membrane reactors instead of conventional reactors. Particularly, Pd-based membranes have received the most attention because of their high hydrogen separation ratio. However, challenges of the Pd-based membranes include the low hydrogen permeability, mechanical resistance, and high costs, making their large-scale industrial applications difficult.

Iulianelli et al. (2010) performed the SMR process in a dense $\mathrm{Pd}-\mathrm{Ag}$ membrane reactor packed with a Nibased catalyst at $400-500^{\circ} \mathrm{C}$ and relatively low pressure (1.0-3.0 bar). They demonstrated that the $\mathrm{Pd}-\mathrm{Ag}$ membrane reactors provided 50\% methane conversion-which is better than a fixed bed reactor under the same conditions - and they also provided a 70\% high-purity hydrogen recovery.

Saric et al. (2012) carried out SMR tests using a bench-scale Pd-membrane reactor under realistic operating conditions of $580^{\circ} \mathrm{C}$ and 28 bar. It was shown that the obtained methane conversion was higher than $90 \%$ with high hydrogen purity (80-95\%), and the process had a reasonably high recovery of 60$80 \%$. Furthermore, the membrane reactor's performance was stable for almost 1,100 hours, and the average conversion for this long-duration test was $86 \%$. The $\mathrm{CO}$ content in the permeate was found to be within a range of 59-154 ppm, whereas the $\mathrm{CO}_{2}$ concentration was at approximately $12 \%$. However, an increase in $\mathrm{CO}_{2}$ concentration was reported in the long-duration experiments, indicating the increase of the leak flow.

Hwang et al. (2012) designed and tested a multi-membrane reformer consisting of two single modules containing coin-shaped nickel-metal catalysts and a Pd-based membrane, for the direct hydrogen production via a steam-reforming reaction of methane. The steam reforming process was conducted in relatively high-pressure operation ranges $(\approx 21$ bar) without sweep gas. The methane conversion and hydrogen production rate were measured for various test conditions. Results were reported for the highperformance and high hydrogen production rate of the Pd-based membrane and the porous metal catalyst. The methane conversion, the rate of hydrogen separation, and the hydrogen purity were $75 \%, 30.6 \mathrm{~L} / \mathrm{h}$, and $99.95 \%$, respectively, under conditions of $540^{\circ} \mathrm{C}$, steam to carbon ratio $\mathrm{S} / \mathrm{C}=3.0$, and 20 bar. Hwang et al. (2012) describe the potential advantages of the simple design and preparation of the compact multimembrane reformer, which can operate in relatively high-pressure ranges, and modules can easily be stacked to further enlarge the reformer for increased hydrogen production capacity.

Dittmar et al. (2013) introduce two types of Pd composite membranes that were developed for the SMR process. The membranes were made of the porous metal support, a porous ceramic diffusion barrier, and a dense Pd layer that was manufactured using physical vapor deposition. The long-term tests show that the SMR can be carried out for several hundred hours using the developed Pd membrane reactors at a high methane conversion and high hydrogen recovery.

Basile et al. (2011) carried out the SMR reaction at relatively high pressures (3.0-9.0 bar) in a Pd-Ag membrane reactor packed with a $\mathrm{Ni}-\mathrm{ZrO}$ catalyst. The test results indicate high thermal stability and strong resistance against coke formation, demonstrating better Pd-Ag membrane performances than the $\mathrm{Ni}-\mathrm{Al}_{2} \mathrm{O}_{3}$ catalyst. At $450^{\circ} \mathrm{C}$ and 4.0 bar, methane conversion of $65 \%$ and $1.2 \mathrm{l} / \mathrm{h}$ hydrogen without $\mathrm{CO}$ were obtained, in addition to recovering $80 \% \mathrm{COx}$-free hydrogen over the total hydrogen produced during the reaction.

Boeltken et al. (2014) developed a novel metal-based modular microstructured reactor with an integrated $\mathrm{Pd}$-membrane ( $\mu$-EnH $\mathrm{H}_{2}$ ancer) for hydrogen production through the SMR process. The Pd membranes used thin Pd foils measuring $12.5 \mu \mathrm{m}$ that were leak-tight integrated with laser welding between microstructured plates. The $\mu-\mathrm{EnH}_{2}$ ancer membrane made a very compact system with subordinated 
concentration gradients to provide high volumetric hydrogen production rates of up to $472 \mathrm{Nm}^{3} \mathrm{H} 2 /\left(\mathrm{m}^{3} \mathrm{~h}\right)$. The $\mu-\mathrm{EnH}_{2}$ ancer membrane was tested in SMR operation at $550^{\circ} \mathrm{C}$ and at retentate pressures up to 12 bar on a highly active $\mathrm{Rh} / \mathrm{Al}_{2} \mathrm{O}_{3}$ catalyst. The results show a high hydrogen purity $(>99.5 \%)$ and ideal $\mathrm{H}_{2} / \mathrm{N}_{2}$ permselectivities at $500^{\circ} \mathrm{C}$ and 6 bar feed pressure.

\section{Fluidized-Bed Membrane Reactors}

Fluidized-bed membrane reactors have been the subject of many studies as part of the effort to develop an alternative solution to conventional reactors.

Chen et al. (2007) investigated the performance of a bubbling fluidized-bed membrane reactor for hydrogen production using Pd-Ag planar membranes, as well as an SMR catalyst and an autothermal reforming (ATR) catalyst. The operating conditions were at $500-600^{\circ} \mathrm{C}$ and $1,500-2,600 \mathrm{kPa}$. The results indicate that the ATR catalyst outperformed the SMR catalyst: the hydrogen permeation fluxes were 9-18 $\mathrm{Nm}^{3} / \mathrm{m}^{2} \mathrm{~h}$ for the ATR catalyst and $4.8-12 \mathrm{Nm}^{3} / \mathrm{m}^{2} \mathrm{~h}$ for the SMR catalyst, and both SMR and ATR operations had higher performance than those reported in the literature.

Mahecha-Botero et al. (2008) tested a pilot-scale fluidized-bed membrane reactor for hydrogen production under the SMR and ATR operating conditions, without membranes and with membranes of different total areas. The results show a very high hydrogen permeation purity $(99.995 \%)$ and a pure- $\mathrm{H}_{2-}$ to-natural-gas yield of 2.07, with only half of the full complement of membrane panels active under SMR conditions. Mahecha-Botero et al. (2008) also determined that the membrane longevity was enhanced by maintaining the axial temperature variations along each membrane panel within $20^{\circ} \mathrm{C}$. However, some reverse reactions in the reactor freeboard were observed, which reduced overall methane conversion.

Andres et al. (2011) tested a novel pilot fluidized-bed membrane reformer with permselective Pdmembranes and used a limestone sorbent to remove $\mathrm{CO}_{2}$ in-situ. This method could shift the thermodynamic equilibrium to enhance pure hydrogen production. The tested reactor was operated at $525-600^{\circ} \mathrm{C}$ and 10 bar and was fed with methane to fluidize a mixture of calcium oxide $(\mathrm{CaO}) /$ limestone $\left(\mathrm{CaCO}_{3}\right)$ and a Ni-alumina catalyst. Results from Andres et al. (2011) indicate the maximum carbon

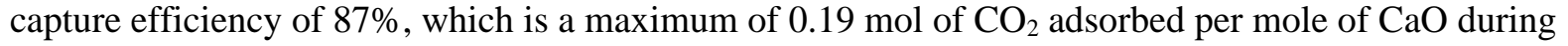
carbonation, thus demonstrating limestone's ability to adsorb $\mathrm{CO}_{2}$ that results from the SMR process. However, the sorbent's ability to capture $\mathrm{CO}_{2}$ decreased with time. Andres et al. argue that the in-situ $\mathrm{CO}_{2}$ capture enhanced the hydrogen production purity to higher than $99.99 \%$.

\section{Oxygen transport membrane (OTM)}

Yang et al. (2013) developed an integrated reactor system combining an oxygen-permeable $\mathrm{La}_{0.6} \mathrm{Sr}_{0.4} \mathrm{Co}_{0.8} \mathrm{Ni}_{0.2} \mathrm{O}_{3-\delta}$ (LSCN) perovskite ceramic hollow fiber membrane with a Ni-based catalyst for hydrogen production through oxy- $\mathrm{CO}_{2}$ reforming methane (OCRM). The OCRM reaction was performed at $650-800^{\circ} \mathrm{C}$ with a packed $\mathrm{Ni} / \mathrm{Al}_{2} \mathrm{O}_{3}$ catalyst around the $\mathrm{LSCN}$ hollow fiber membrane. $\mathrm{CH}_{4}$ and $\mathrm{CO}_{2}$ were used as reactants, and the air was used as the oxygen source. It is reported that the OCRM reactor had a very high methane conversion (up to 100\%), a very high CO selectivity (almost 100\%), and an $\mathrm{H}_{2} / \mathrm{CO}$ ratio of 0.93 . Compared to the dry reforming of methane reactors, the proposed process had a lower $\mathrm{CO}_{2}$ conversion but higher energy efficiency, catalyst stability, and hydrogen yield.

Anderson et al. (2016) summarized recent developments of Air Products and Ceramatec in ion transport membranes (ITMs) for oxygen and syngas production. The OTM using ceramic mixed conducting ion transport membranes was demonstrated at an industrial scale to produce large quantities of oxygen. The OTMs were tested for a very long duration as required for commercial applications, and they maintained high purity oxygen production. 
Zhou et al. (2019) carried out laboratory-scale tests using a $\mathrm{Ce}_{0.8} \mathrm{Sm}_{0.2} \mathrm{O}_{2-\delta-40} \mathrm{Sr}_{2} \mathrm{Fe}_{1.5} \mathrm{Mo}_{0.5} \mathrm{O}_{5+\delta}$ (CSOSFMO) dual-phase oxygen-permeable membrane with a porous layer for syngas production from methane and a mixture of water and air. When the developed OTM was used as a membrane reactor, two synthetic gases with an $\mathrm{H}_{2} / \mathrm{N}_{2}$ ratio of 3 and an $\mathrm{H}_{2} / \mathrm{CO}$ ratio of 2 were obtained.

\section{Micro Membrane Reactors}

Micro membrane reactors are an emerging research topic and are being developed in various planar microchannel, hollow-fiber, and monolithic configurations for hydrogen production. However, some challenges associated with micro-membrane reactors must be addressed. For instance, very thin membranes characterized by very small grains and a high-density grain border could lead to grain size growth, impurities, grain border diffusion, and alloy segregation.

Mejdell et al. (2009) tested the performance of a microchannel membrane configuration with a thin selfsupported $\mathrm{Pd} / \mathrm{Ag} 23$ wt. $\%$ membrane $(\approx 1.4 \mu \mathrm{m})$ on top of six parallel channels with dimensions of $1 \times 1 \times$ $13 \mathrm{~mm}$. The influence of feed flow rate and pressure was analyzed with respect to effects arising when hydrogen permeates from mixtures. Mejdell et al. (2009) found that the membrane could withstand differential pressures up to $470 \mathrm{kPa}$, and recommend designing a compact, efficient microchannel membrane reactor system for hydrogen production and separation.

García-García et al. (2010) developed a novel catalytic hollow fiber membrane microreactor consisting of a thin $\mathrm{Pd}$ layer and a $30 \% \mathrm{CuO} / \mathrm{CeO}_{2}$ catalyst supported on an asymmetric $\mathrm{Al}_{2} \mathrm{O}_{3}$ hollow fiber. The WGS process was conducted at $1 \mathrm{~atm}, 200-500^{\circ} \mathrm{C}$, and different sweep gas flow rates ranged from 50 to 75 $\mathrm{ml} / \mathrm{min}$. García-García et al. (2010) report that the catalytic activity of the hollow fiber membrane microreactor was $35 \%$ higher than that in the conventional fixed-bed reactor.

Gil et al. (2012) developed a catalytic hollow fiber membrane microreactor combining the SMR/WGS processes and hydrogen separation into a single compact unit. The membrane had a Pd-based hydrogen separation layer and an asymmetric alumina hollow fiber substrate. The catalyst composed of the microchannels provided very high membrane surface area-to-volume ratios compared to traditional membrane systems. The tests were carried at $300-600^{\circ} \mathrm{C}$. The permeation flux was $14 \mathrm{~L} \cdot \mathrm{m}^{-2} \cdot \mathrm{s}^{-1}$ at $450^{\circ} \mathrm{C}$ and $\mathrm{dP}=3$ atm, indicating that the catalyst designs had sufficient activity in the temperature range shown above.

\section{Partial Oxidation (POX) Method}

The partial oxidation (POX) method converts steam, oxygen, and hydrocarbons to hydrogen and carbon oxides. POX process is an exothermic process; therefore, it requires less energy input than the steam reforming method. The POX method is the most appropriate technology for converting heavy hydrocarbon feedstocks such as oil residues, naphtha, coal, and light hydrocarbon (methane) to hydrogen. One of the major disadvantages of the POX process is the pure oxygen supply and high safety risk. In the POX process, a significant portion of the hydrogen is produced from steam due to the lower hydrogen-tocarbon ratios of heavy feedstocks used.

Non-catalytic POX can occur with methane, heavy oil, and coal at $1,150-1,315^{\circ} \mathrm{C}$, whereas catalytic POX can occur at a lower temperature of $950^{\circ} \mathrm{C}$ with methane and naphtha (Steinberg and Cheng 1989). In non-catalytic POX, the syngas produced has a very high temperature at $1,200-1,400^{\circ} \mathrm{C}$ and high impurities resulting from the heavy hydrocarbon feedstocks that must be cleaned and cooled (Elbadawi et al. 2021). Texaco and Shell developed a non-catalytic POX that resulted in a high syngas yield at high temperatures and pressures (Pen et al., 1996). 
The catalytic POX process has been intensively investigated for many years. In general, introducing a suitable catalyst into the $\mathrm{POX}$ process could significantly reduce the required high-temperature range of $1,200-1,500^{\circ} \mathrm{C}$ to $800-900^{\circ} \mathrm{C}$. However, catalytic POX is negatively affected by sulfur content in the feed, so a desulfurization system must be included before the catalysts, which otherwise, could be poisoned. In the catalytic POX process, syngas is produced from hydrocarbon feedstocks and oxygen with noble metals, such as Pt, Rh, Ir, and Pd, and non-noble metals, such as $\mathrm{Ni}$ and $\mathrm{Co}$, in a single step (Ghoneim et al. 2016). Schicks et al. (2003) tested nanoengineered catalysts for the high-temperature direct oxidation of methane to syngas via a microemulsion-mediated sol-gel route. Developed catalysts were added to Pt-salts and had large surface areas and homogeneous distributions of highly active Ptnanoparticles. It was demonstrated that the syngas yields significantly exceeded those of conventional catalysts. In addition, high-temperature stability of the materials was observed, and there was no measurable deactivation or metal particle sintering over the long duration of reactor operation.

Chemical-looping reforming is a novel process for partial oxidation of hydrocarbons that eliminates the need for the addition of pure $\mathrm{O}_{2}$. In the chemical looping process, oxygen was provided by an oxygen carrier catalyst, and $\mathrm{NiO}$ and $\mathrm{MgAl}_{2} \mathrm{O}_{4}$ particles were used as bed material. The required temperature range was $820-930^{\circ} \mathrm{C}$. As in the steam reforming process, soots and carbon formation were typically detected in this process. Kang et al. (2018) obtained syngas production with a ratio of $\mathrm{H}_{2} / \mathrm{CO}=2$ by using a chemical looping process with a $\mathrm{CH}_{4}-\mathrm{CO}_{2}$ feed mixture on a ceria-enhanced mesoporous $\mathrm{Fe}_{2} \mathrm{O}_{3} / \mathrm{Al}_{2} \mathrm{O}_{3}$ oxygen carrier. The promoted dry reforming by $\mathrm{CO}_{2}$ was observed with the suppressed carbon deposition and the increased syngas selectivity by $\mathrm{CeO}_{2}$. The proposed oxygen carrier increased syngas production with a minimum carbon coking during the chemical looping process. Zhang et al. (2017) tested and found that $\mathrm{CaFe}_{2} \mathrm{O}_{4}$ and $\mathrm{Ca}_{2} \mathrm{Fe}_{2} \mathrm{O}_{5}$ were good candidates for oxygen carriers in the chemical looping oxidation of solid fuels like coal and biomass. They showed a fast reaction rate, large oxygen-carrying capacity, good reactivity, high $\mathrm{CO}$ selectivity, and good regeneration performance.

In the short contact time catalytic POX method, the feed flows through the gas-solid contact zone within $6-10$ seconds at a temperature of $600-1,200^{\circ} \mathrm{C}$. This process facilitates selective syngas formation and inhibits chain reactions in the gas phase, resulting in high conversion of methane to syngas (Elbadawi et al., 2021). Rennard et al. (2009) tested a short-time (30-90 ms) catalytic POX conversion of glycerol to syngas and other chemicals using a nebulizer over $600^{\circ} \mathrm{C}$. Rhodium catalysts were found to enhance equilibrium selectivity to syngas, whereas platinum catalysts should be used with methylglyoxal, hydroxyacetone, acetone, acrolein, acetaldehyde, and olefins. It was also noted that introducing water steam could increase $\mathrm{H}_{2}$ composition in the produced syngas due to the WGS reaction.

Membrane reactors are quite suitable for the POX process because of their continuous and controllable oxygen supply and chemical reaction in a single unit without hot spots (Bhavsar and Veser 2014). Bhavsar and Veser (2014) contend that this technology could reduce operating costs and safety risks compared with conventional POX reactors. However, membrane reactors often have stability issues due to their low mechanical strength and the ability to scale up the process. The tubular membrane module could overcome such challenges and might provide higher stability and the possibility to scale up (Wang et al. 2019). Wang et al. (2019) tested a dual-function catalytic perovskite hollow fiber membrane reactor for simultaneous NO decomposition and partial oxidation of the methane reaction. They found that the coupled POX reaction on the other side of the hollow fiber membrane increased the driving force for oxygen permeation and produced syngas. This novel membrane reactor showed high NO removal capacity at $675-700^{\circ} \mathrm{C}$, which was $100-200^{\circ} \mathrm{C}$ lower than other membrane reactors reported in the literature. 


\section{Autothermal Reforming (ATR) Method}

The autothermal reforming (ATR) method uses the exothermic partial oxidation process to provide the thermal energy needed and the endothermic steam reforming process to increase hydrogen production. Generally, in the autothermal reforming process, steam and oxygen or air are injected into the reformer, and the oxidation and reforming processes occur simultaneously (Nikolaidis and Poullikkas 2017). Using methane as the feedstock, the autothermal reforming process had the thermal efficiency of $60-75 \%$, the optimum operating conditions were at inlet temperatures of approximately $700^{\circ} \mathrm{C}$ for steam to carbon ratio $\mathrm{S} / \mathrm{C}=1.5$ and oxygen to carbon ratio $\mathrm{O}_{2} / \mathrm{C}=0.45$, and the maximum hydrogen yield was about 2.8 (Ersöz 2008, Holladay et al. 2009). Pd-based membrane reactors were applied and slightly improved the fuel processor's efficiency with a $20 \%$ volume reduction. In the studied simulations, Lattner and Harold (2004) observed higher $\mathrm{CH}_{4}$ conversions, lower concentrations of $\mathrm{H}_{2}$ and $\mathrm{CO}_{2}$, and higher $\mathrm{CO}$ concentration at the retentate side. The efficiency improvement in the presence of membranes was limited, because a temperature increase to $900^{\circ} \mathrm{C}$ could damage the membrane structures.

\subsubsection{Hydrocarbon Pyrolysis}

Hydrocarbon pyrolysis is a well-known process that involves thermal decomposition (or cracking, pyrolysis) of methane and other hydrocarbons in air and/or a water-free environment with a production of hydrogen and carbon (Muradov 2001). Thermo-catalytic decomposition of light hydrocarbons (the boiling point between 50 and $200^{\circ} \mathrm{C}$ ) is a single process producing hydrogen and carbon elements. In the case of heavy residual fractions (boiling point higher than $350^{\circ} \mathrm{C}$ ), hydrogen is produced by a two-step process consisting of hydrogasification and cracking of methane (Muradov 1993, Nikolaidis and Poullikkas 2017).

Direct de-carbonization of natural gas can occur at temperatures up to $980^{\circ} \mathrm{C}$ at atmospheric pressure. The methane decomposition pyrolysis reaction is a moderately endothermic process, so less than $20 \%$ of the heat of methane combustion is required to drive the process (Muradov 2001). Furthermore, the hydrocarbon pyrolysis process does not require WGS and $\mathrm{CO}_{2}$ removal processes, and it produces an essential product as clean carbon (Muradov and Veziroglu 2005). These factors could help reduce capital investments for large hydrocarbon pyrolysis plants compared to those using the processes of steam conversion or partial oxidation (Muradov 1993). Furthermore, the process can be considered better for the environment because it produces both hydrogen and carbon, whereas the SMR is required with a $\mathrm{CO}_{2}$ sequestration system.

Several new reactor designs for the thermal decomposition of methane have been proposed in the literature. Steinberg (1999) proposed a reactor in which methane bubbles would be heated when flowing through a molten metal $(\mathrm{Sn}$ or $\mathrm{Cu})$ bath, decomposing at $900^{\circ} \mathrm{C}$ and higher temperatures. Gaudernack and Lynum (1998) developed a high-temperature pyrolysis process and operated plasma-assisted decomposition of methane into hydrogen and carbon black.

Various catalysts were built and tested to reduce the maximum temperature of the methane thermal decomposition process. For instance, Muradov (1998) performed thermal decompositions of hydrocarbon gases (methane and propane) and liquids (hexane, gasoline, and diesel fuel) using metal-oxide and carbon-based catalysts. It was shown that using metal catalysts produced a higher initial hydrogen concentration. However, their activity quickly reduced due to the carbon deposition, but carbon-based catalysts provided advantages over metal catalysts, because carbon separation was not required. Aiello et al. (2000) showed that a $15 \mathrm{wt} . \% \mathrm{Ni} / \mathrm{SiO}_{2}$ catalyst maintained its catalytic activity for the methane decomposition for up to 10 process cycles due to the mechanism of carbon filament formation. However, a small amount of carbon resisted gasification and remained on the catalyst. Other metal catalysts, including $\mathrm{Fe}, \mathrm{Co}, \mathrm{Pd}$, and others, have also been used for methane decomposition (Beebe Jr. et al. 1987, 
Poirier and Sapundzhiev, 1997). However, a catalyst deactivation problem was associated with the carbon build-up on the catalyst surface.

Membranes can also be applied to continuously remove hydrogen during the thermal decomposition process of hydrocarbons. Pd-Ag alloys are typically used to allow operation at lower temperatures and to reduce coke formation. However, the main drawback of the membrane technology for hydrogen separation is the low hydrogen partial pressures in the reaction mixture and membrane durability at high temperatures (De Falco et al., 2011).

\subsubsection{Hydrogen Production from Renewable Sources}

\subsubsection{Biomass Process}

Feedstocks used in the biomass-based process for hydrogen production can be obtained from organic plant and animal materials such as crops and their waste byproducts, wood from forests and wood wastes, animal and municipal wastes, wastes from food processing and aquatic plants, and algae (Demirbas 2001a, Nikolaidis and Poullikkas 2017). Thermochemical and biological methods are the two primary methods that have been recently applied for hydrogen production from biomass resources. Although biological processes have low hydrogen production rates and yields ( $\mathrm{mol} \mathrm{H}_{2} / \mathrm{mol}$ feedstock), they are considered environmentally friendly approaches. They require fewer energy inputs because the processes are carried out under mild conditions. However, thermochemical processes require higher energy inputs, making the processes faster and providing a higher stoichiometric hydrogen yield.

\section{Thermochemical Processes of Biomass}

The thermochemical process, which mainly involves pyrolysis and gasification technologies, transforms biomass into hydrogen and hydrogen-rich gases that could effectively contribute to decarbonization pathways and zero-emission of greenhouse gases. Pyrolysis and gasification are the two leading technologies applied in the thermochemical process to produce methane, $\mathrm{CO}$, and other derivative gaseous products. The mixture of methane and $\mathrm{CO}$ can be processed further for more hydrogen production through the SMR process and the WGS reaction.

\section{Biomass Pyrolysis}

Biomass pyrolysis is a process of converting biomass or carbonaceous feedstocks into gaseous compounds, liquid oils, and solid charcoal by heating the biomass at a relatively low-temperature range of $375-750^{\circ} \mathrm{C}$ and a low-pressure range of $0.1-0.5 \mathrm{MPa}$ without the presence of oxygen, except for cases in which partial combustion is required to provide the thermal energy needed for the process (Demirbas 2002, Evans et al. 2003). The main drawbacks of biomass pyrolysis are low efficiency and an undesirable formation of tar and char. The amount of gaseous products generated from the process is low, so there is minimal hydrogen recovery.

Demirbas (2001b) carried out biomass pyrolysis to convert ground biomass samples, including cotton cocoon shells, tea factory waste, and olive husk, to generate hydrogen-rich gaseous products using catalyst additives within a range of $500-750^{\circ} \mathrm{C}$. The yield of gas increased with an increase in temperature. The yield of hydrogen-rich gaseous products increased with the $\mathrm{ZnCl}_{2}$ catalyst, but the yield of pyrolytic gas decreased, despite the increasing yield of charcoal and liquid products.

Chen et al. (2008) performed a pyrolysis process using pine wood sawdust as the biomass feedstock. The tests were conducted using a microwave heating method at $470^{\circ} \mathrm{C}$ under a dynamic nitrogen atmosphere and eight inorganic additives. All tested additives significantly increased solid product yields and 
decreased gaseous product yields. The hydrogen-rich gases produced from the pyrolysis included $\mathrm{H}_{2}$, $\mathrm{CH}_{4}, \mathrm{CO}$, and $\mathrm{CO}_{2}$.

Zhao et al. (2010) studied a biomass pyrolysis process using Ni/cordierite catalyst and combined it with the secondary decomposition of gaseous intermediate to significantly promote hydrogen content. The hydrogen content was above $60 \%$, and the hydrogen yield was approximately $65 \mathrm{~g} / \mathrm{kg}$ biomass at the optimum operating conditions: a pyrolysis temperature of $650^{\circ} \mathrm{C}, 18 \mathrm{~min}$ of residence time, a secondary decomposition temperature of $850^{\circ} \mathrm{C}$, and a molar steam-to-carbon ratio of 2 .

Lam et al. (2012) used waste automotive engine oil as the biomass feedstock in a pyrolysis process, and microwave energy was used as the heat source. It was found that the microwave-heated pyrolysis of waste engine oil generated an $88 \mathrm{wt} . \%$ yield of condensable pyrolysis oil, the properties of which are comparable to traditional liquid transportation fuels derived from fossil fuel. In addition, the oil product had a very high recovery (90\%) of the energy present in the waste oil and very low contaminant levels of sulfur, oxygen, and toxic polycyclic aromatic hydrocarbon (PAH) compounds. Microwave-heated pyrolysis was recommended as a green approach to the treatment and recycling of automotive lubricating oil.

Fidalgo and Menéndez (2012) carried out a lab-scale pilot plant for a microwave-assisted $\mathrm{CO}_{2}$ reforming of methane over carbon-based catalysts (the activated carbon, FY5, a heterogeneous mixture of FY5, and an in-lab prepared $\mathrm{Ni} / \mathrm{Al}_{2} \mathrm{O}_{3}$ ) to study the energy conversion and consumption. High and steady $\mathrm{CH}_{4}$ and $\mathrm{CO}_{2}$ conversion were achieved, regardless of the catalyst used in the biomass pyrolysis process.

Liu et al. (2014) studied the catalytic pyrolysis process to generate hydrogen-rich gas in a two-stage fixed-bed reactor system. It was demonstrated that the high productivity of hydrogen was obtained by increasing the catalytic bed temperature, residence time, and catalysts. For the best hydrogen production, the first-stage pyrolysis was at $650-700^{\circ} \mathrm{C}$, the second-stage catalytic bed was at $800^{\circ} \mathrm{C}$, the catalytic pyrolysis reaction time was 17 min, and nickel content was at $9 \%$ (wt \%).

\section{Biomass Gasification}

The biomass gasification process thermochemically converts biomass feedstocks into syngas in a gasification medium such as air, oxygen, and/or steam. Depending on the plant scale, the final use of produced syngas, and the reactor types, the gasification process typically occurs at temperatures ranging from 500 to $1,400^{\circ} \mathrm{C}$ and at pressures ranging from atmospheric to 33 bar. The syngas produced from biomass gasification can be further processed in the same way as those produced from the biomass pyrolysis process to increase hydrogen production. During the gasification process, biomass may undergo several drying steps to remove moisture, pyrolysis to remove volatiles $\left(\mathrm{CO}, \mathrm{CO}_{2}\right.$, light hydrocarbons, and tar), and reduction and combustion reactions.

Nipattummakul et al. (2011) investigated high-temperature steam gasification of residual wastes from oil palm trees to produce hydrogen-rich syngas in a semi-batch reactor with temperatures ranging from 600$1,000^{\circ} \mathrm{C}$. The steam and solid fuel ratio decreased from $18.5 \mathrm{~g} / \mathrm{g}$ to approximately $2.1 \mathrm{~g} / \mathrm{g}$. The energy ratio increased by approximately $33 \%$ when the temperature increased from 600 to $1,000^{\circ} \mathrm{C}$.

Wang et al. (2015) carried out biomass gasification of commercial pellets of pine wood sawdust and cotton stalk in a pilot-scale two-stage gasification gasifier. With $99.5 \mathrm{v} \%$ oxygen applied to the tests, the carbon conversion efficiency was at $80 \%$, with syngas containing more than $70 \mathrm{v} \% \mathrm{of}_{2}+\mathrm{CO}$ and an $\mathrm{H}_{2} / \mathrm{CO}$ ratio of 1 . 
In the biomass gasification via the steam critical water approach, water is subjected to its supercritical state $\left(374^{\circ} \mathrm{C}\right.$ and $\left.22.1 \mathrm{MPa}\right)$ and becomes an oxidant. When biomass feedstocks react with supercritical water, the oxygen molecules in water are transferred to carbon atoms of biomass to generate the carbon monoxide, which reacts with steam to produce $\mathrm{CO}_{2}$ and hydrogen via the WGS reaction. Supercritical steam gasification is considered one of the most effective and efficient techniques of generating hydrogen from biomass. It offers high efficiency and hydrogen yield with a lower rate of tar formation (Xu and Antal Jr. 1998, Lu et al. 2006).

Several types of biomass feedstocks used in the supercritical steam gasification process were studied, such as cellulose, starch, and glucose (Hao et al. 2003, Williams and Onwudili, 2006). For instance, Hao et al. (2003) used glucose as the biomass compound in a tubular supercritical water gasification system at $650^{\circ} \mathrm{C}$ and $35 \mathrm{MPa}$ to produce a gas composed of $\mathrm{H}_{2}, \mathrm{CO}, \mathrm{CH}_{4}, \mathrm{CO}_{2}$, and a small amount of $\mathrm{C}_{2} \mathrm{H}_{4}$ and $\mathrm{C}_{2} \mathrm{H}_{6}$. These conditions were later adapted to a raw biomass feedstock of sawdust with some sodium carboxymethylcellulose (CMC) and found that the gasification efficiency was higher than $95 \%$. Williams and Onwudili (2006) carried out subcritical and supercritical water gasification processes of cellulose, starch, and glucose that were considered biomass compounds and biomass in the form of cassava waste in a heated batch reactor. The mixture gases produced included $\mathrm{CO}_{2}, \mathrm{CO}$, hydrogen, methane, and other hydrocarbons, in addition to a large amount of oil and char. Williams and Onwudili (2006) also note that glucose produced the highest hydrogen yield, whereas cellulose produces a higher yield of char, carbon monoxide, and $\mathrm{C}_{1}-\mathrm{C}_{4}$ hydrocarbons compared to starch and glucose.

Other waste products like cassava waste, corn silage, fruit shells, sawdust, rice straw, corn and clover grass, and sewage sludge were also used as biomass feedstocks for the biomass gasification in supercritical water (Xu and Antal Jr 1998, Hao et al. 2003, Demirbas 2004, D’Jesús et al. 2006a,b). D'Jesús et al. (2006b) performed gasification of $5 \mathrm{wt} \%$ corn silage at supercritical water conditions in a continuous flow reactor at a temperature range of $300-700^{\circ} \mathrm{C}$ and a pressure range of $250-400 \mathrm{bar}$. The biomass gasification process was partially converted at a lower temperature, and the gas yield decreased. However, biomass conversion in supercritical water was completed as the temperature increased and more hydrogen, methane, and ethane were obtained. In Demirbas's (2004) study, an aqueous conversion of whole fruit shells was conducted under low temperature and supercritical conditions to generate hydrogen-rich gas. It was (2004) found that the yields of gases and liquids produced by the biomass supercritical water extraction increased with increasing temperature, and the hydrogen yields increased with increasing temperature and pressure. The required input energy for the drying process of biomass feedstocks could be significantly minimized when the wet biomass was gasified directly via the supercritical steam gasification process. Furthermore, it was found that the reactor could be built compact to facilitate the high-pressure reaction, and the produced hydrogen gas could be pressurized, making it convenient for storage and transportation (Hahn 2006, Zhang et al. 2010).

\section{Biological Processes of Biomass}

Hydrogen production based on the biological process of biomass feedstocks has received much attention in recent years because (i) it requires less thermal energy inputs as most biological processes take place at the ambient temperature and pressure, and (ii) it uses various waste materials as feedstocks and renewable energy resources that positively contribute to the waste management process. The main biological processes of biomass for hydrogen production consist of bio-photolysis, photo and dark fermentation, and a hybrid system of dark and photo-fermentation. Fermentation processes can occur with or without oxygen: organic feed materials are microbially transformed to alcohols, acetone, a small amount of $\mathrm{H}_{2}$, and $\mathrm{CO}_{2}$. In the fermentative processes, feedstocks are biomass wastes or carbohydrate-containing materials that are first converted to organic acids and hydrogen-rich gas. 


\section{Bio-Photolysis}

Principles of bio-photolysis are similar to those found in plants and algal photosynthesis; however, they are adapted for hydrogen generation. Bio-photolysis feedstock is water, whereas bacteria, green algae, and blue-green algae split water molecules into hydrogen ions and oxygen via photosynthesis. The generated hydrogen ions are converted into hydrogen gas by hydrogenase enzymes. Several ordinary hydrogen-producing algae and green algae include chlamydomonas reinhardtii (Melis 2002), scenedesmus obliquus (Florin et al. 2001), chlorococcum littorale (Ueno et al. 1999), playtmonas subcordiformis (Guan et al. 2004), and chlorella fusca (Winkler et al. 2002). The hydrogenase activity of different algae species is discussed by Winkler et al. (2002).

\section{Dark Fermentation}

Dark fermentation uses mainly anaerobic bacteria on carbohydrate-rich substrates without oxygen presence and dark conditions. Glucose is a preferred biomass source, but it is not cost-effective and is not always available in large quantities. Starch-containing materials and cellulose, abundant in nature and plant biomass, can be alternatively used (Kapdan and Kargi 2006). Dark fermentation is often considered because it has a simple process, uses numerous potential substrates (refuse and wastes), and does not require a large surface area (it does not rely on the light sources) that could maintain the hydrogen production rate constant, regardless of day or night (Das and Veziroglu 2001). Holladay et al. (2009) note that hydrogen produced during the dark fermentation process must be removed to maintain the relatively low-pressure environment and hydrogen yield.

\section{Photo-Fermentation}

Photo-fermentation is realized in deficient nitrogen conditions using solar energy and organic acids. Several kinds of photosynthetic bacteria convert organic acids, such as acetic, lactic, and butyric, industrial effluent, and other carbohydrates, into hydrogen and carbon dioxide under anaerobic conditions in the presence of light (Kapdan and Kargi 2006, Das and Veziroglu 2008). Several purple photosynthetic bacteria are rhodobacter spheroides (Eroglu et al. 2004, Kim et al. 2006), rhodobacter capsulatus (He et al. 2005, Fang et al. 2005), rhodovulum sulfidophilum W-1S (Maeda et al. 2003), and rhodopseudomonas palustris (Barbosa et al. 2001). Barbosa et al. (2001) and Shi and Yu (2005) note that light intensity might affect the efficiency of photo-fermentation and the consumption rates of organic acids. For instance, Shi and $\mathrm{Yu}(2005)$ found that increasing light intensity positively affected hydrogen production but lowered light efficiency.

A hybrid system of dark and photo-fermentation consists of non-photosynthetic (anaerobic) and photosynthetic bacteria that provide higher hydrogen production yields and require less light energy. First, anaerobic bacteria convert carbohydrates into hydrogen and organic acids under dark conditions, which later become sources for photosynthetic bacteria to produce additional hydrogen (Das and Veziroglu 2001).

Among the biological processes to produce hydrogen, bio-photolysis based on algae could be considered an economical and sustainable approach in water utilization and $\mathrm{CO}_{2}$ consumption. However, a relatively low hydrogen potential and no waste product utilization are disadvantages of algae's hydrogen production in the bio-photolysis process. The fermentation and its hybrid system have more advantages, because they provide higher hydrogen production yields and contribute to the waste treatment process (Kapdan and Kargi 2006). 


\subsubsection{Water-Splitting Process}

Water can be used to produce hydrogen via water-splitting processes such as electrolysis, thermolysis, and photo-electrolysis (Steinfeld 2005, Nikolaidis and Poullikkas 2017). As water is plentiful and inexhaustible, hydrogen produced through the water-splitting process can be considered a green energy carrier if energy inputs are supplied from renewable and/or sustainable energy sources such as wind, hydro, solar, and nuclear power.

\section{Electrolysis}

Under development for many years, electrolysis has been an established, well-known method and is the most effective method for water-splitting processes (Bamberger and Richardson 1976). The primary issue associated with hydrogen production via electrolysis is the high demand for electricity for electrolyzers (Rossmeisl et al., 2005). However, with the recent development and advanced technologies to provide electrical energy from renewable and sustainable energy sources such as hydro, wind, solar, and nuclear, water-splitting based on the electrolysis process can be further applied to produce green hydrogen (the cleanest energy carrier).

An electrolysis unit (electrolyzer) typically consists of a cathode and an anode immersed in an electrolyte. An electrical current splits the water to produce hydrogen at the cathode, while oxygen is evolved on the anode side (Levene et al., 2007). The most widely applied electrolysis technologies are alkaline, proton exchange membrane (PEM), and solid oxide electrolysis cells (SOECs). In the electrolyzers of alkaline and SOEC, water introduced at the cathode is split into hydrogen and hydrogen ions (OH-). The produced hydrogen is separated from water using a separator, and $\mathrm{OH}$ - travels through the electrolyte to the anode side to create oxygen (Rossmeisl et al., 2005). In the PEM electrolyzer, water introduced at the anode side is split into protons (hydrogen ions, $\mathrm{H}+$ ) and oxygen.

Oxygen remains within the water, but hydrogen ions $\mathrm{H}+$ travel through membranes to the cathode sides and form hydrogen. Under standard conditions, a thermodynamic potential of $1.23 \mathrm{~V}$ is enough to activate the electrochemical water splitting process. However, because of the sluggish kinetics of hydrogen evolution reaction (HER) and oxygen evolution reaction (OER), very high overpotentials are required to reach a suitable current density, yielding a relatively low energy conversion efficiency for the electrolysis water splitting process. Many efforts have been dedicated to enhancing the efficiency of electrolytic water splitting. These efforts have primarily been focused on fabricating high-performance electrocatalysts that are typically noble metal-based catalysts (e.g., Pt for HER and $\mathrm{IrO}_{2}$ or $\mathrm{RuO}_{2}$ for OER) for acidic media, and transition metal-based catalysts (e.g., Ni electrodes for HER and stainless steel composites for OER) for alkaline electrolytes (You and Sun 2018, Zheng et al. 2020). However, challenges associated with noble metal electrocatalysts, such as high cost, low reverse, and scarcity, have limited their large-scale use to industry (Liu et al., 2015).

Most recent studies aim to develop non-noble-metal electrocatalysts that could provide high efficiency and low cost while realizing a high current density at a low overpotential for the sluggish kinetics of twoelectron transfer in HER, and a high energy barrier for breaking the $\mathrm{O}-\mathrm{H}$ and forming the $\mathrm{O}-\mathrm{O}$ bond in OER (Zheng et al. 2020). Among the investigated and developed electrocatalysts, transition-metal phosphide shares a high similarity with hydrogenase and could be applied as electrocatalysts for water splitting (Lin et al. 2019, Sun et al. 2019). Chen et al. (2018) and Guan et al. (2018) tested their designs of electrocatalysts based on cobalt phosphides (CoP). They found that CoP exhibited a significant improvement in electrocatalytic performance for both HER and OER. Additionally, the CoP-based electrocatalysts are low cost, offer high electrical conductivity, and boast metalloid characteristic properties that could enhance design possibilities for the industry. Several carbon-based materials can also 
be applied to improve the integrity and morphologies of electrocatalysts and accelerate electron transfer for the HER or OER process (Yao et al. 2018, Yu et al. 2018).

\section{Thermolysis}

Thermolysis, or thermochemical water splitting, utilizes thermal energy input to decompose water into hydrogen and oxygen at a very high temperature $\left(>2,500^{\circ} \mathrm{C}\right)$. When the temperature is very high, the Gibbs function ( $\Delta \mathrm{G}$, or free energy) becomes zero, and hydrogen can feasibly be separated from the equilibrium mixture (Funk 2001). The energy needed for the thermolysis process is substantial and can not be provided by some types of sustainable energy sources. Several thermochemical water-splitting cycles have been adopted to lower the required high temperature and to improve process efficiency. Thermochemical cycles usually consist of a series of chemical reactions at different temperatures, such as a two-step $\mathrm{SnO}_{2} / \mathrm{SnO}$ cycle (Abanades et al. 2008) and a multi-stage $\mathrm{Cu}-\mathrm{Cl}$ cycle (Orhan et al. 2008) that will convert thermal energy (heat) into hydrogen as an energy carrier. Maximum temperatures required for thermochemical cycles are approximately $1600{ }^{\circ} \mathrm{C}$ for the two-step $\mathrm{SnO}_{2} / \mathrm{SnO}$ cycle and $500^{\circ} \mathrm{C}$ for the multi-stage $\mathrm{Cu}-\mathrm{Cl}$ cycle. These temperatures can be attained using solar energy or nuclear energy.

Currently, two-step $\mathrm{Cu}-\mathrm{Cl}$ and $\mathrm{Mg}-\mathrm{Cl}$ thermochemical cycles are the most promising, with relatively low temperatures required $\left(550^{\circ} \mathrm{C}\right)$ without exhausting any greenhouse gases.

With recent progress on solar collectors, large-scale concentrated solar radiation using parabolic reflectors, namely trough, tower, and dish systems (Bamberger and Richardson 1976), can serve as the energy source to provide high-temperature heat for driving the endothermic chemical reactions of thermochemical cycles. Kolb et al. (2006) found that using a sulfuric acid/hybrid thermochemical cycle with a power tower could provide a solar-to-hydrogen efficiency of $21 \%$ with a hydrogen cost of $2.80 \$ / \mathrm{kg}$. The thermochemical cycles provided a lower cost of hydrogen at a higher overall efficiency than solar plant systems using electrolysis. Giaconia et al. (2007) proposes a combined solar and natural gas system for hydrogen production. The system based on the sulfur-iodine reaction would use methane conversion for the high-temperature sulfuric process. Concentrated solar energy would be used as a heat source for the lower temperature hydrogen-iodide section of the reaction.

Among candidate thermochemical cycles of water splitting process for hydrogen production investigated and evaluated (Ponomarev-Stepnoi; 2004; Forsberg; 2005; Nelson et al.; 2007), the high-temperature steam electrolysis (HTSE) and the Westinghouse hybrid sulfur process (WSP), and the sulfur-iodine (SI) thermochemical process are the most developed (Orhan et al.; 2008). However, these technologies are still at the lab-scale test stage and require further development and technology demonstration on a large scale to test their system integrity and their operational and economic feasibility. General Atomics (GA) developed the SI thermochemical cycle in the 1970's and reported that the cycle had the highest predicted efficiency and the greatest potential for further improvement (Mathias et al.; 2003). Japan, Korea, Europe (Le Duigou et al.; 2007) and USA have tested and further improved the SI thermochemical cycle and the efficiency reported are within 35-45\% (Elder and Allen; 2009). Collaborative research between U.S. DOE and French-CEA I-NERI was to develop an integrated lab scale experiment of the SI cycle (Pickard et al.; 2008). CEA developed the Bunsen section, Sandia National Laboratory (SNL) developed the $\mathrm{H}_{2} \mathrm{SO}_{4}$ section, while GA integrated these two parts from CEA and SNL to develop the HI section. JAEA demonstrated bench-scale experiments of the SI cycle and reported a stable production of hydrogen (Kubo et al.; 2004).

The hybrid copper chloride $\mathrm{Cu}-\mathrm{Cl}$ has been recently developed at U.S. Argonne National Laboratory with the advantage of the highest operating temperature is at $550^{\circ} \mathrm{C}$ (Ratlamwala and Dincer 2015). Naterer et al. (2011) and Ratlamwala and Dincer (2015) discussed that the lower operating temperature of the $\mathrm{Cu}-\mathrm{Cl}$ cycle $\left(\approx 530^{\circ} \mathrm{C}\right)$ could reduce the costs of materials and maintenance when compared to other thermochemical cycles having higher operating temperatures. Besides, Masin et al. (2006) and 
Zamfirescu et al. (2010) pointed out that the $\mathrm{Cu}-\mathrm{Cl}$ thermochemical cycle has high efficiency up to 55\%, depending on the design and operating conditions.

Different concepts can be developed to provide required thermal energy using a heat-exchanger reactor from nuclear power plants into the endothermic chemical process for hydrogen generation (Le Duigou et al., 2007). Forsberg et al. (2003) compares the costs of nuclear hydrogen generation in Japan. The cost of nuclear-based thermochemical $\mathrm{H}_{2}$ production could be as low as $60 \%$ of that for nuclear $\mathrm{H}_{2}$ production by water electrolysis. Onuki et al. (2005) summarize bench-scale tests of a process control method for continuous hydrogen production that was aimed to facilitate the high-temperature gas-cooled reactor (HTGR) technology at the Japan Atomic Energy Research Institute (JAERI). Integrating the hydrogen production system into the HTGR is one of the significant challenges to bridge the nuclear energy sector to resolving global issues on the energy crisis, climate change, and global warming. The Japan Atomic Energy Agency (JAEA) has been performing research and development to incorporate hydrogen production and HTGR technologies. For example, Nishihara and Inagaki (2006) and Inagaki et al. (2007) summarize the developed system integration technology to connect a hydrogen production system to an HTGR, including (i) a control technology to maintain reactor normal operating conditions with respect to thermal disturbance from the integrated hydrogen production system (most thermochemical cycles require thermal energy with temperatures exceeding $850-900^{\circ} \mathrm{C}$ ), (ii) a tritium permeation into the hydrogen from the reactor, (iii) a countermeasure against the explosion of combustible gas, and (iv) a hightemperature isolation valve to isolate the reactor and hydrogen production systems in cases of accidents. $\mathrm{Wu}$ and Onuki (2005) conducted a lab-scale experimental demonstration of hydrogen production based on the thermochemical SI process. They also employed membrane technology to improve the decomposition efficiency; they found that the maximum attainable one-pass hydrogen conversion rate increased up to $90 \%$, and the equilibrium rate was about $20 \%$.

In the detailed assessment of various reactor types for thermochemical hydrogen production considering a matrix of basic requirements, such as chemical and coolant stabilities, pressure and temperature, feasibility (development requirement and development risks), safety, capital costs, intermediate loop compatibility, and other merits and issues, Brown et al. (2003) concluded that the advanced nuclear reactors are suitable candidates. The authors suggested that while heavy metal and molten salt reactors appear to be promising candidates with relatively high development costs, HTGRs are well-suited for hydrogen production using thermochemical cycles. Brown et al. (2003) discussed that HTGRs successfully operated over years can provide the required heat energy and no major development work is identified. Fast breeder reactor technologies can also be a potential candidate for providing long-term energy sources for hydrogen production. Chikazawa et al. (2006) designed a hydrogen production plant based on thermochemical and electrolytic hybrid processes using a sulfuric acid cycle requiring a maximum temperature of $500^{\circ} \mathrm{C}$. A sodium-cooled fast reactor could supply the hydrogen production system's required heat, and a high efficiency of $44 \%$ could be obtained.

\section{Photoelectrolysis}

In the photo-electrolysis process, specialized semiconductors called photoelectrochemical materials, absorb sunlight energy to directly dissociate water molecules into hydrogen and oxygen, or water splitting. This is a long-term technology pathway for generating hydrogen with very low or no emissions of greenhouse gases. The semiconductor materials used in the photoelectrolysis product are somewhat similar to those used in photovoltaic solar electricity generation. However, in the photoelectrolysis watersplitting applications, the semiconductor is immersed in a water-based electrolyte, where the sunlight strikes the surfaces and energizes the water-splitting process.

Photoelectrolysis has a low efficiency $(\approx 0.06 \%)$ due to the lack of effective photocatalytic materials (Nikolaidis and Poullikkas 2017). Mavroides (1978) lists some materials that can be used as electrodes in 
photoelectrolysis cells. Among those, Akikusa and Khan (2002) point out that the combination of SiC and $\mathrm{TiO}_{2}$ can act as a self-driven system to photo-split water without any externally applied potential at a photoconversion efficiency of $0.06 \%$. Further studies are recommended to improve efficiency by utilizing proper sensitizer on high bandgap semiconductor surfaces.

Gholipour et al. (2015) lists various semiconductor heterojunctions for photocatalytic hydrogen generation and notes that $\mathrm{TiO}_{2}$ - and CdS-based systems have been most studied. As one of the commercial photocatalysts, $\mathrm{TiO}_{2}$ can be applied for various photocatalysis processes, and nano-sized $\mathrm{TiO}_{2}$-based photocatalysts exhibit an improvement in hydrogen production from the visible light region. CdS-based photocatalysts are currently among the best photocatalysts for hydrogen generation under visible light. Gholipour et al. (2015) concludes that coupling semiconductors improved the efficiency of the photocatalyst, but the overall efficiency of photo-electrolysis for hydrogen production remains very low.

\subsubsection{Summary}

Table 1 summarizes information regarding feedstocks, efficiency, advantages, and disadvantages of various hydrogen production processes using fossil fuels and renewable sources.

Hydrocarbon reforming processes are the most mature technologies that are commonly used throughout the industry via existing infrastructures. Of these processes, SMR is the most cost-effective process for hydrogen production. In addition, the steam reforming process has the lowest operating temperature and does not require oxygen. The autothermal reforming and partial oxidation processes have the same efficiency, and both require oxygen presence in their reactions. Hydrocarbon pyrolysis offers advantages of reduced reactions in the thermal decomposition via the single and two-step schemes and no emission of greenhouse gases. Carbon is the only byproduct requiring treatment for this process. Recent developments of membrane reactors, oxygen, and hydrogen transport membranes can further improve the efficiency, maximum operating temperature, and capital investments of hydrogen production processes using fossil fuels. For example, the lower required temperature of $550^{\circ} \mathrm{C}$ could be provided from the exhaust gases of a gas turbine in a combined cycle for both power and hydrogen production, from concentrated solar energy (Nikolaidis and Poullikkas 2017), or nuclear energy (Brown et al. 2003, Schultz 2003, Wood 2010). However, major challenges of hydrocarbon reforming processes are the dependence on fossil fuels and $\mathrm{CO}_{2}$ byproducts released into the atmosphere that require the integration of $\mathrm{CO}_{2}$ capture and storage. These challenges will affect the hydrogen cost.

Biomass feedstocks for biohydrogen production processes are abundant and available almost anywhere. Dark fermentation has the highest efficiency (60-80\%) among all hydrogen production processes using renewable sources. In contrast, biophotolysis and photofermentation have very low efficiencies, and they require sunlight inputs in their processes. Thermochemical processes such as pyrolysis and gasification have a significant efficiency in the range of 35-50\%, whereas the fermentative processes positively contribute to waste recycling and management. Among all hydrogen production processes using biomass, biophotolysis is considered $\mathrm{CO}_{2}$-consumed because of the photosynthesis involved. Besides the negative effect of tar formation, the produced hydrogen content of thermochemical processes are varied due to feedstock impurities and seasonal availability (Berndes et al. 2003, Demirbas 2006).

The water-splitting process offers a clean, sustainable pathway for hydrogen production, producing only hydrogen and oxygen from Earth's most abundant raw materials. Electrolysis is the most advanced technology, with an efficiency of 40-60\%. However, it has high capital costs and is responsible for $\mathrm{CO}_{2}$ emission if the electricity required is provided from fossil fuels. This limitation can be overcome by utilizing electricity produced from other clean energy sources such as solar, wind, and nuclear energy (Le Duigou et al., 2007). Thermolysis has an efficiency of 20-45\%. However, its main limitations are the 
element toxicity and the high capital cost from the required high heat, which can be solved using high temperatures produced from advanced nuclear reactors (Orhan et al. 2008, Naterer et al., 2009).

Photoelectrolysis is the least efficient process $(0.06 \%)$ because of the lack of effective photocatalytic materials. In general, solar-based processes have low conversion efficiency, hydrogen rates, and yields, followed by biological methods, which operate under mild conditions. Water-splitting processes have been becoming the most promising methods to produce clean hydrogen, with considerable conversion efficiency and moderate temperatures required for both electrolysis and thermolysis that can be supplied from nuclear energy (Le Duigou et al. 2007, Dincer and Balta 2011). 
Table 1. Summary of hydrogen production processes, adapted from Nikolaidis and Poullikkas (2017)

\begin{tabular}{|c|c|c|c|c|c|c|}
\hline & Sources & Process & Feedstocks & $\begin{array}{l}\text { Efficiency } \\
\quad(\%)\end{array}$ & Major advantages & Major disadvantages \\
\hline & \multirow{3}{*}{$\begin{array}{l}\text { Hydrocarbon } \\
\text { Reforming }\end{array}$} & Steam reforming & Hydrocarbons & $70-85$ & Most developed technology, existing infrastructure & $\mathrm{CO} 2$ byproduct, dependence on fossil fuels \\
\hline & & Partial oxidation & Hydrocarbons & $60-75$ & Proven technology, existing infrastructure & $\mathrm{CO} 2$ byproduct, dependence on fossil fuels \\
\hline \multirow{4}{*}{\multicolumn{2}{|c|}{ 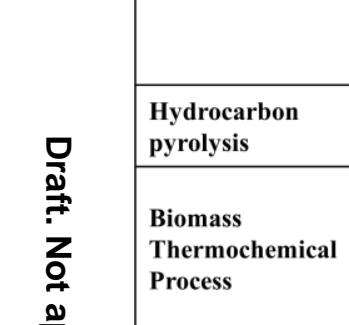 }} & $\begin{array}{l}\text { Autothermal } \\
\text { reforming }\end{array}$ & Hydrocarbons & $60-75$ & Proven technology, existing infrastructure & $\mathrm{CO} 2$ byproduct, dependence on fossil fuels \\
\hline & & $\begin{array}{l}\text { Hydrocarbon } \\
\text { pyrolysis }\end{array}$ & Hydrocarbons & NA & Emission-free, reduced-step procedure & Carbon byproduct, dependence on fossil fuels \\
\hline & & Biomass pyrolysis & Biomass & $35-50$ & $\mathrm{CO} 2$-neutral, abundant and cheap feedstock & $\begin{array}{l}\text { Tar formation, varying } \mathrm{H} 2 \text { content due to seasonal availability } \\
\text { and feedstock impurities }\end{array}$ \\
\hline & & $\begin{array}{l}\text { Biomass } \\
\text { gasification }\end{array}$ & Biomass & NA & CO2-neutral, abundant and cheap feedstock & $\begin{array}{l}\text { Tar formation, varying } \mathrm{H} 2 \text { content due to seasonal availability } \\
\text { and feedstock impurities }\end{array}$ \\
\hline \multirow{6}{*}{ 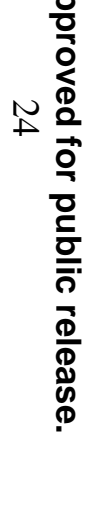 } & \multirow{3}{*}{$\begin{array}{l}\text { Biomass } \\
\text { Biological } \\
\text { Process }\end{array}$} & $\begin{array}{l}\text { Biomass- } \\
\text { photolysis }\end{array}$ & Water + sunlight & 10 & CO2-consumed, $\mathrm{O} 2$ byproduct, mild operating conditions & $\begin{array}{l}\text { Requires sunlight, low } \mathrm{H} 2 \text { rates and yields, requirement of large } \\
\text { reactor volume, } \mathrm{O} 2 \text { sensitivity, high raw material cost }\end{array}$ \\
\hline & & Dark fermentation & Biomass & $60-80$ & $\mathrm{CO} 2$-neutral, without light, contributes to waste recycling & $\begin{array}{l}\text { Fatty acids removal, low } \mathrm{H} 2 \text { rates and yields, low conversion } \\
\text { efficiency, requirement of large reactor volume }\end{array}$ \\
\hline & & $\begin{array}{l}\text { Photo } \\
\text { fermentation }\end{array}$ & $\begin{array}{l}\text { Biomass + } \\
\text { sunlight }\end{array}$ & 0.1 & $\begin{array}{l}\mathrm{CO} 2 \text {-neutral, contributes to waste recycling, can use various } \\
\text { organic wastes and wastewaters }\end{array}$ & $\begin{array}{l}\text { Requires sunlight, low } \mathrm{H} 2 \text { rates and yields, low conversion } \\
\text { efficiency, requirement of large reactor volume, } \mathrm{O} 2 \text { sensitivity }\end{array}$ \\
\hline & \multirow{3}{*}{$\begin{array}{l}\text { Water Splitting } \\
\text { Process }\end{array}$} & Electrolysis & $\begin{array}{l}\text { Water + } \\
\text { electricity }\end{array}$ & $40-60$ & $\begin{array}{l}\text { No pollution with electricity from renewable sources, proven } \\
\text { technology, existing infrastructure, abundant feedstock, } \\
\text { O2 byproduct, contributes to renewable energy resource }\end{array}$ & Low overall efficiency, high capital costs \\
\hline & & Thermolysis & Water + heat & $20-45$ & Clean and sustainable, abundant feedstock, $\mathrm{O} 2$ byproduct & Element toxicity, corrosive problems, high capital costs \\
\hline & & Photo-electrolysis & Water + sunlight & 0.06 & Emission-free, abundant feedstock, $\mathrm{O} 2$ byproduct & $\begin{array}{l}\text { Requires sunlight, low conversion efficiency, non-effective } \\
\text { photocatalytic material }\end{array}$ \\
\hline
\end{tabular}




\subsection{IMPROVING THE MODELS IN COMSOL MULTIPHYSICS}

\subsubsection{Introduction}

The COMSOL model simulated in this report includes the 8 ceramic tubes and the air regions with partially reformed syngas as a fuel inlet, as shown in Figure 6. The main chemical reactions in the OTM tubes are summarized in Figure 7. Because the primary reformer was not simulated in this work, the surface-to-ambient radiation model was used in the current COMSOL models instead of the surface-tosurface radiation model.

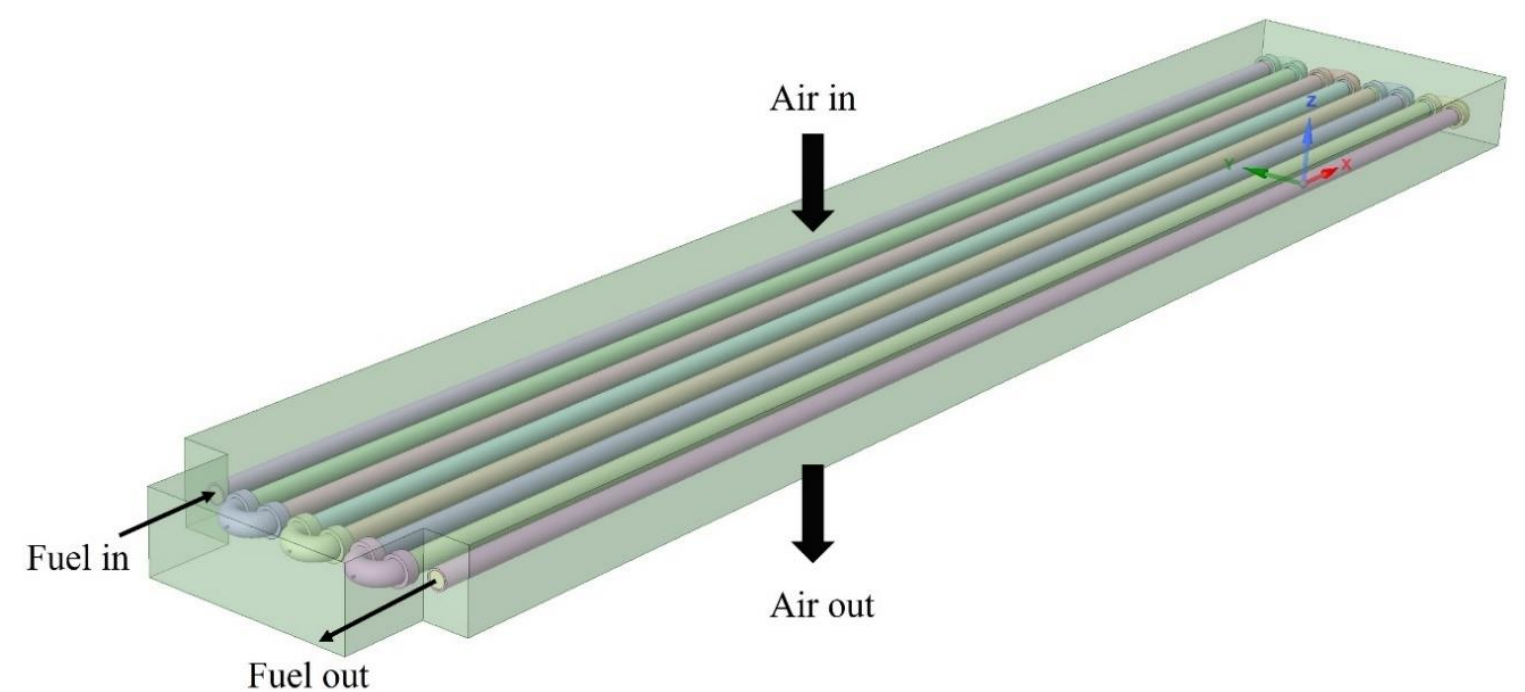

Figure 6. Geometry. 


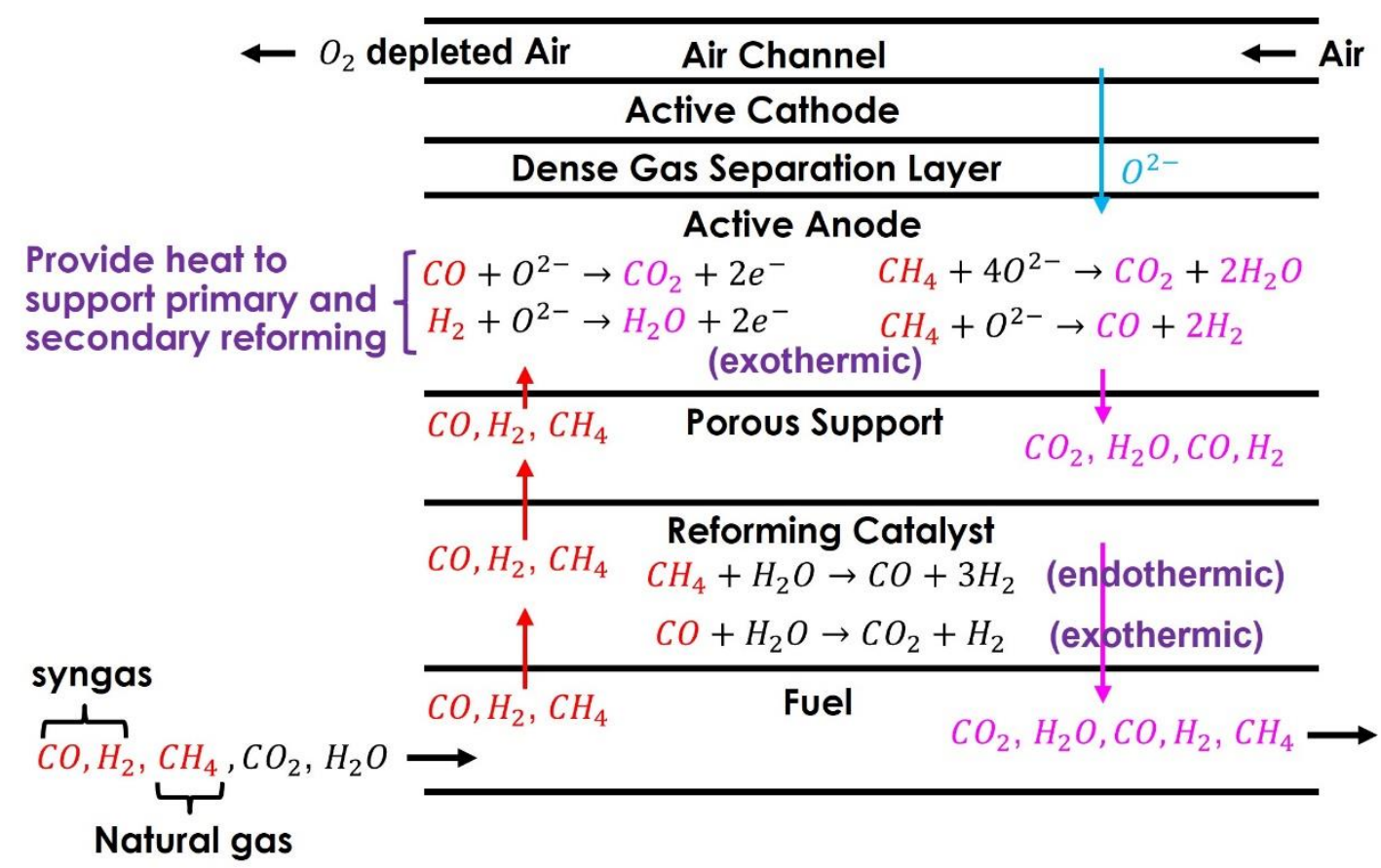

Figure 7. Chemical reactions in the oxygen transport membrane (OTM) tubes.

\subsubsection{COMSOL Model Description}

The endothermic steam-methane reforming reaction, presented in Eq. (3-1), as well as the exothermic water-gas shift reaction shown Eq. (3-2) [4], occur in the reforming catalyst layer in the OTM tubes, as shown in Figure 7:

$$
\begin{array}{ll}
\mathrm{CH}_{4}+\mathrm{H}_{2} \mathrm{O} \rightarrow \mathrm{CO}+3 \mathrm{H}_{2} & -206 \mathrm{~kJ} / \mathrm{mol}, \\
\mathrm{CO}+\mathrm{H}_{2} \mathrm{O} \rightarrow \mathrm{CO}_{2}+\mathrm{H}_{2} & +41.2 \mathrm{~kJ} / \mathrm{mol} .
\end{array}
$$

The combustion reactions that occur in the active anode are

$$
\begin{gathered}
\mathrm{H}_{2}+\mathrm{O}^{2-} \rightarrow \mathrm{H}_{2} \mathrm{O}+2 e^{-}, \\
\mathrm{CO}+\mathrm{O}^{2-} \rightarrow \mathrm{CO}_{2}+2 e^{-}, \\
\mathrm{CH}_{4}+4 \mathrm{O}^{2-} \rightarrow \mathrm{CO}_{2}+2 \mathrm{H}_{2} \mathrm{O}, \\
\mathrm{CH}_{4}+\mathrm{O}^{2-} \rightarrow \mathrm{CO}+2 \mathrm{H}_{2} .
\end{gathered}
$$

The thickness of the reforming catalyst, active anode, active cathode, and the dense gas separation layer shown in Figure 7 are very small, and therefore, were not explicitly (or, geometrically) modeled in COMSOL. The related chemical reactions in these four thin layers were simulated in gPROMS® (Process Systems Enterprise, http://www.psenterprise.com/), and results such as temperature-dependent reactions 
rates, consumptions and productions of species, and the utilization of the oxygen flux, were treated as interface conditions in the COMSOL models.

The COMSOL simulation domains are shown in Figure 8.

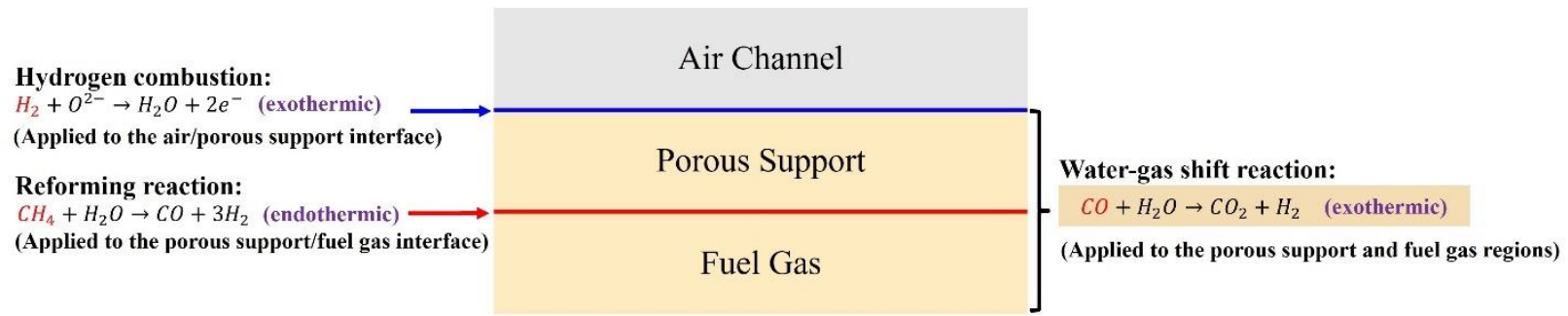

Figure 8. Simulation domains in the COMSOL models.

(a)

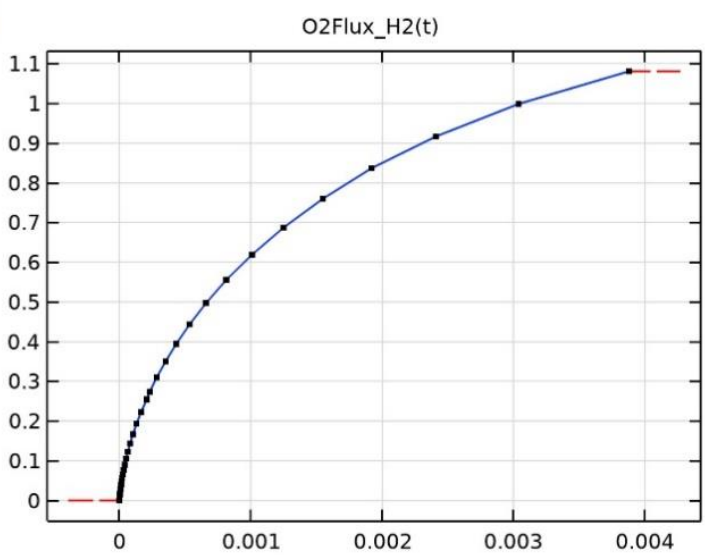

(c)

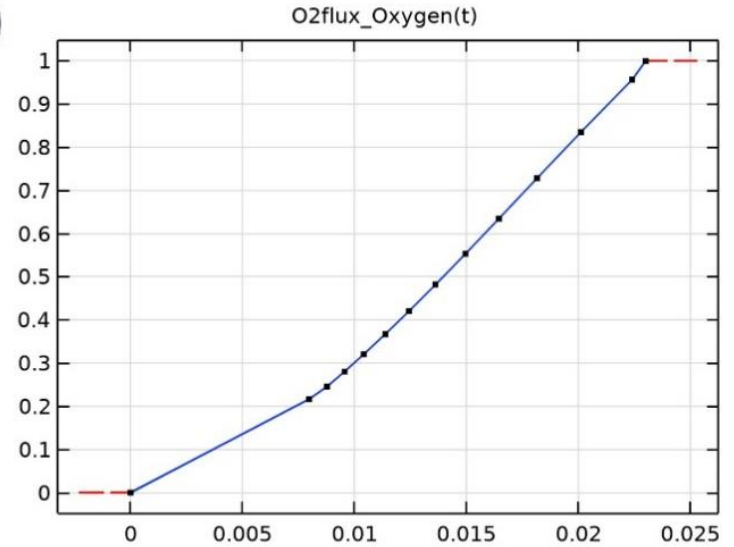

(b)

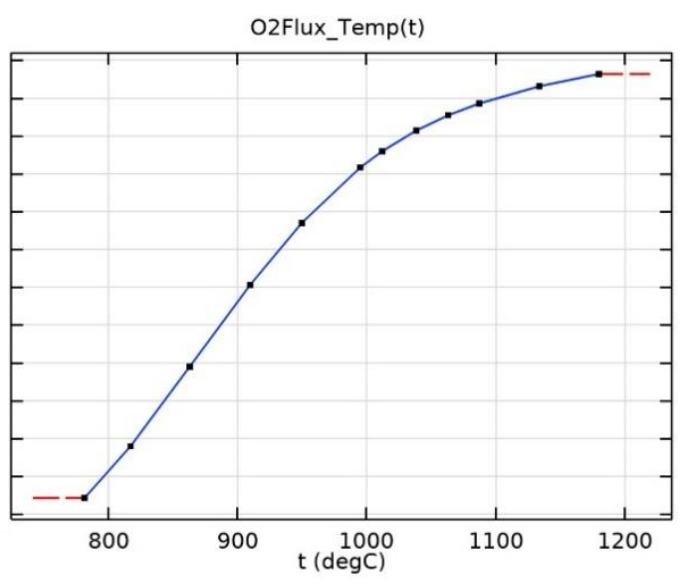

(d)

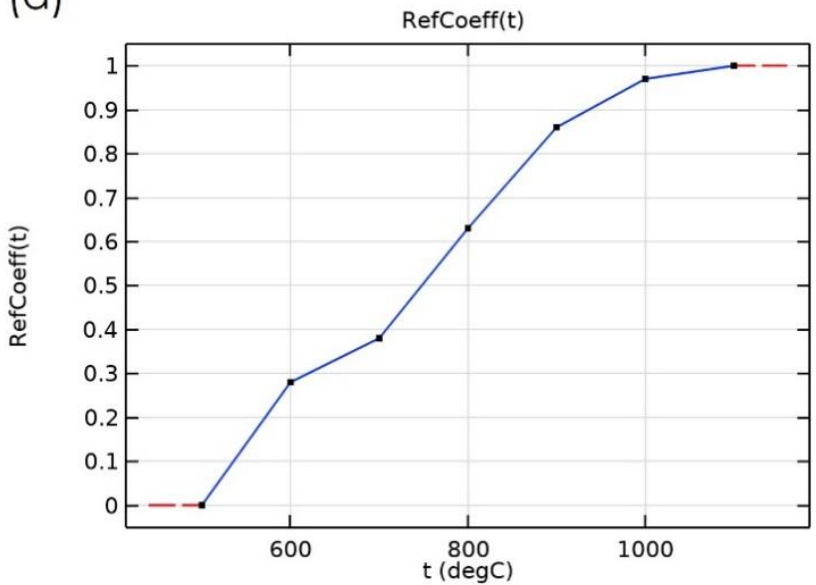

Figure 9. Reaction coefficients from gPROMS ${ }^{\circ}$ (The $\mathrm{x}$ axis label is molar fraction for (a) and (c) and is temperature for (b) and (d).).

The reaction coefficients shown in Figure 9 that were obtained from gPROMS $®$ were imported into COMSOL as interpolation function tables. As indicated in Figure 9 (a), (b), and (c), the inward oxygen flux at the boundary between the air channel and the porous support (Figure 8) is a function of hydrogen 
and oxygen concentrations and is also a temperature-dependent function. The inward oxygen flux at the boundary between the air channel and the porous support is defined by

$$
\begin{aligned}
& \text { O2Flux } \left.=\text { O2Flux_Temp }(T) \times \text { O2Flux_H2(chem } 2 . m_{-} H 2\right) \\
& \quad \times \text { O2flux_Oxygen }\left(\text { chem } . m_{-} \text {OO2 }\right)
\end{aligned}
$$

and

$$
\text { O2_mass_flux }\left[\mathrm{kg} / \mathrm{m}^{2} \cdot \mathrm{s}\right]=-C 1\left[\mathrm{~mol} / \mathrm{m}^{2} / \mathrm{s}\right] \times C 2[\mathrm{~kg} / \mathrm{mol}] *(\mathrm{O} 2 \mathrm{Flux} / \mathrm{C} 3) \text {. }
$$

Figure 9 (d) implies that the steam-methane reforming presented in Eq.(3-1) is a function of temperature, and the reaction rate is defined by

$$
\text { ref_rate }\left[\mathrm{mol} / \mathrm{m}^{2} \cdot \mathrm{s}\right]=C 4 \times \operatorname{RefCoeff}(T)
$$

and

$$
\text { reaction_rate }\left[\mathrm{mol} / \mathrm{m}^{3} \cdot \mathrm{s}\right]=\text { ref_rate } *(3.14 * \text { Fuel_Radius } * 2 * \text { TubeL }) / \text { TubeV. }
$$

In the COMSOL models, the discontinuities of mass flux at the interface between the fuel and the porous support (Figure 8) for different species caused by the SMR reaction shown in Eq.(3-1) were defined as follows,

$$
\begin{aligned}
& \text { consumption of CH4 }\left[\mathrm{kg} / \mathrm{m}^{2} \cdot \mathrm{s}\right]=- \text { ref_rate } \times 0.016[\mathrm{~kg} / \mathrm{mol}] \text {, } \\
& \text { consumption of } \mathrm{H} 20\left[\mathrm{~kg} / \mathrm{m}^{2} \cdot \mathrm{s}\right]=- \text { ref_rate } \times 0.018[\mathrm{~kg} / \mathrm{mol}] \text {, } \\
& \text { production of } \mathrm{CO}\left[\mathrm{kg} / \mathrm{m}^{2} \cdot \mathrm{s}\right]=\text { ref_rate } \times 0.028[\mathrm{~kg} / \mathrm{mol}],
\end{aligned}
$$

$$
\text { production of } H 2\left[\mathrm{~kg} / \mathrm{m}^{2} \cdot \mathrm{s}\right]=3 \times \text { ref_rate } * 0.002[\mathrm{~kg} / \mathrm{mol}] .
$$

A boundary heat flux $\left(\mathrm{W} / \mathrm{m}^{2}\right)$,

$$
-268[\mathrm{~kJ} / \mathrm{mol}] \times \text { ref_rate, }
$$

was also applied to the same interface due to the endothermic reforming reaction. The exothermic watergas shift reaction described in Eq.(3-2) was applied to the fuel and the porous support regions (Figure 8). For the combustion and oxidation reactions shown in Eqs. (3-3)-(3-6) in the active anode, only Eq. (3-3) was modeled as an interface condition at the interface between the air channel and the porous support in current COMSOL models, as shown in Figure 8. The consumption and production of $\mathrm{H}_{2}$ and $\mathrm{H}_{2} \mathrm{O}$ due to the reaction shown in Eq. (3-3) at the air and porous support interface are

$$
\text { consumption of } \mathrm{H} 2\left[\mathrm{~kg} / \mathrm{m}^{2} \cdot \mathrm{s}\right]=C 5
$$

and 


$$
\text { production of } H 2 O\left[\mathrm{~kg} / \mathrm{m}^{2} \cdot \mathrm{s}\right]=C 6
$$

A boundary heat flux $\left(\mathrm{W} / \mathrm{m}^{2}\right)$,

$$
\text { boundary heat flux }=C 7 \text {, }
$$

was applied to the same interface due to the exothermic reaction shown in Eq. (3-3).

$\mathrm{C} 1$ to $\mathrm{C} 7$ in above equations depicts process dependent values and parameters.

\subsubsection{Material Properties, Boundary Conditions, and Physics Models}

The material properties for the fuel gases were computed using the thermodynamic properties database in the Chemical Reaction Engineering Module in COMSOL 5.6. Composition- and temperature-dependent fluid properties such as heat capacity, viscosity, density, thermal conductivity, diffusion coefficients, the heat of reactions, heat of formations, and so on, can be computed with the thermodynamic properties database (COMSOL 2021), which is suitable for a reacting system like the OTM tubes. In this study, the Peng-Robinson equation of state (COMSOL 2021) is used for the gas mixture in the fuel region. The fuel outlet pressure is maintained at 125 psi.

The free and porous media flow (FP) interface in COMSOL multiphysics can be used to compute the velocity and the pressure fields for a free flow connected to porous media. This physics interface is suitable for the simulation domains containing slow flow governed by the Brinkman equations in porous media and the fast flow governed by the Navier-Stokes equations in channels (COMSOL 2021). Therefore, the FP interface was used for the fuel and the porous support regions in the OTM tubes. For the fuel region (Reynolds number ranges from 2100 to 4100), the simplest algebraic yPlus turbulence model was used, as this model is less mesh sensitive than the $\mathrm{k}-\varepsilon$ model, and this study is focused on the chemical reactions. The air in this study was also assumed to be laminar and incompressible $(\mathrm{Re}=38$ and $\mathrm{Ma}=0.003$ ) because the flow pattern and the pressure distribution of air was not expected to have a significant impact on the chemical reactions inside the OTM tubes.

\subsubsection{Mesh-Independence Study}

Results from several mesh configurations were compared to ensure that sufficient meshes were used to capture the significant phenomena in the OTM tubes with acceptable numerical errors and appropriate computing resources. Figure 10 shows a mesh configuration with a midplane cut through the whole domain to show the meshes used for the OTM tubes and nearby air. Four types of mesh configurations shown in Figure 11 were used for the mesh-independent study. The numbers of mesh elements for Mesh_1, Mesh_2, Mesh_3, and Mesh_4 are 0.8, 1.2,3.4, and 6.1 million, respectively. As shown in Figure 11, layers of prisms were gradually increased along the fuel stream direction, and tetrahedral meshes were used for the remaining domains, including air.

As shown in Figure 12, with coarse mesh (Mesh_1), the predicted air temperature is not smooth around the first five tubes close to the fuel inlet, and there is no appreciable difference between the Mesh_2 and the Mesh_3 configurations. The minimum temperature calculated by Mesh_4 is around $15^{\circ} \mathrm{C}$ lower than that by Mesh_2 and Mesh_3.

Since the steam-methane reforming reaction occurs at a relatively high temperature regime, the $15^{\circ} \mathrm{C}$ temperature difference was not expected to cause an apparent impact on the chemical reactions in this study. The predictions from different mesh configurations for individual species- $\mathrm{CO}, \mathrm{CO}_{2}, \mathrm{H}_{2} \mathrm{O}, \mathrm{H}_{2}$, and 
$\mathrm{CH}_{4}$ - are presented in Figure 13, through Figure 17, respectively. As can be observed, there are also no apparent differences in the distributions of these species as a result of different mesh configurations.

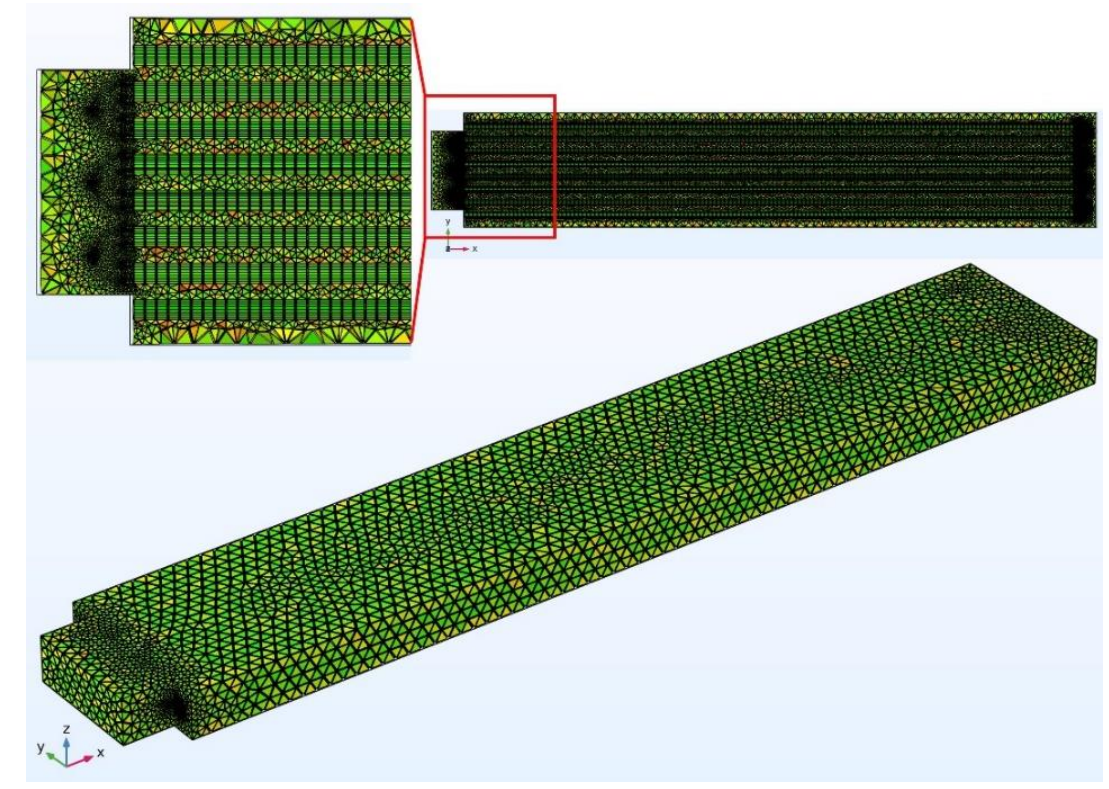

Figure 10. Mesh configuration for air and OTM tubes.
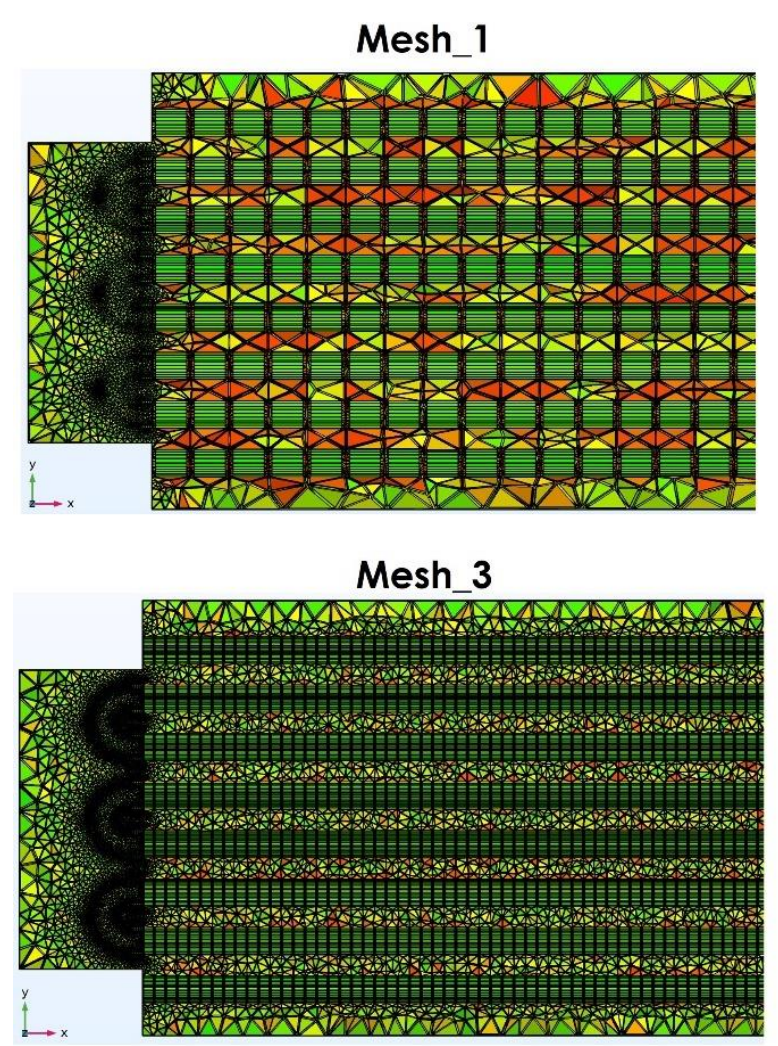
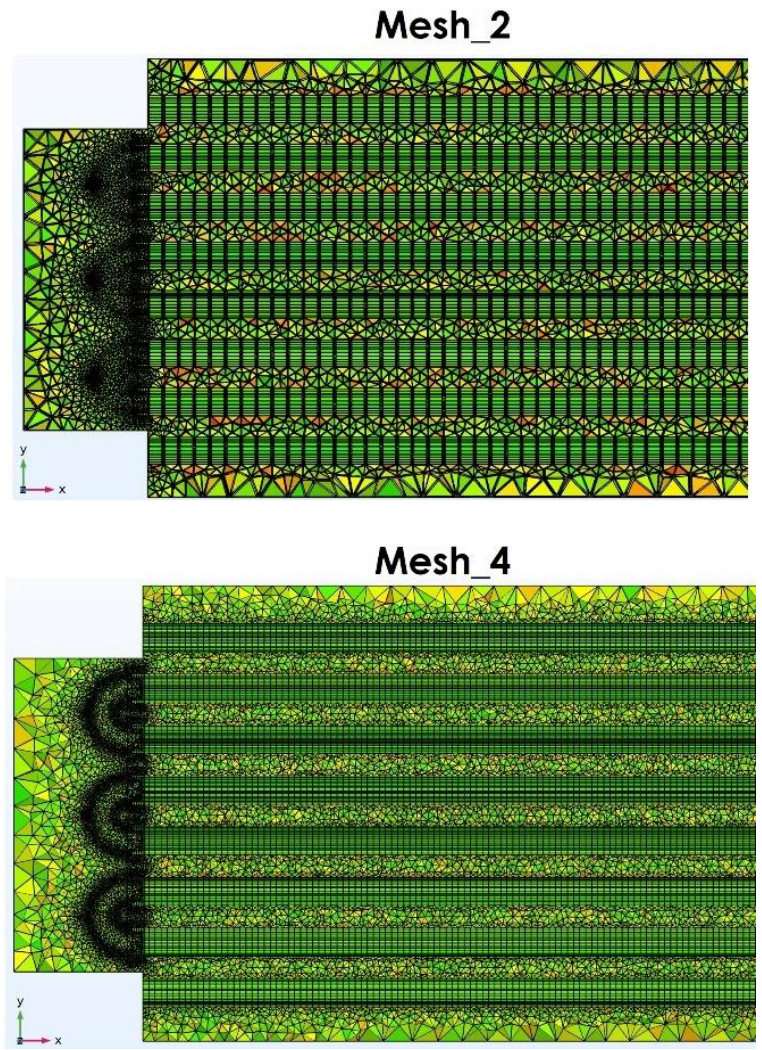

Figure 11. Different mesh configurations for the mesh-independence study. 


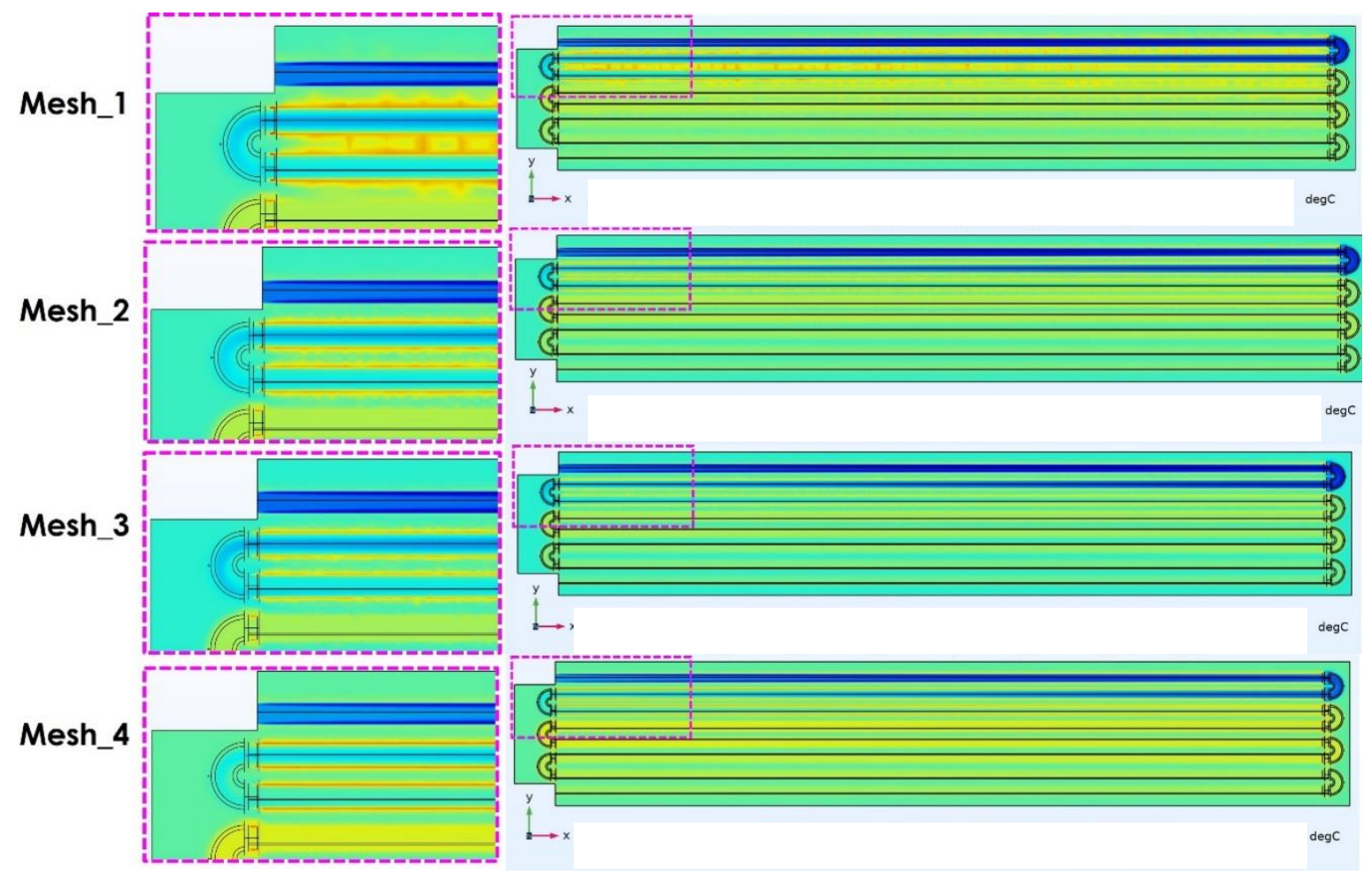

Figure 12. Temperature distributions for different mesh configurations (color scale is redacted).

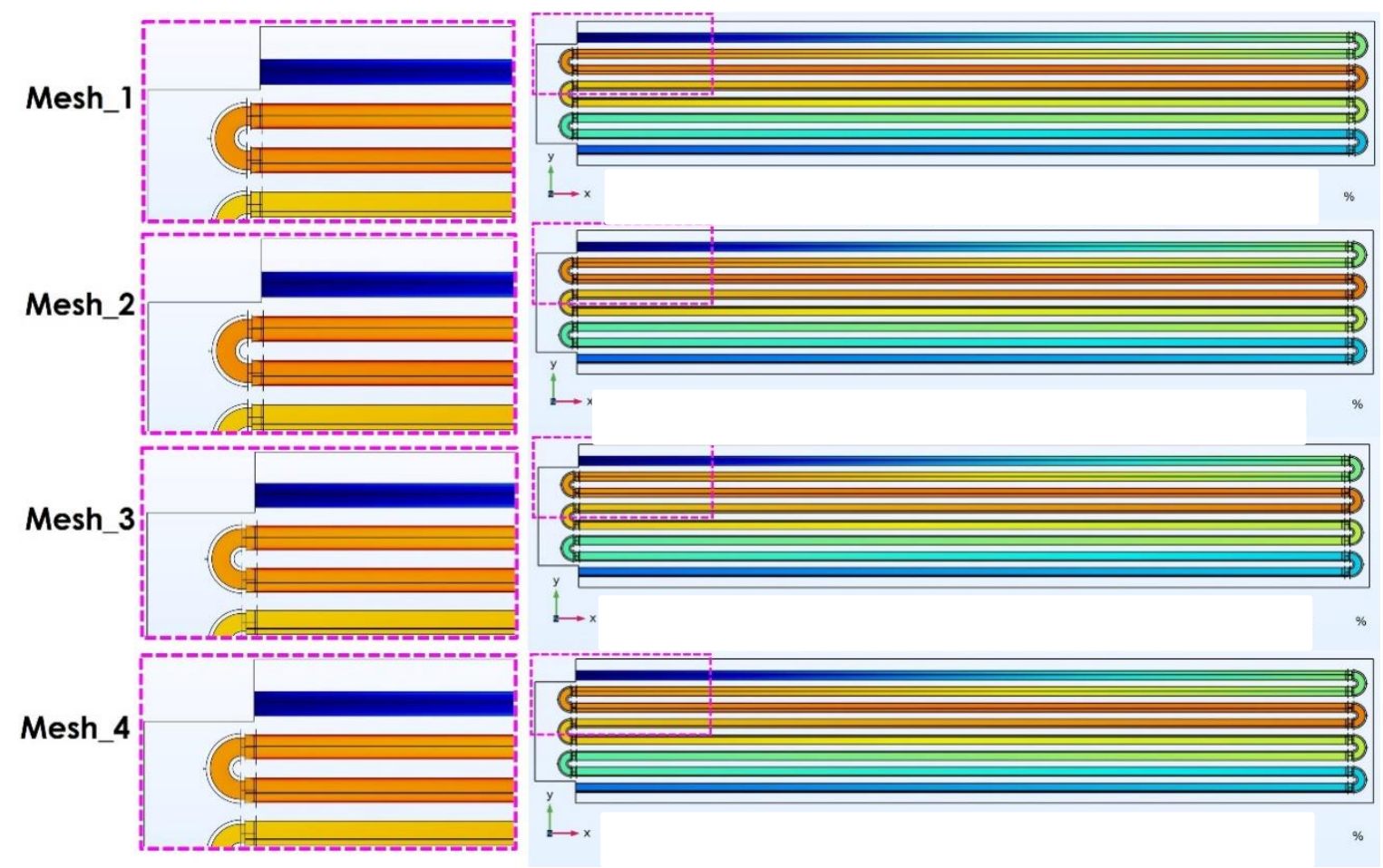

Figure 13. Mass fraction of $\mathrm{CO}(\%)$ for different mesh configurations (color scale is redacted). 

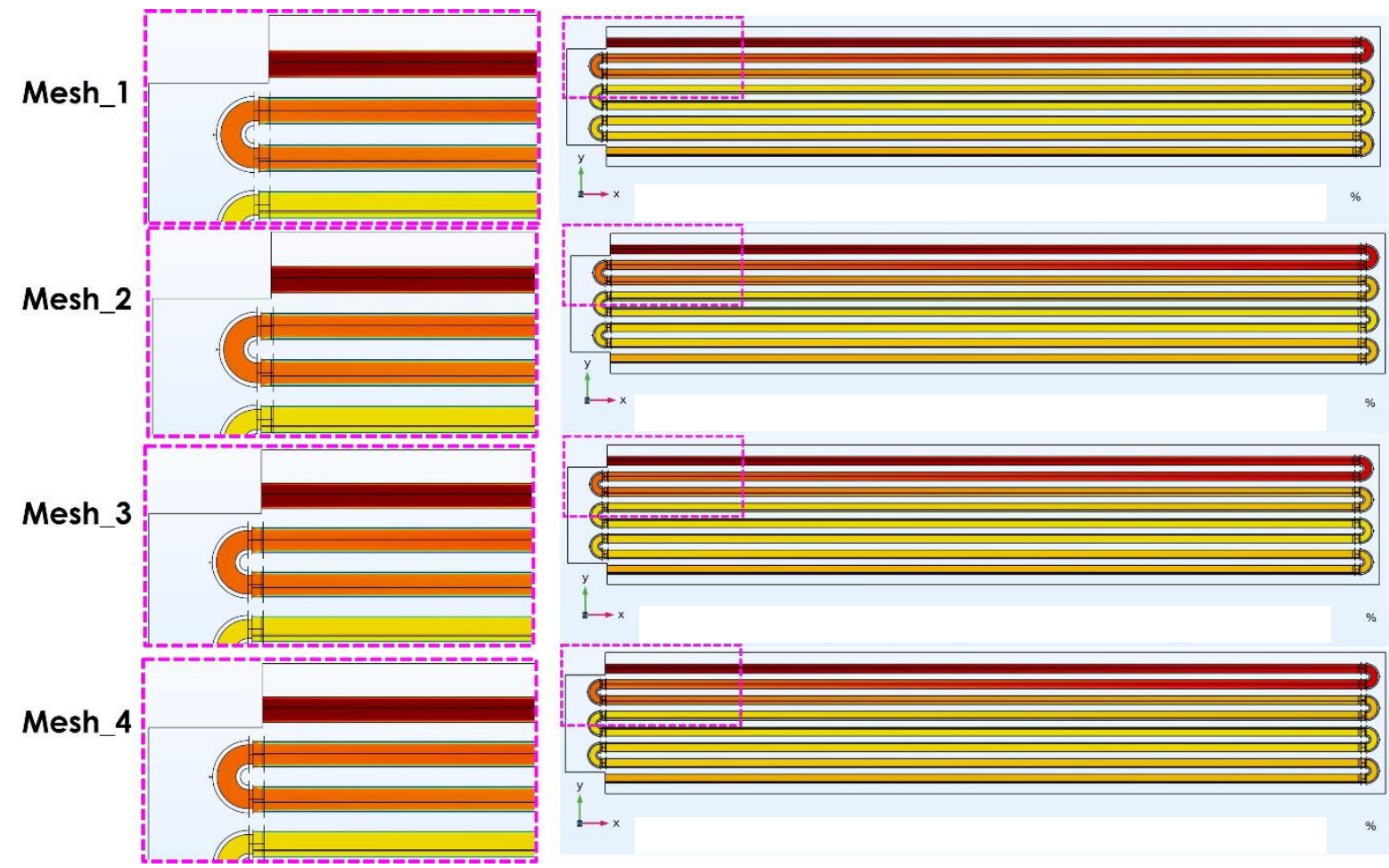

Figure 14. Mass fraction of $\mathrm{CO}_{2}(\%)$ for different mesh configurations (color scale is redacted).

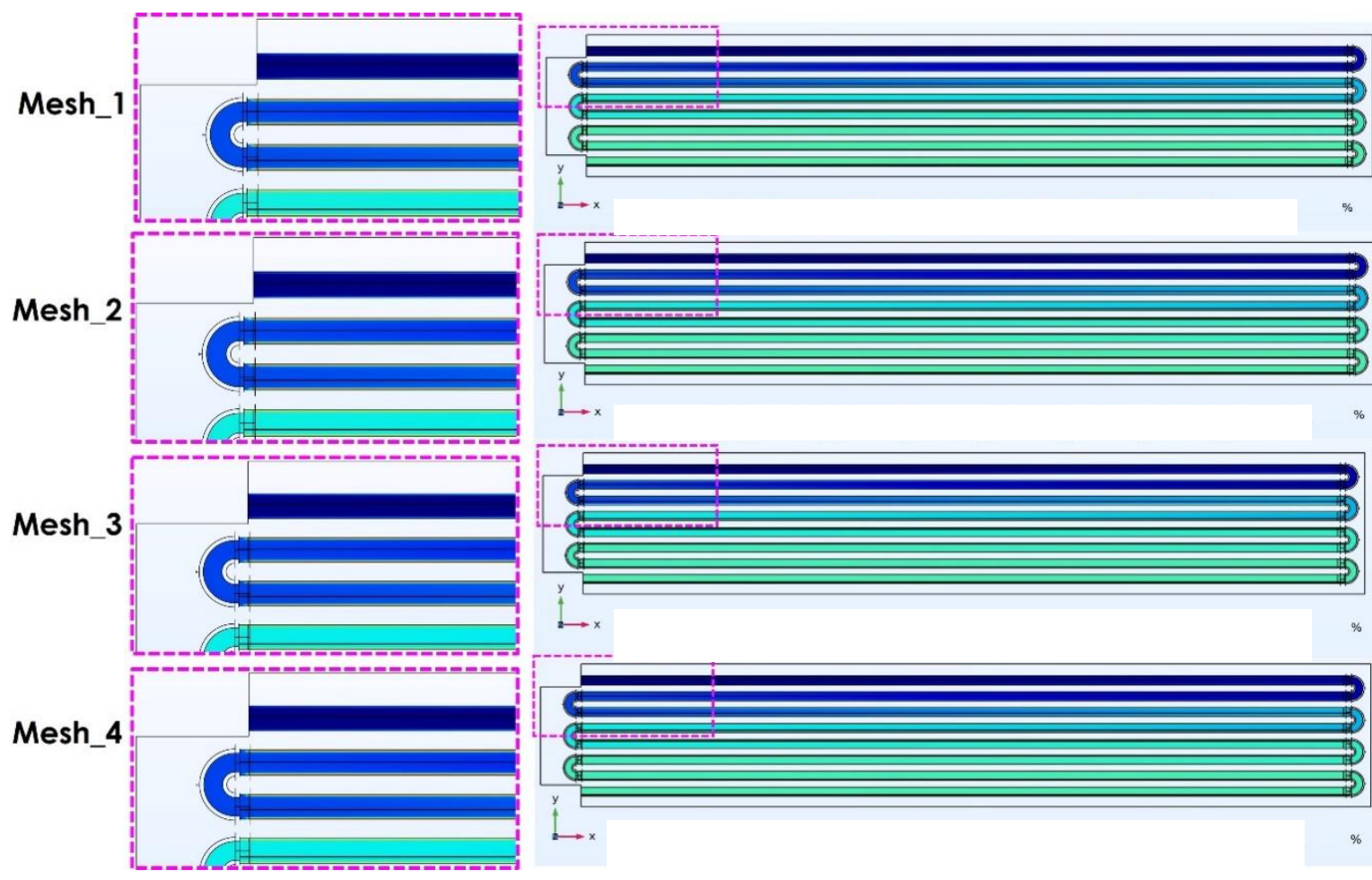

Figure 15. Mass fraction of $\mathrm{H}_{2} \mathrm{O}(\%)$ for different mesh configurations (color scale is redacted). 

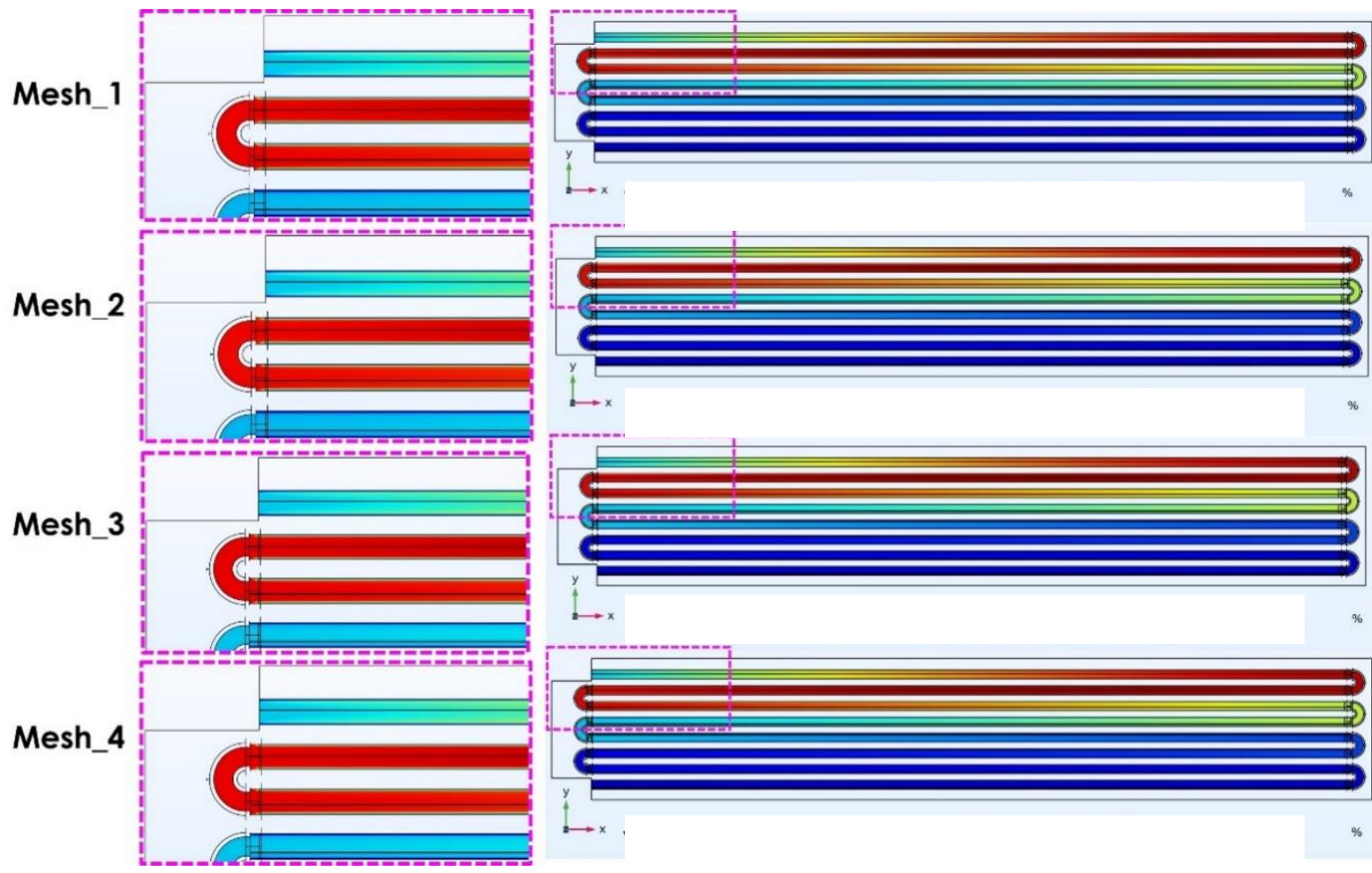

Figure 16. Mass fraction of $\mathrm{H}_{2}(\%)$ for different mesh configurations (color scale is redacted).
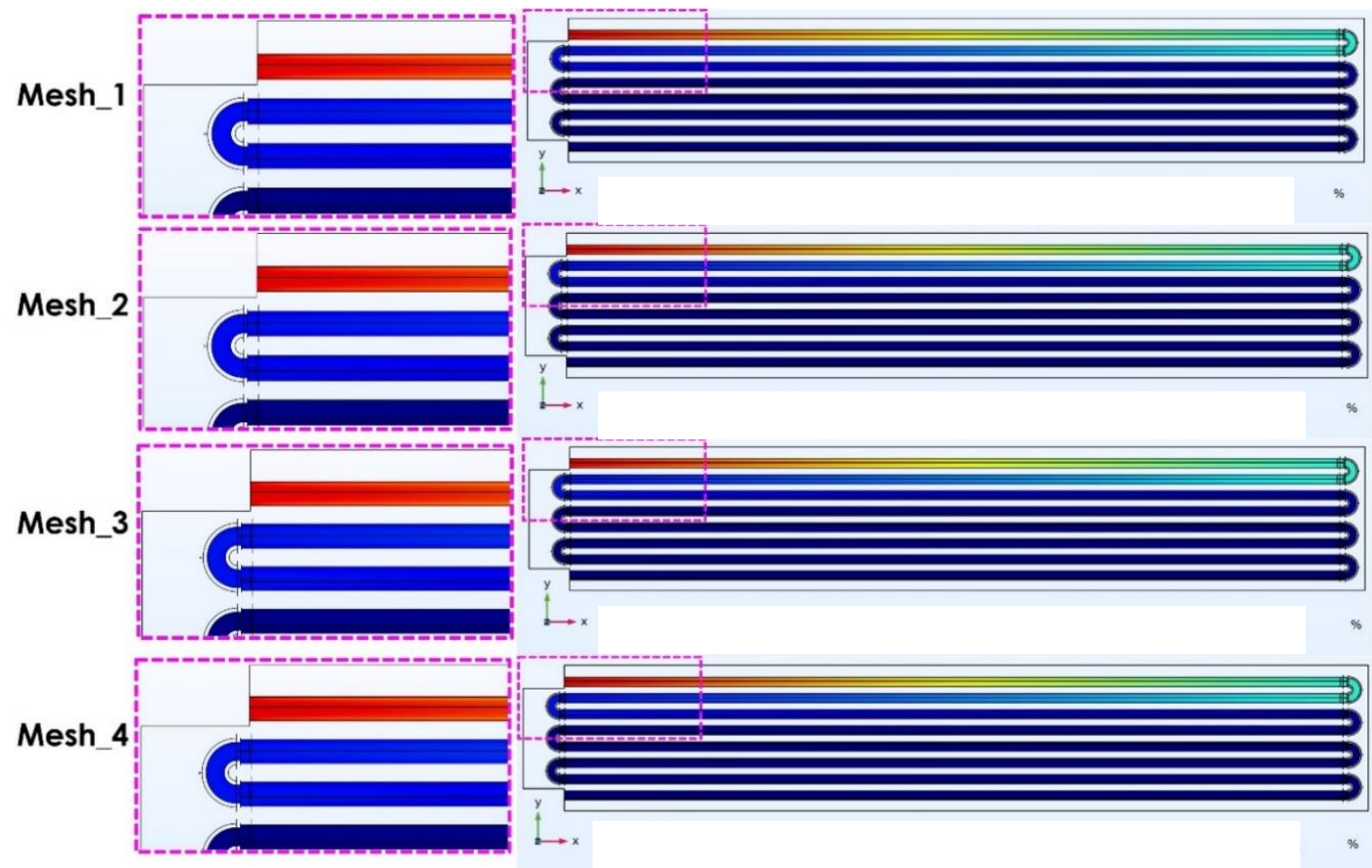

Figure 17. Mass fraction of $\mathrm{CH}_{4}(\%)$ for different mesh configurations (color scale is redacted). 
The result from Mesh_4 was used as a reference for the error estimations. The error between Mesh_3 and Mesh_4 is $0.02-0.05 \%$. The grid convergence index (GCI) was also computed for each component. For GCI calculations, a refinement ration of 1.67 and a safety factor of 1.25 were used. With Mesh_3 the GCI for $\mathrm{CO}_{2}$ is $0.076 \%$ and the $\mathrm{GCI}$ for $\mathrm{H}_{2} \mathrm{O}$ is $0.025 \%$. Therefore, the mesh configuration, Mesh_3, was considered sufficient for this study, and the corresponding results were used for further discussions in the later section.

\subsubsection{Results and Discussions}

All the results discussed in this section were from the simulation with Mesh_3. As shown in Figure 18, the OTM tubes operates within a wide range of temperatures. The temperature for the first two tubes drops below the inlet temperature, due to the endothermic reforming reaction, Eq. (3-1).

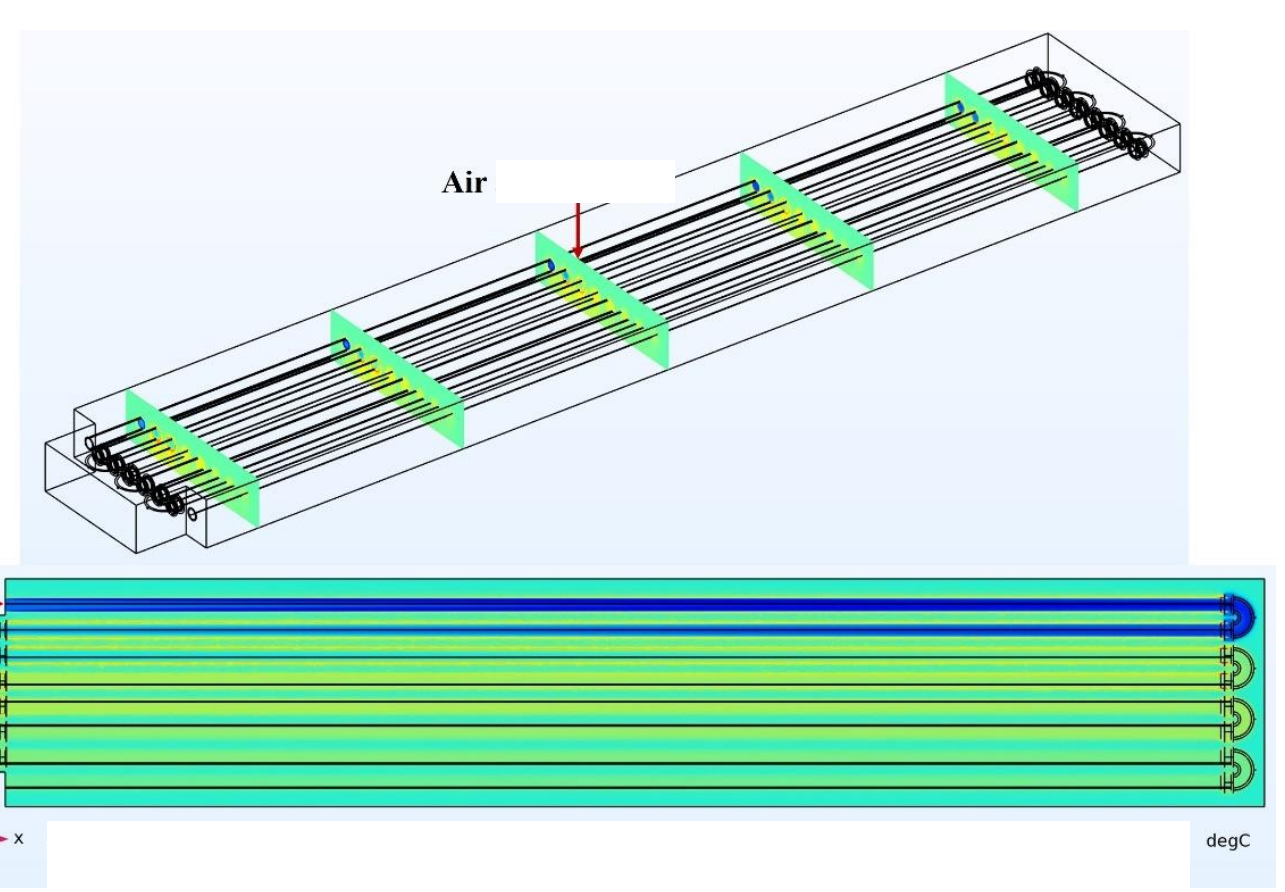

Figure 18. Temperature distribution for air and OTM tubes (color scale and values are redacted).

The velocity distributions in the OTM tubes and air are shown in Figure 19 and Figure 20, respectively. The outlet pressure was maintained at $125 \mathrm{psi}$, and the pressure drop between the inlet and the outlet is around $1 \mathrm{psi}$, as shown in Figure 21. Figure 22 shows the molar concentration of oxygen, $\mathrm{O}_{2}\left(\mathrm{~mol} / \mathrm{m}^{3}\right)$. The $\mathrm{O}_{2}$ in the air was actively selected by the OTM tubes and was diffused to the active anode layer where the combustion reactions took place. The heat was generated to support the endothermic reforming reaction. A boundary heat flux, Eq.(3-18), was applied to the boundary between the air channel and the porous support (Figure 8) to account for the heat released by the combustion reaction, Eq.(3-3). Similarly, the inward oxygen mass flux at this boundary was simulated by Eq.(3-8). 


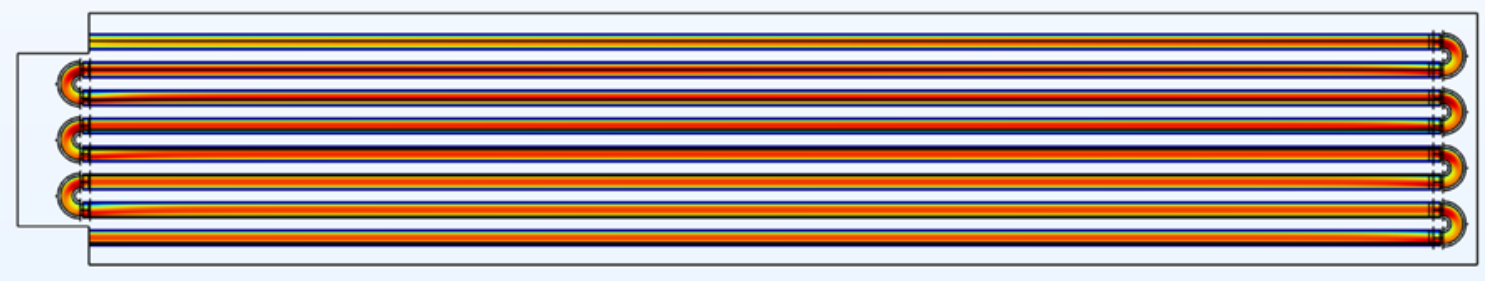

Figure 19. Velocity distribution in the OTM tubes (color scale is redacted).

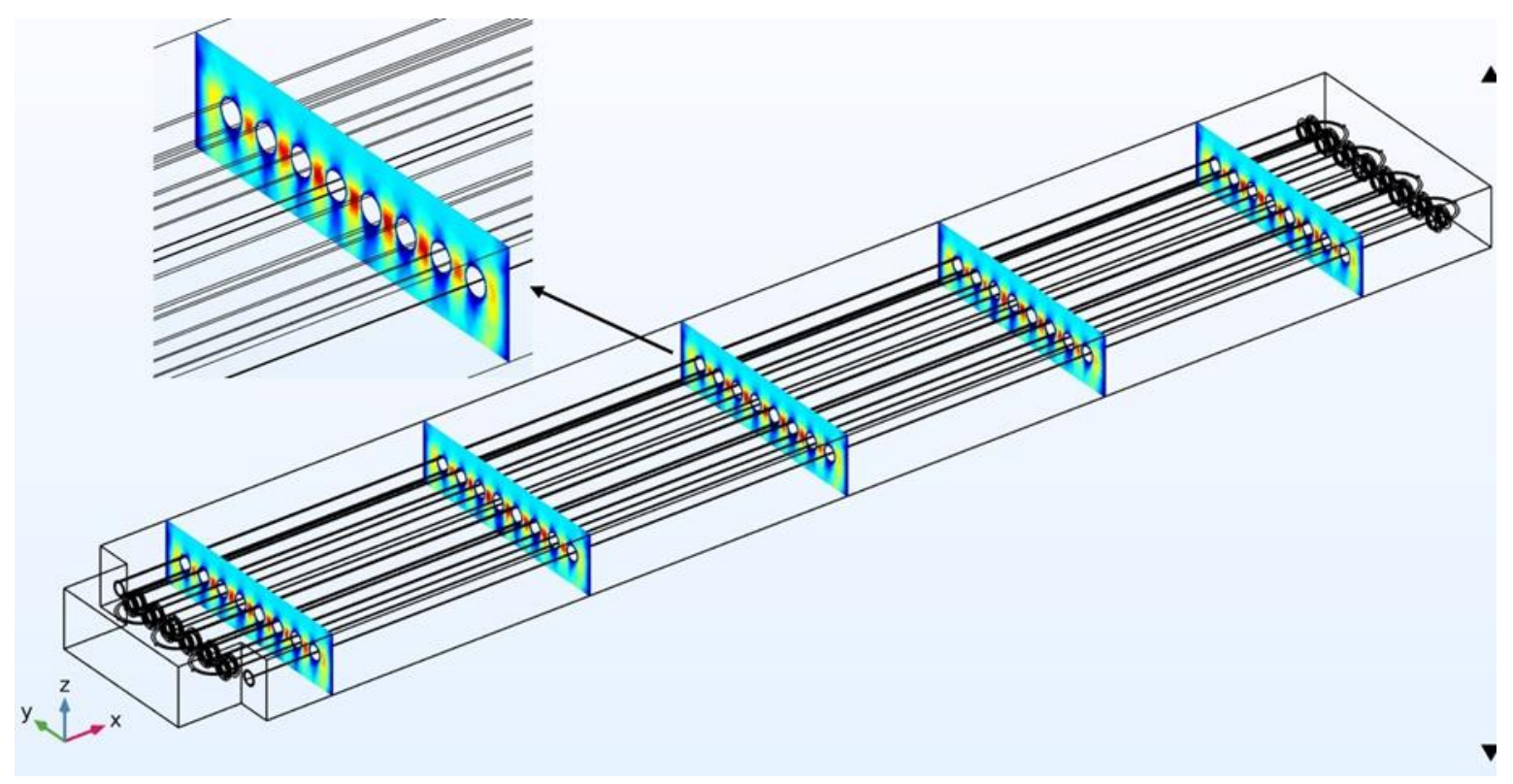

Figure 20. Velocity distribution of air (color scale is redacted).

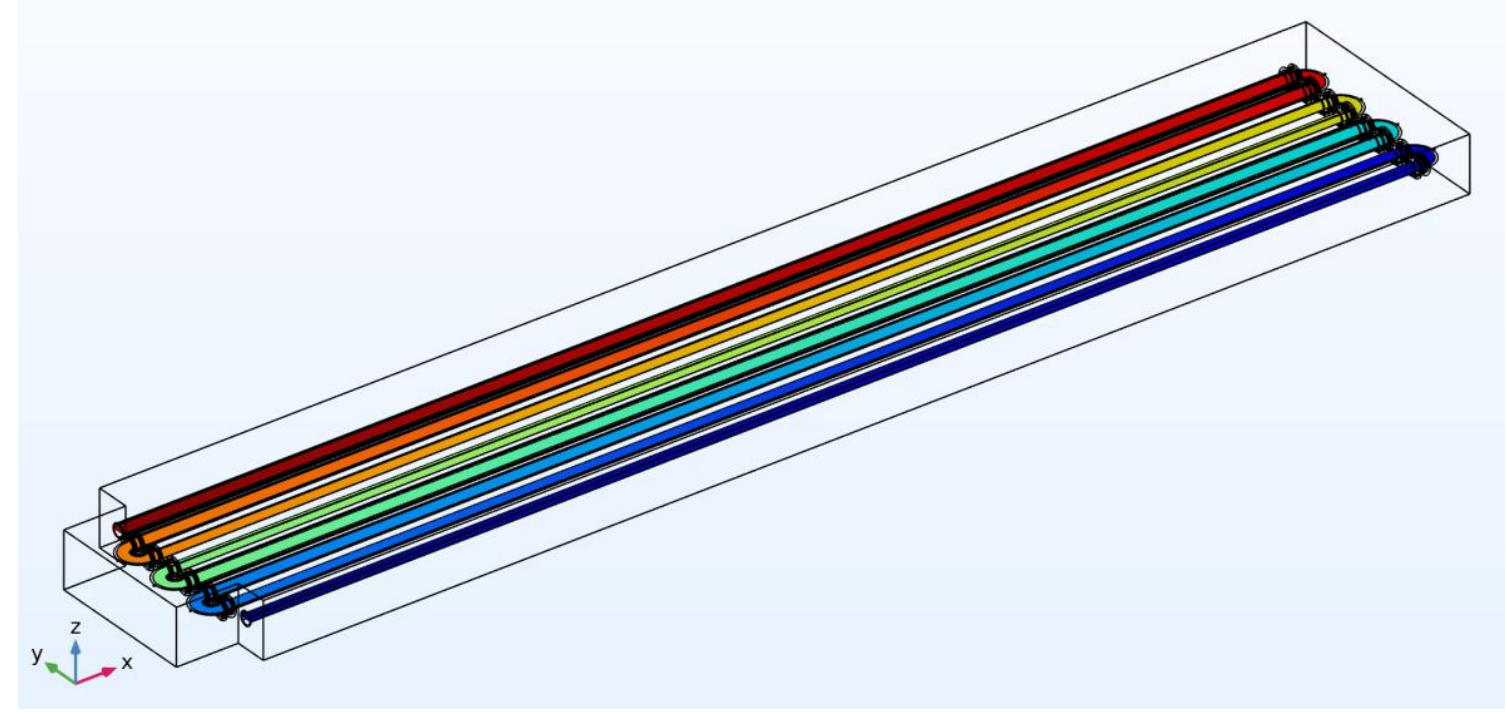

Figure 21. Pressure distribution in the OTM tubes (color scale is redacted). 


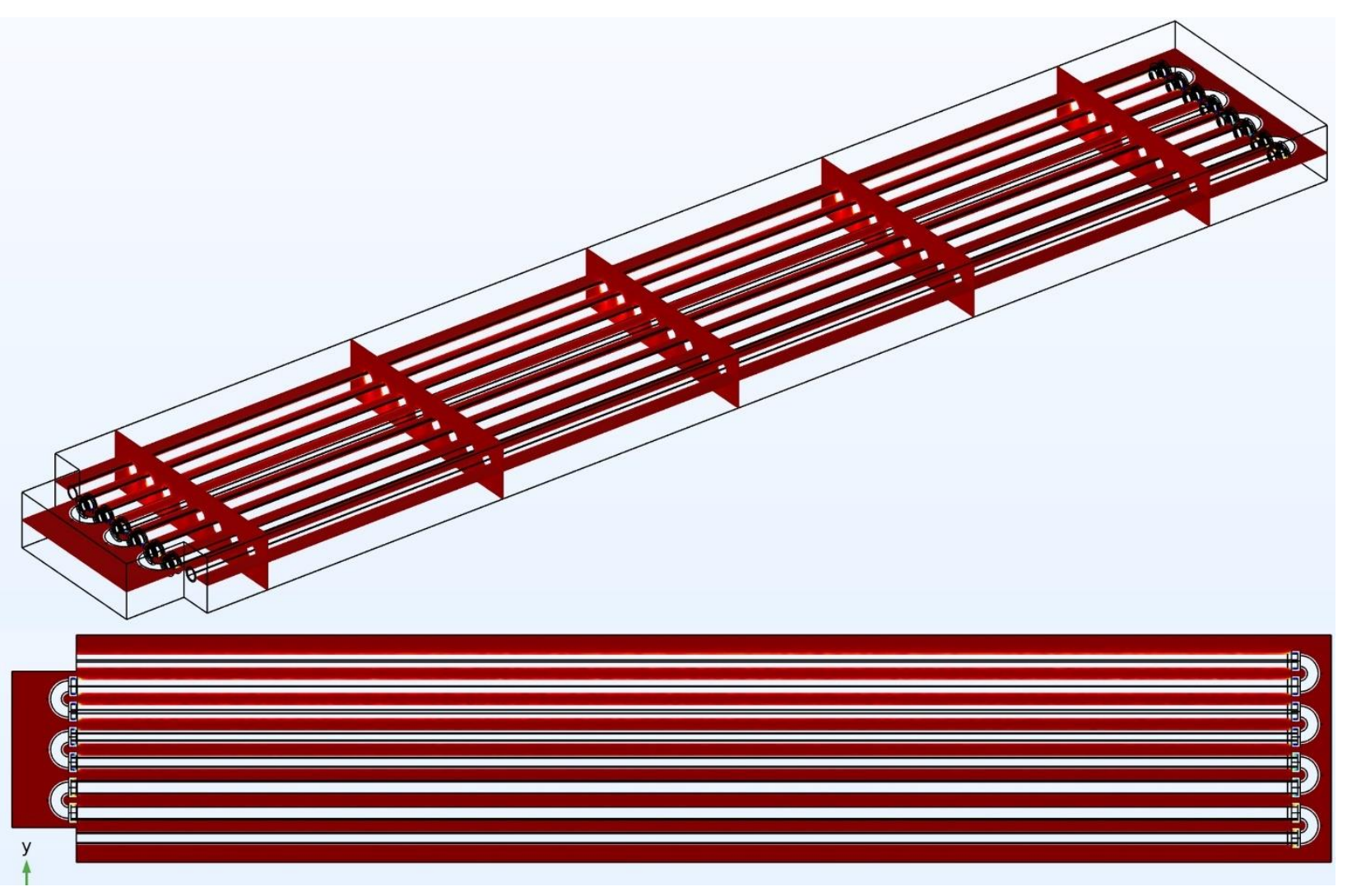

Figure 22. The molar concentration of $\mathrm{O}_{2}\left(\mathrm{~mol} / \mathrm{m}^{3}\right)$ (color scale is redacted).

The fuel gases- $\mathrm{CO}, \mathrm{H}_{2}, \mathrm{CH}_{4}, \mathrm{CO}_{2}$, and $\mathrm{H}_{2} \mathrm{O}$ (Figure 7) - enter the fuel channel, and methane $\left(\mathrm{CH}_{4}\right)$ diffuses and reacts with steam $\left(\mathrm{H}_{2} \mathrm{O}\right)$ in the catalyst layer (Figure 7 and Figure 8). The molar concentrations of $\mathrm{CH}_{4}$ and $\mathrm{H}_{2} \mathrm{O}$ are shown in Figure 23 and Figure 24, respectively. All methane is consumed in the first three tubes. Similarly, steam $\left(\mathrm{H}_{2} \mathrm{O}\right)$ is consumed in the first 3 tubes, and hydrogen gas $\left(\mathrm{H}_{2}\right)$ is produced from the SMR reaction, as shown in Figure 25. Inside the OTM tubes, CO is consumed through the WGS reaction shown in Eq. (3-2) and is also generated through the reforming reaction shown in Eq. (3-1). Therefore, as shown in Figure 26, the concentration of CO is first reduced as a result of the WGS reaction, and then it is increased from the reforming reaction, and then is consumed again (WGS reaction) to produce $\mathrm{CO}_{2}$ and $\mathrm{H}_{2}$, because there is almost no methane left for the reforming reaction after the third tube. The molar concentration of $\mathrm{CO}_{2}$ is presented in Figure 27.

As shown in Figure 24 and Figure 25, the concentration of steam $\left(\mathrm{H}_{2} \mathrm{O}\right)$ is initially reduced because of the SMR and the WGS reactions, and $\mathrm{H}_{2}$ is generated. However, the concentration of $\mathrm{H}_{2}$ is not continuously increased or maintained when the fuel gases flow downstream. Instead, the $\mathrm{H}_{2}$ diffuses to the active anode layer and reacts with oxygen (Figure 7 and Figure 8). Therefore, the steam $\left(\mathrm{H}_{2} \mathrm{O}\right)$ concentration is increased (Figure 24), but all $\mathrm{H}_{2}$ is consumed, as shown in Figure 25.

The concentration of $\mathrm{CO}_{2}$ is directly related to the $\mathrm{CO}$ concentration through the WGS reaction. As shown in Figure 27, in the first few tubes, there is sufficient $\mathrm{CH}_{4}$ for the SMR reaction to produce CO. Thus, the concentration of $\mathrm{CO}_{2}$ in the fuel channel is higher (WGS reaction) than that in the porous support region. As shown in Figure 26, the concentration of $\mathrm{CO}$ is maintained at its peak value at the fourth and the fifth tubes and is gradually reduced to generate $\mathrm{CO}_{2}$ through the WGS reaction. The $\mathrm{CO}_{2}$ in the fuel channel is also gradually diffused to the porous support layer and is eventually uniformly distributed across the OTM tubes, as shown in Figure 27. 
Reforming reaction:

$\mathrm{CH}_{4}+\mathrm{H}_{2} \mathrm{O} \rightarrow \mathrm{CO}+3 \mathrm{H}_{2}$ (endothermic)

Water-gas shift reaction:

$\mathrm{CO}+\mathrm{H}_{2} \mathrm{O} \rightarrow \mathrm{CO}_{2}+\mathrm{H}_{2} \quad$ (exothermic)

Hydrogen combustion:

$\mathrm{H}_{2}+\mathrm{O}^{2-} \rightarrow \mathrm{H}_{2} \mathrm{O}+2 e^{-}$(exothermic)
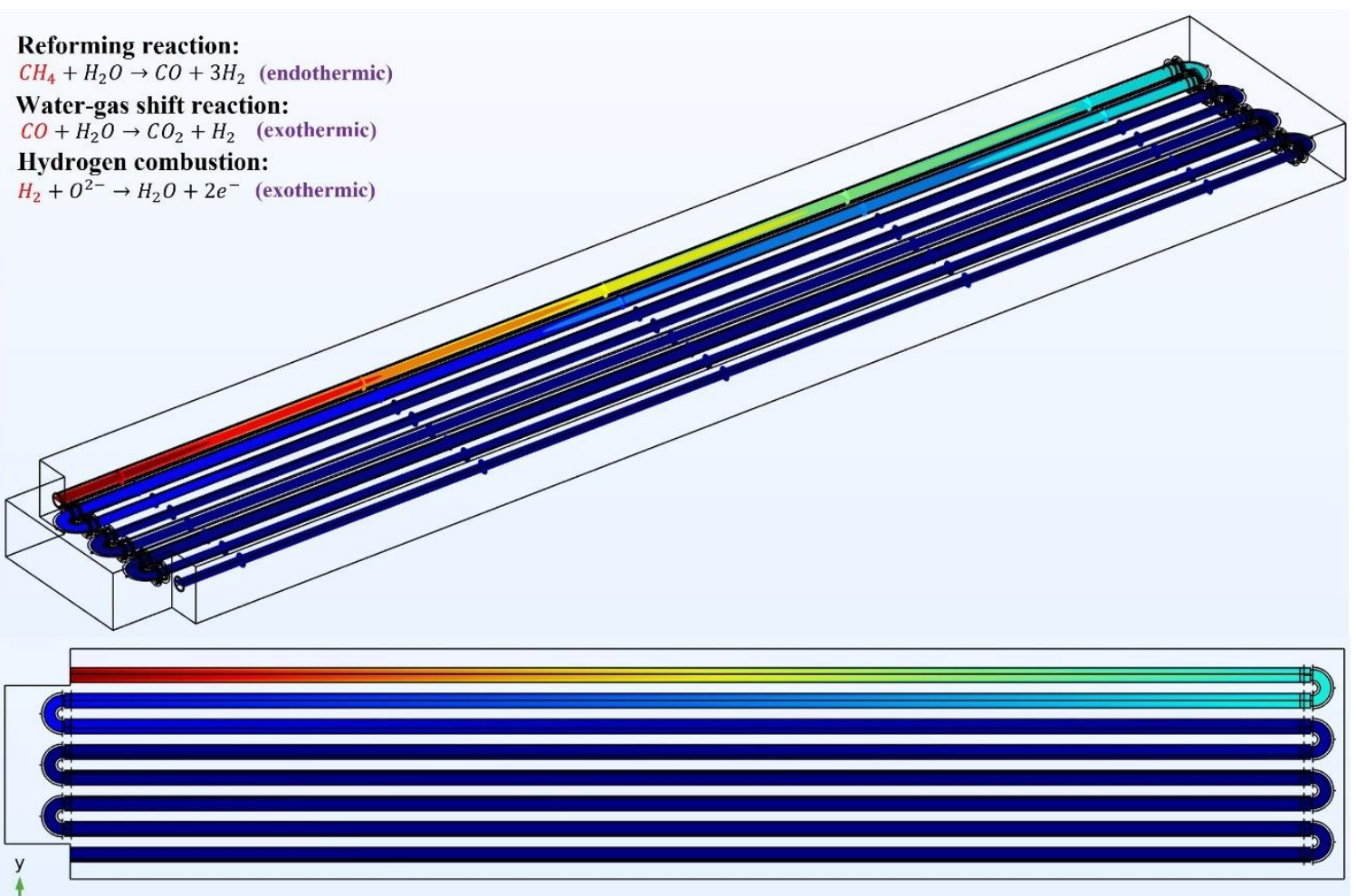

Figure 23. The molar concentration of $\mathrm{CH}_{4}\left(\mathrm{~mol} / \mathrm{m}^{3}\right)$ (color scale is redacted).

Reforming reaction:

$\mathrm{CH}_{4}+\mathrm{H}_{2} \mathrm{O} \rightarrow \mathrm{CO}+3 \mathrm{H}_{2}$ (endothermic)

Water-gas shift reaction:

$\mathrm{CO}+\mathrm{H}_{2} \mathrm{O} \rightarrow \mathrm{CO}_{2}+\mathrm{H}_{2}$ (exothermic)

Hydrogen combustion:

$\mathrm{H}_{2}+\mathrm{O}^{2-} \rightarrow \mathrm{H}_{2} \mathrm{O}+2 e^{-}$(exothermic)
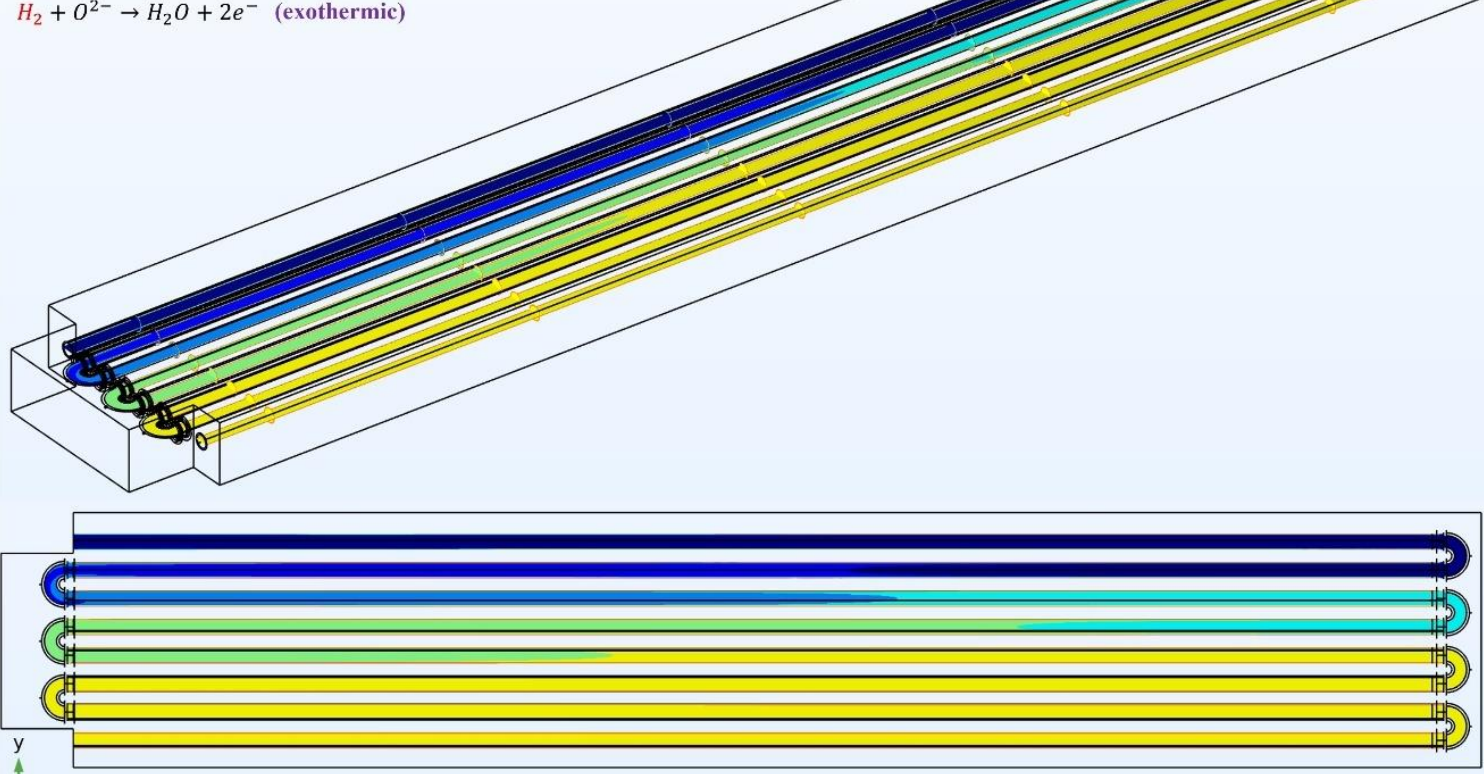

Figure 24. The molar concentration of $\mathrm{H}_{2} \mathrm{O}\left(\mathrm{mol} / \mathrm{m}^{3}\right)$ (color scale is redacted). 


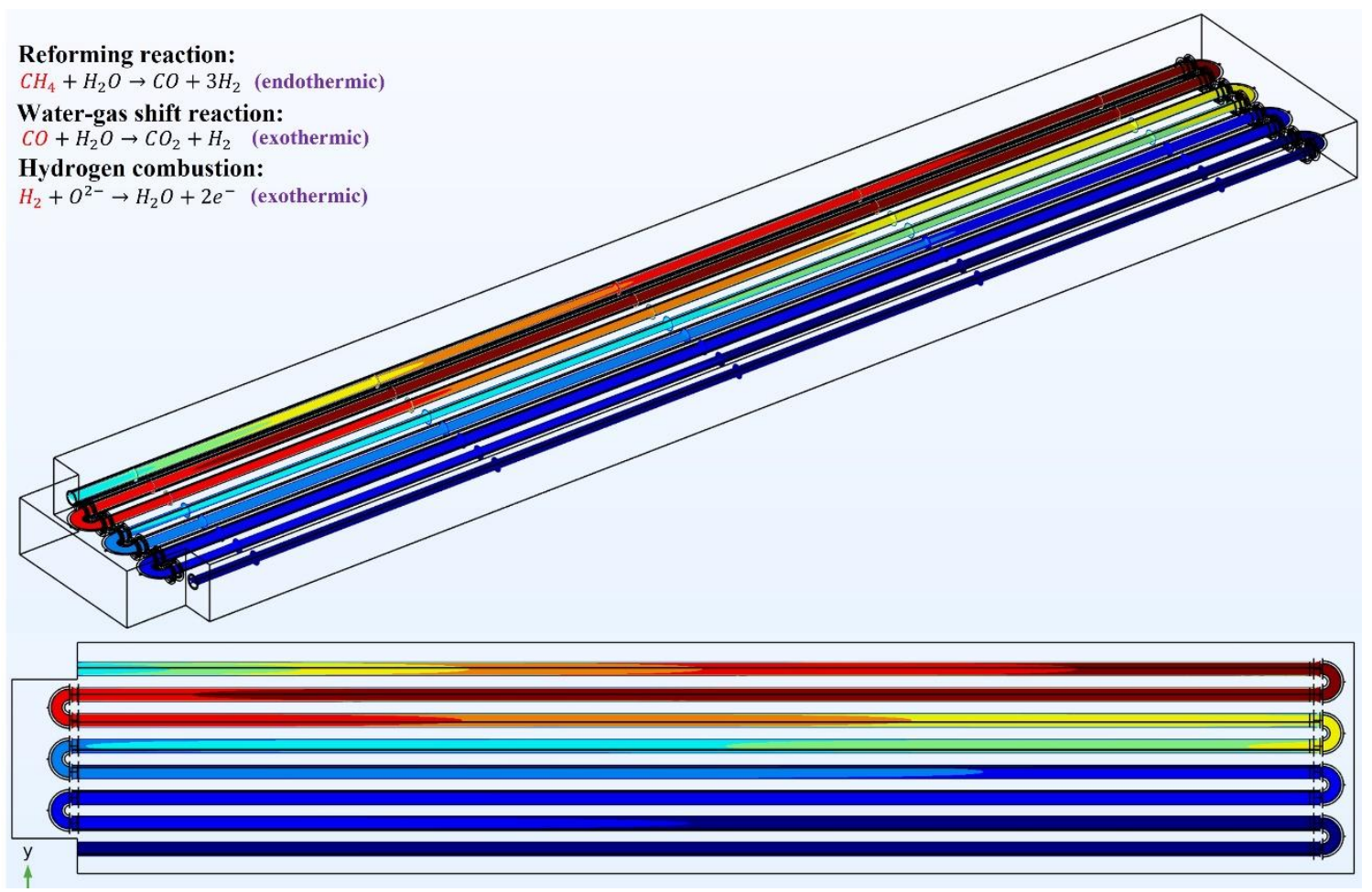

Figure 25. The molar concentration of $\mathrm{H}_{2}\left(\mathrm{~mol} / \mathrm{m}^{3}\right)$ (color scale is redacted).

Reforming reaction:

$\mathrm{CH}_{4}+\mathrm{H}_{2} \mathrm{O} \rightarrow \mathrm{CO}+3 \mathrm{H}_{2}$ (endothermic)

Water-gas shift reaction:

$\mathrm{CO}+\mathrm{H}_{2} \mathrm{O} \rightarrow \mathrm{CO}_{2}+\mathrm{H}_{2}$ (exothermic)

Hydrogen combustion:

$\mathrm{H}_{2}+\mathrm{O}^{2-} \rightarrow \mathrm{H}_{2} \mathrm{O}+2 e^{-}$(exothermic)

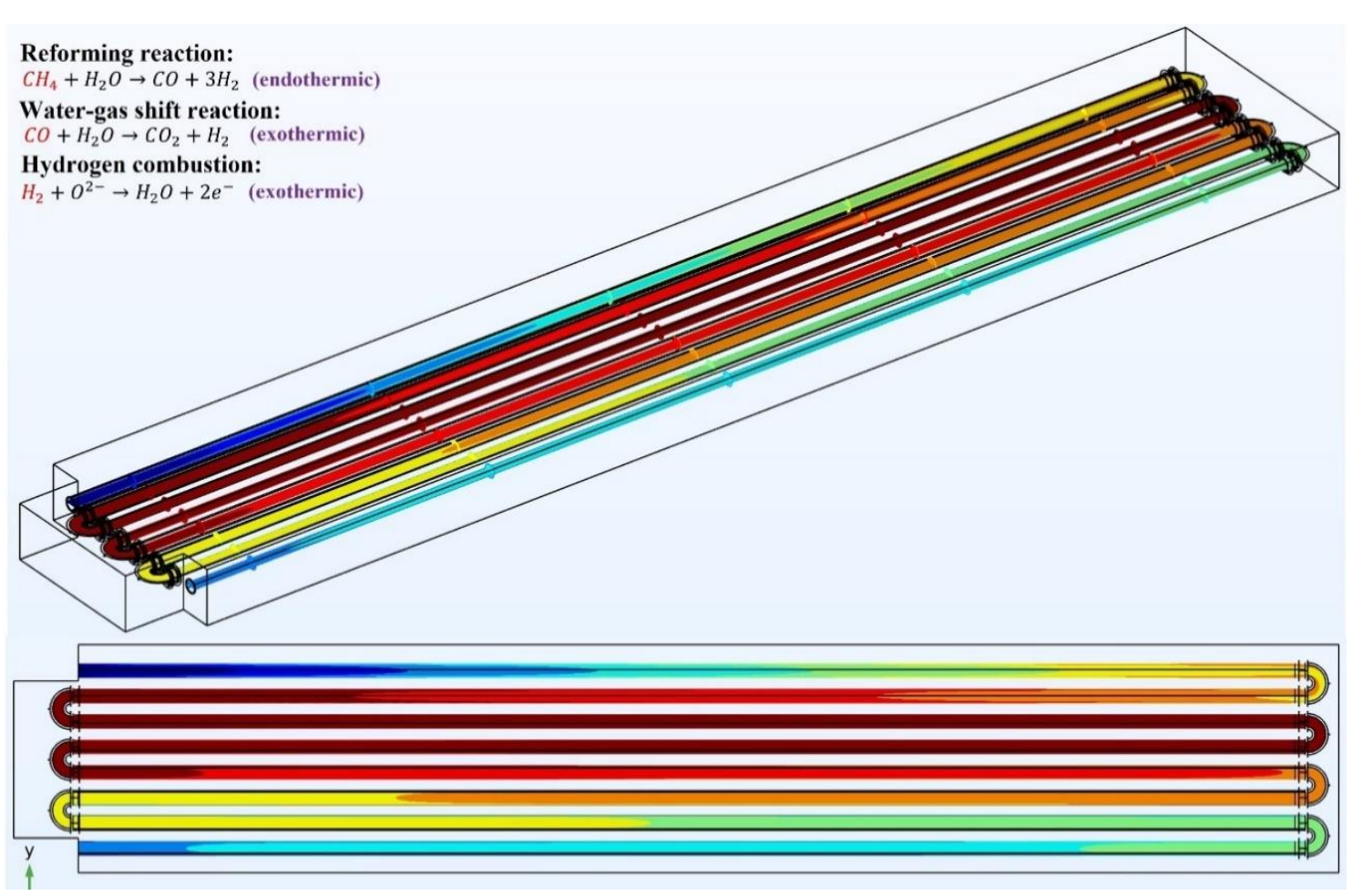

Figure 26. The molar concentration of $\mathrm{CO}\left(\mathrm{mol} / \mathrm{m}^{3}\right)$ (color scale is redacted). 


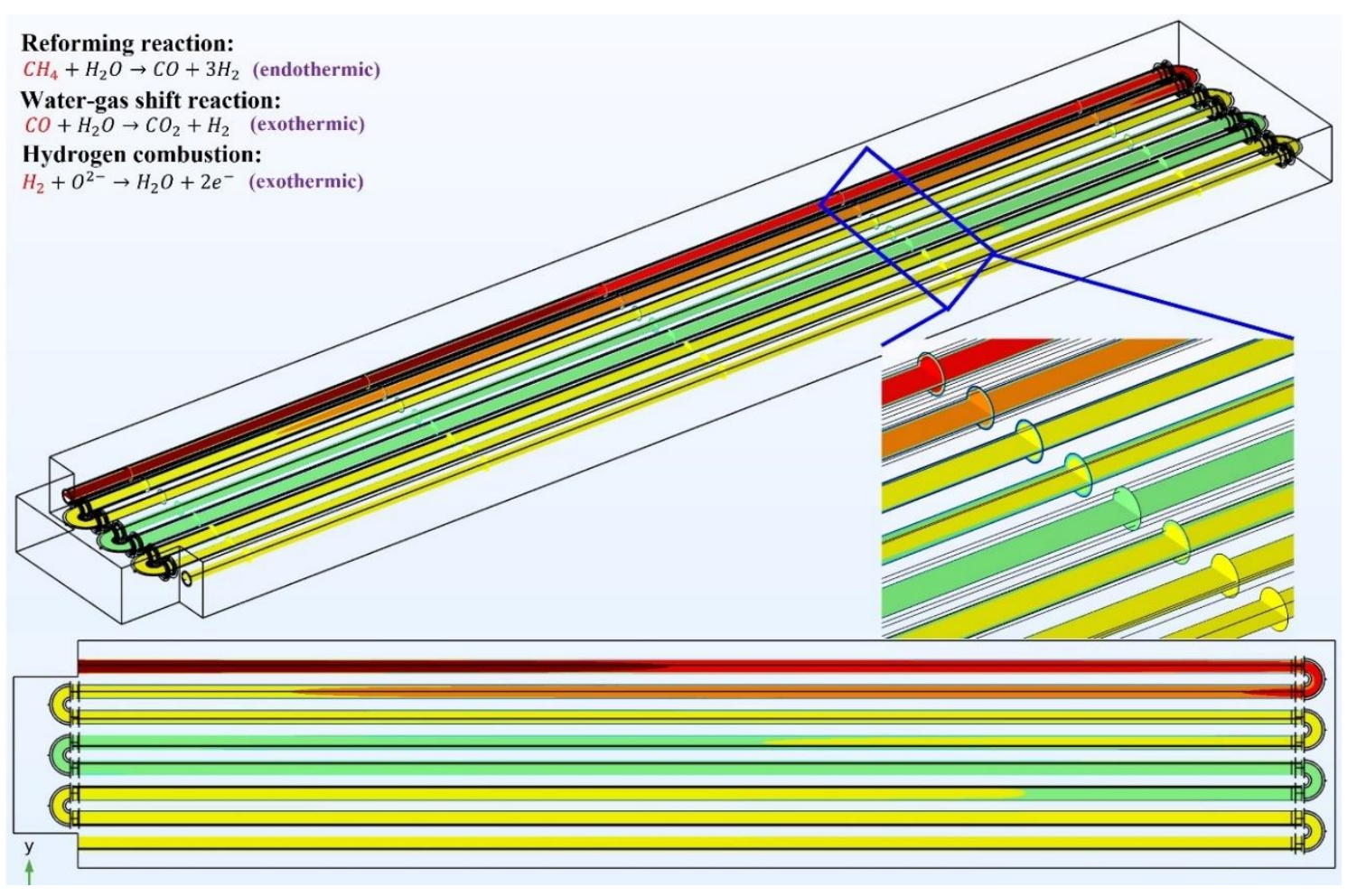

Figure 27. The molar concentration of $\mathrm{CO}_{2}\left(\mathrm{~mol} / \mathrm{m}^{3}\right)$ (color scale is redacted).

\subsubsection{HPC Performance Analysis}

All simulations in this report were run on the Libby cluster at ORNL. On Libby, for nodes 1-10, each node has two 12-core Intel Xeon E5-2680v3 processors with 512 GB RAM. Nodes 11-32 have two 16core Intel Xeon E5-2683v4 processors with 512 GB RAM. A different number of nodes was used for Mesh_2 and Mesh_3 to investigate the High-performance computing for this problem.

Strong scaling (run a fixed problem with different number of cores) was used for HPC performance evaluation. The run times for Mesh_2 and Mesh_3, each with a different number of cores, are

summarized in Table 2 and Table 3, respectively, and are compared in Figure 28. With Mesh_2, the error is around $0.1-0.4 \%$, and the run time was reduced from 12.9 hours with one node to 4.3 hours with ten nodes, about 3 times faster. Similarly, with Mesh_3, the error is around $0.02-0.05 \%$, and the run time was reduced from 27.9 hours with one node to 11.7 hours with eight nodes, about 2.4 times faster. In conclusion, the Mesh_2 configuration has better HPC performance and provides results with acceptable numerical errors.

Table 2. HPC strong scaling speedup for Mesh_2

\begin{tabular}{cccc}
\hline \multicolumn{4}{c}{ Mesh 2, 1.2 million elements } \\
\hline Number of Nodes & Number of Cores & Run Time (hour) & Speedup (= t (1 node)/ t (N nodes)) \\
\hline 1 & 48 & 12.93 & 1.00 \\
4 & 192 & 8.27 & 1.56 \\
8 & 384 & 4.78 & 2.71 \\
10 & 480 & 4.28 & 3.02 \\
\hline
\end{tabular}


Table 3. HPC strong scaling speedup for Mesh_3

\begin{tabular}{cccc}
\hline \multicolumn{3}{c}{ Mesh 3,3.4 million elements } \\
\hline Number of Nodes & Number of Cores & Run Time (hour) & Speedup (= t (1 node)/ t (N nodes)) \\
\hline 1 & 48 & 27.88 & 1.00 \\
2 & 96 & 22.90 & 1.22 \\
6 & 288 & 13.30 & 2.10 \\
8 & 384 & 11.71 & 2.38 \\
\hline
\end{tabular}

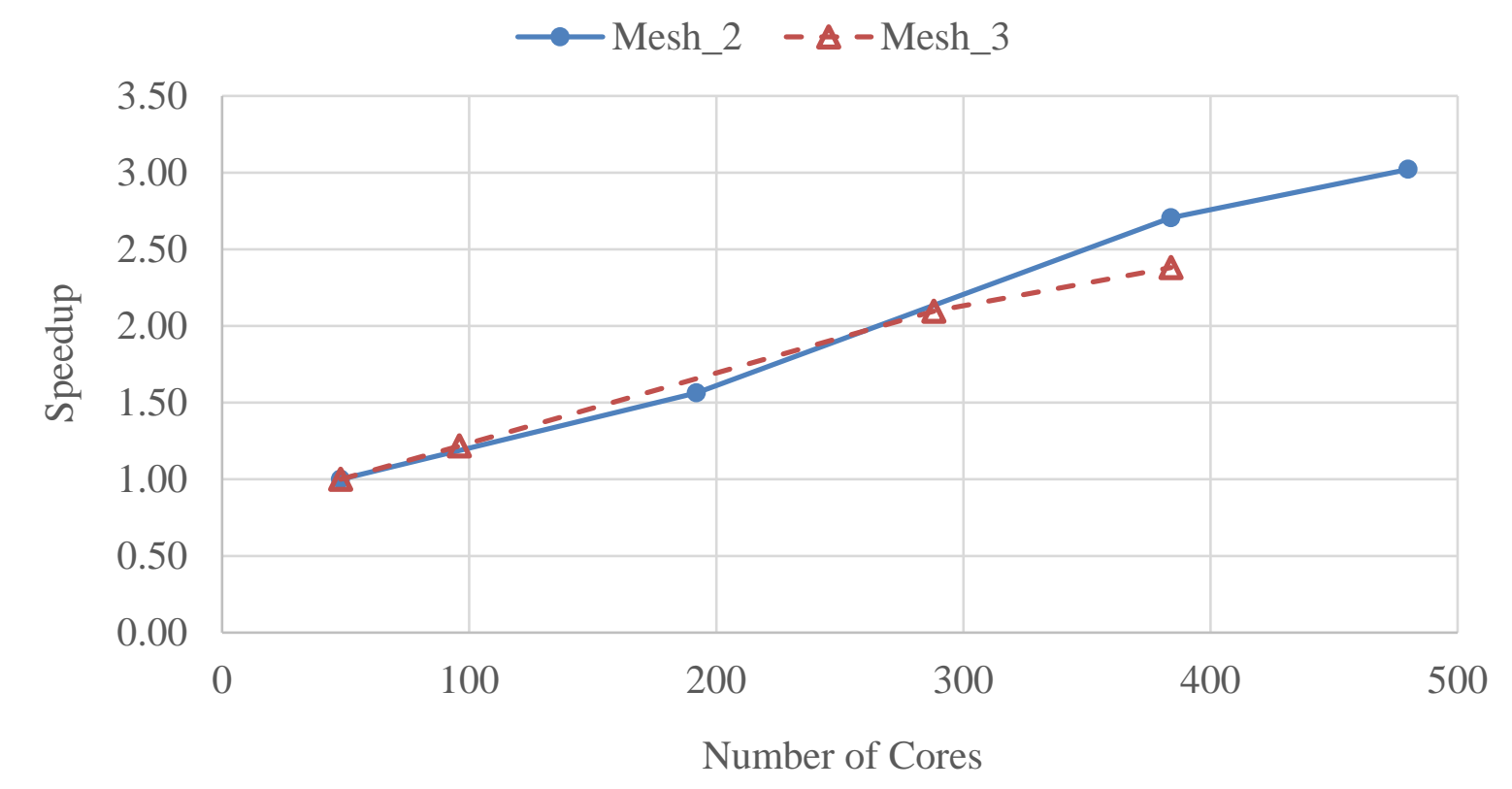

Figure 28. HPC strong scaling speedup for Mesh_2 and Mesh_3. 


\subsection{DEVELOPING A HIGH-FIDELITY CFD MODEL IN STAR-CCM+}

\subsubsection{Problem Formulation}

An array of OTM tubes forms the domain for the internal flow of the fuel gas and combustion products. Around the OTM tubes, ambient air in the auto-thermal reforming unit provides the necessary oxygen for catalyzed-oxidation reactions in the fuel-air mixture within the OTM tubes. The porous thickness of the OTM tubes provides a ceramic substrate for molecular oxygen to ionize and for oxide ions to diffuse toward the fuel mixture. Molecular hydrogen and water vapor provide chemical reduction of reforming products, which are proposed to diffuse downstream into the internal stream. Figure 29 and Figure 30 illustrate sectional views of an axisymmetric OTM tube and the electrochemical reactions which occur within, respectively.

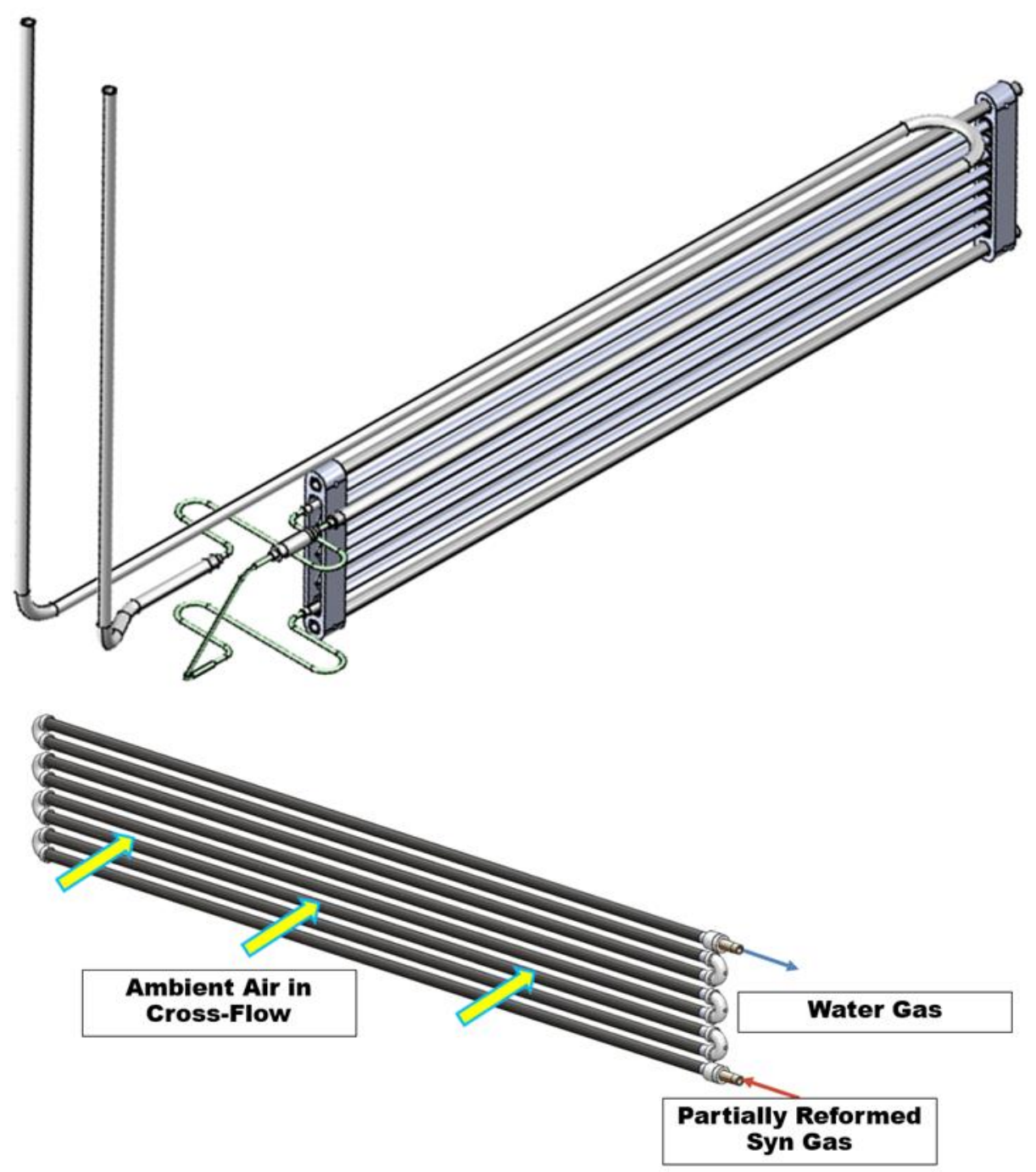

Figure 29. An array of OTM tubes: physical model (top) and computational model (bottom). 


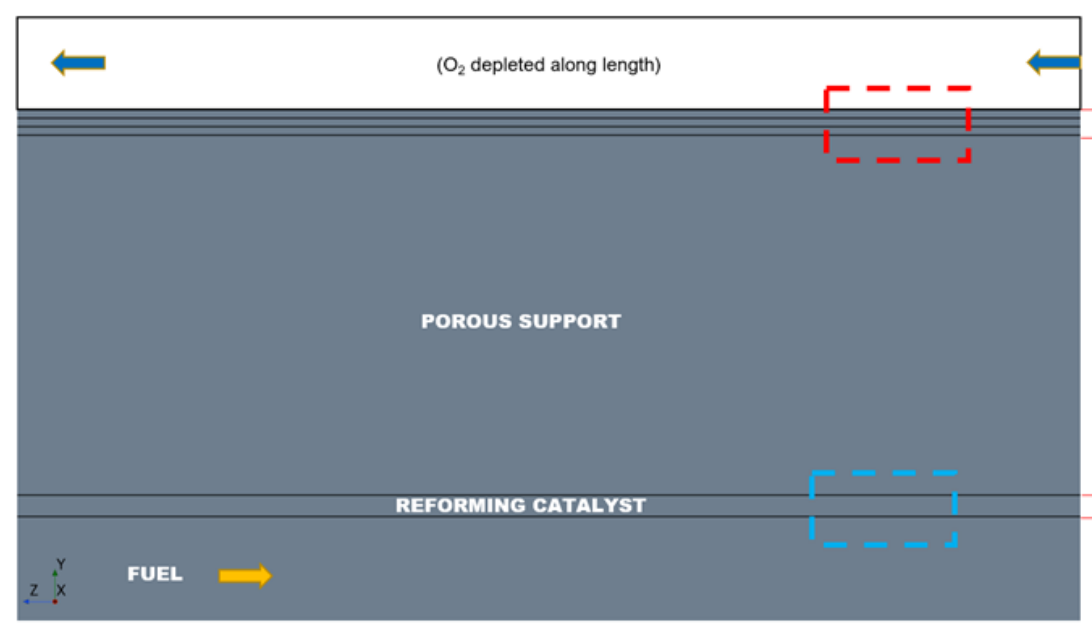

$z=1 \mathrm{~m}$

$z=1$

Figure 30. A sectional view of fluid streams and solid volumes within a single OTM tube.

A detailed representation of electrochemical reactions which govern flameless oxidation within the OTM tube is represented graphically in Figure 31. The electrochemical transformations occur by electron exchange at the anode prior to diffusion of the combustion products away from the anode toward the fuel channel through the porous support and reforming catalyst. It is recommended that all oxidation and reforming reactions occur in the presence of a catalytic surface.
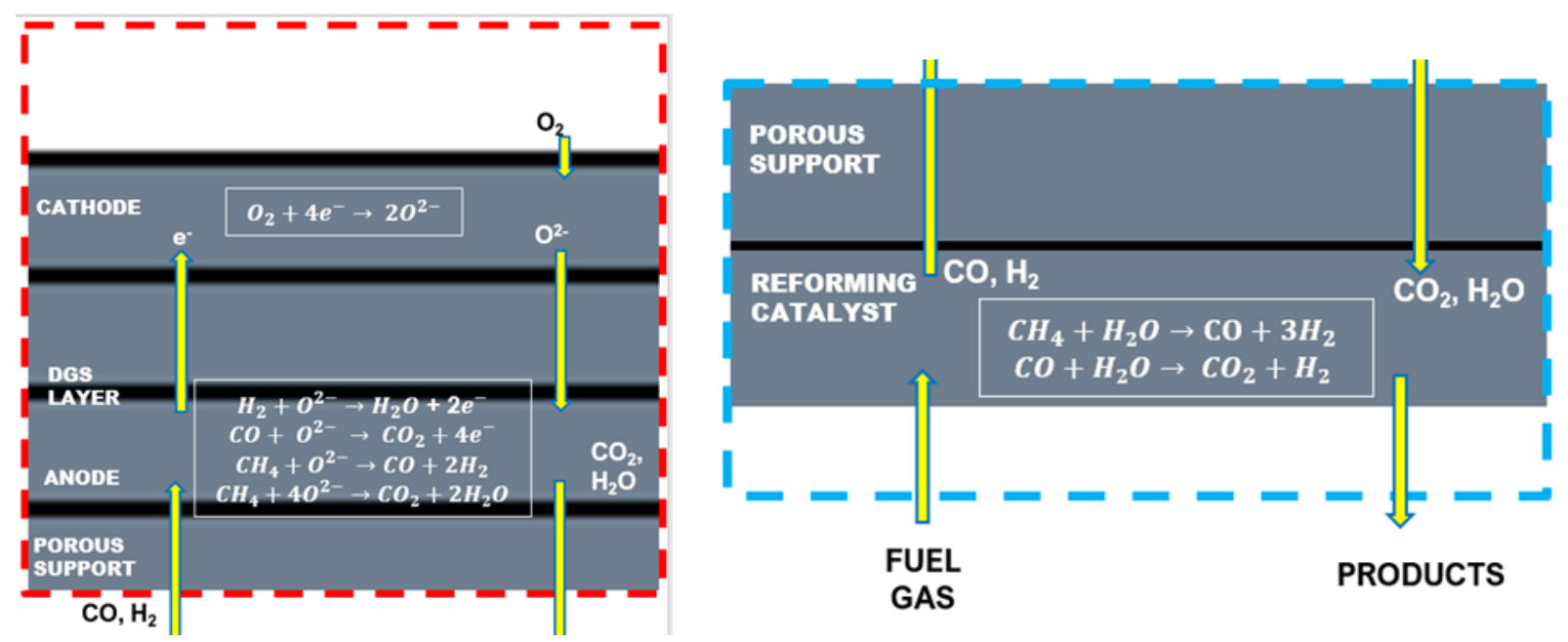

Figure 31. Detailed representation of flow streams and electrochemical reactions in the porous ceramic tube.

\subsubsection{Numerical Approach}

The following sections describe modifications made to the physical domain and associated materials and provide qualified assumptions in justification. 


\subsubsection{Fluid Volumes}

The OTM tube is fed by a mixture of partially reformed natural gas, including $\mathrm{CH}_{4}, \mathrm{CO}_{2}, \mathrm{H}_{2} \mathrm{O}$, $\mathrm{CO}$, and $\mathrm{H}_{2}$. These species comprise the fuel stream entering the inner channel of the OTM tube. The transport of these species is preserved by a Eulerian formulation for the gas mixture, with mass fractions conserved to a value of 1 . The equations for conservation of continuity, momentum, energy, and species are given below.

continuity:

$$
\frac{\partial}{\partial t}\left(\oiiint_{V} \rho d V\right)+\oiint_{S} \rho v \cdot d S=\oiiint_{V} S d V
$$

momentum:

$$
\begin{gathered}
\frac{\partial}{\partial t}\left(\oiiint_{V} \rho \boldsymbol{v} d V\right)+\oiint_{S} \rho(\boldsymbol{v} \times \boldsymbol{v}) \cdot d S=\oiiint_{V} \rho \boldsymbol{g} d V-\oiint_{S} \boldsymbol{I} \cdot d S+\oiint_{S} T \cdot d S+\oiiint_{V} f_{b} d V- \\
\sum_{i} \oiint_{S} \alpha_{i} \rho_{i} \boldsymbol{v}_{d, i} \times \boldsymbol{v}_{d, i} \cdot d S
\end{gathered}
$$

energy:

$$
\begin{gathered}
\frac{\partial}{\partial t}\left(\oiiint_{V} \rho E d V\right)+\oiint_{S}\left[\rho H \boldsymbol{v}+p+\sum_{\boldsymbol{i}} \rho_{i} \alpha_{i} H_{i} \boldsymbol{v}_{\boldsymbol{d}, \boldsymbol{i}}\right] \cdot d S=\oiiint_{V} S_{E} d V-\oiint_{S} q^{\prime \prime} \cdot d S+\oiint_{S} T \cdot \boldsymbol{v} d S+ \\
\oiiint_{V} \boldsymbol{f}_{b} \cdot \boldsymbol{v} d V
\end{gathered}
$$

species:

$$
\frac{\partial}{\partial t}\left(\oiiint_{V} \rho Y_{i} d V\right)+\oiint_{S}\left[\rho Y_{i}\left(\boldsymbol{v}+\boldsymbol{M}_{\boldsymbol{i}}\right)\right] \cdot d S=\oiint_{S}\left[\rho Y_{i}\left(J_{i}+\frac{\mu_{t}}{\sigma_{t}} \nabla Y_{i}\right)\right] \cdot d S+\oiiint_{V} S_{Y_{i}} d V
$$

On the fuel side, a mixture of reactant and product gas compounds is used. A single gas called "air" is used to emulate heat transfer to the OTM tube on the air side. The molecular oxygen adsorbs onto the cathode surface, where it is ionized to oxide ions $\left(\mathrm{O}^{2-}\right)$. The oxide ions accumulate as a dense layer, and from this layer, the migration of ions is driven by the gradient in partial pressure of oxygen. This gradient drives the oxidation reactions at the anode, which form products of combustion/oxidation, primarily $\mathrm{CO}_{2}$ and $\mathrm{H}_{2} \mathrm{O}$ vapor. The exchange of electrons is suggested to stabilize over operating time and generate a steady outflow of combustion products from several arrays of OTM tubes.

The flow of gases within and around the OTM tubes is turbulent. Turbulence in flow through arrays of OTM tubes is thought to be primarily influenced by near-wall interactions where boundary layers are formed. Boundary layers very close to the wall exhibit molecular-scale behavior, and they transition to eddy-like behavior in the bulk flow through a buffer region. To capture these effects, the realizable kepsilon model is used to solve for turbulent kinetic energy $(\mathrm{k})$ and the dissipation rate of turbulent eddies (epsilon), thus providing closure to the Reynolds-averaged formulation of the Navier-Stokes equation for conservation of momentum. A two-layer wall treatment model is used to resolve the boundary layers at all walls in the computational domain.

\subsubsection{Solid Volumes}

The total solid volume consists of electrode layers supported on a porous ceramic substrate, radially interior to the location where oxidation and reforming reactions occur. The thickness of each layer is provided in Figure 30. The modeling of each layer is essential for simulating the electrochemical 
reactions involved and resolving the diffusivity of oxygen with variation in surface temperature of the OTM tubes facing air. However, preliminary studies at the Linde Group have already measured the variation of oxygen diffusivity with temperature, as shown in Figure 32. Therefore, to simplify the computational domain, the measured oxygen flux is imposed as a temperature-dependent boundary condition at the surface of the anode facing the porous support volume.

Furthermore, the porous support and reforming catalyst are modeled as a single porous layer with an effective porosity value, so the oxygen that enters the porous support can diffuse within at a rate corresponding to the temperature of the porous support. This oxygen is suggested to mix with the fuel species diffusing into the reforming catalyst where combustion products are formed. The products will diffuse back to the fuel channel and mix with the depleted fuel mixture.

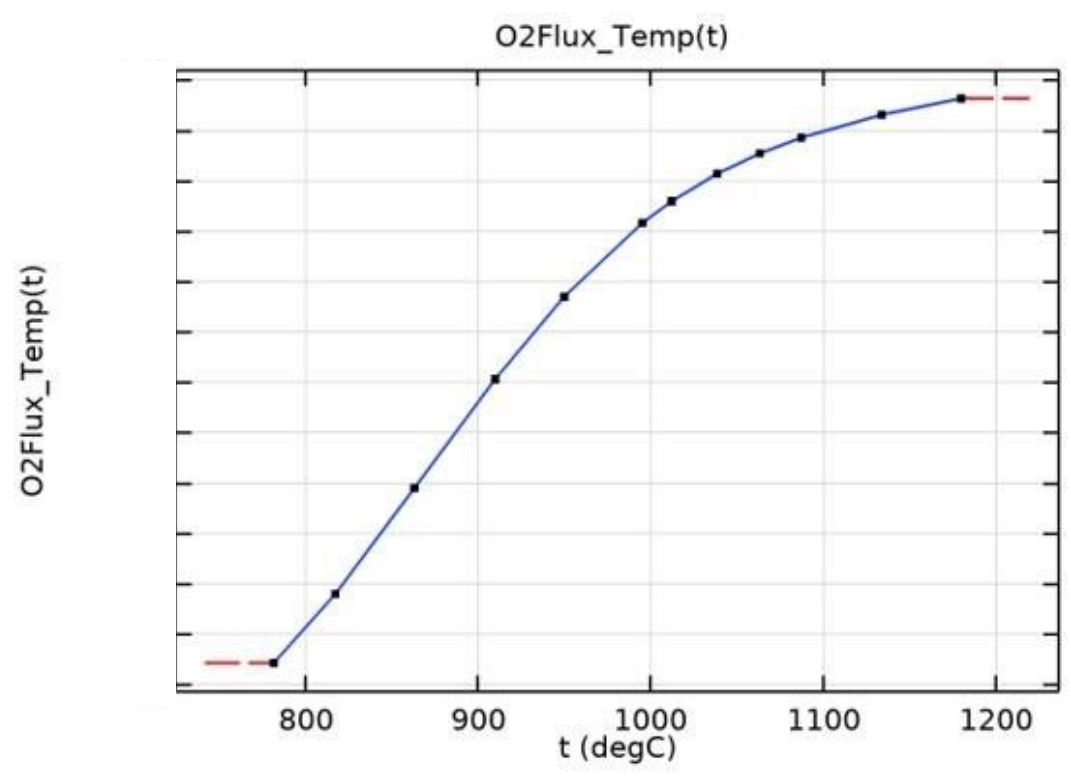

Figure 32. Dependence of oxygen influx on temperature.

\subsubsection{Finite-Volume Mesh \& Inputs}

The geometric array of OTM tubes is merged into a single continuous path for the partially-reformed fuel mixture. This stream consists of $\mathrm{CH}_{4}, \mathrm{CO}, \mathrm{H}_{2}, \mathrm{H}_{2} \mathrm{O}$, and $\mathrm{CO}_{2}$. The OTM tube thickness comprises ceramic electrodes and a porous support catalyst within which oxidation and reforming reactions occur. Oxygen for these reactions is supplied by ambient air in cross flow. In the CAD model, this results in three distinct fluid volumes, so the interfaces between each pair of adjacent fluid volumes are treated as thermally conducting baffles. Furthermore, finite-volume cells must be capable of emulating the temperaturedependent influx of oxygen across the interfaces, thus accurately resolving the desired product yields. Figure 33 illustrates the size of cells near the interfaces and within fluid volumes. 


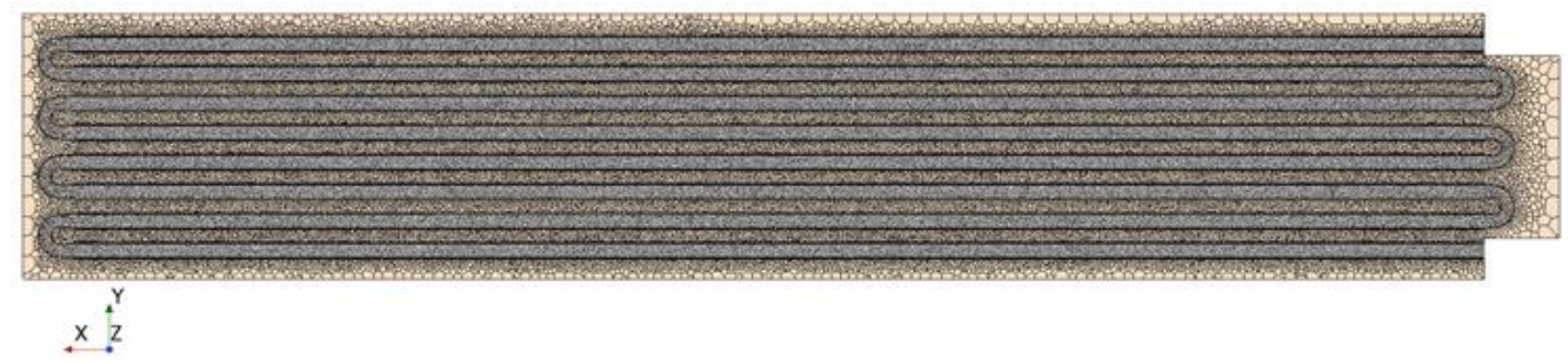

Figure 33. A representative cross-section of the finite-volume mesh on the OTM tube array.

\subsubsection{Solver Setup}

STAR-CCM+ v. 15.02.007-R8 (Siemens 2021) was used to run all simulations. Two sets of models were used: one for the fuel mixture and one for ambient air. The fuel mixture is modeled using a multicomponent gas mixture model, and the air is modeled using a single component fluid model.

A single set of transport equations is solved for each fluid, as described in Section 3.3.2, with an additional species-transport equation solved for the gas mixture where mass fractions of species are conserved. The eddy break-up model was used for reacting flows to simulate the mixing of gaseous reacting species at a length scale comparable to turbulent mixing.

All simulations were run on a high-performance computing mid-size cluster in the Nuclear Energy and Fuel Cycle Division at Oak Ridge National Laboratory, with 48 to 64 CPU cores per node and 500 GB RAM per node. Each calculation was completed in approximately 12 hours.

\subsubsection{StarCCM+ Results: Simple Reacting Flow in the OTM Tube}

First, a bundle of tubes extracted within an ambient volume of air was isolated to model fluid streams for the partially reformed syngas within the tubes, and the ambient air outside the tubes. Both fluid streams enter the simulation domain at high temperatures. Endothermic reactions require a constant supply of heat to sustain a continuous yield of desired products, in this case, supplied by ambient air. Within the FOx tubes, both reforming and oxidation reactions are simulated. This is conducted with the Jones-Lindstedt 4-step mechanism for oxy-fuel combustion of natural gas (Yin, 2011). The reactions provide a simple estimate of expected yields of syngas from the FOx tubes as a combination of reforming and oxidative combustion. No influx of oxygen is additionally modeled through the thickness of FOx tubes, and the material of the thickness is modeled by air as a simple approximation. All thermal contacts are set as baffles. A representative profile of temperatures in this scenario is given in Figure 34. 


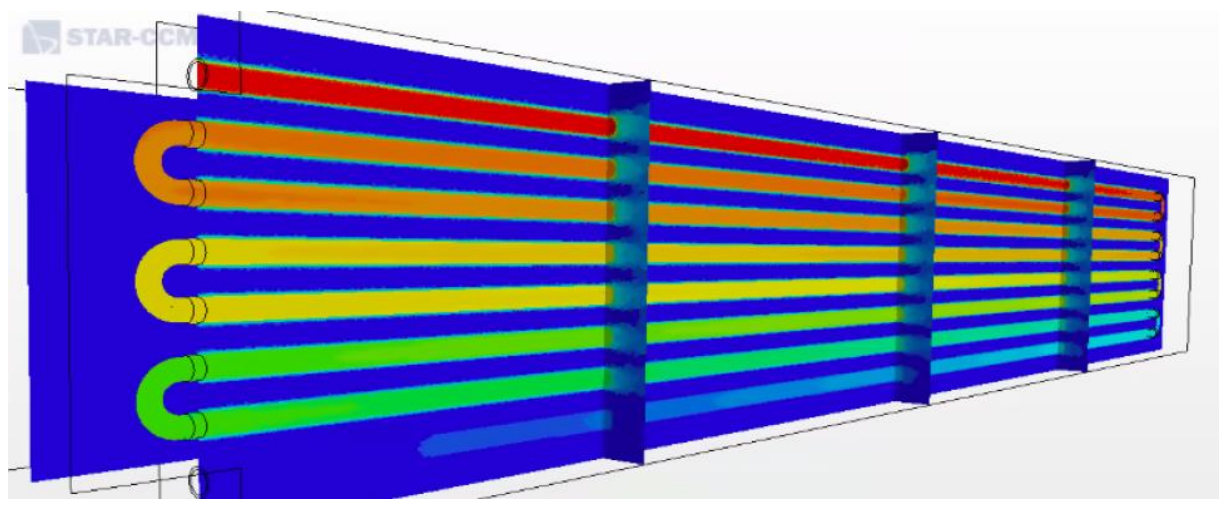

Figure 34. Axial distribution of temperature in FOx tubes and air (color scale is redacted).

\subsubsection{StarCCM+ Results: Modeling Oxygen Influx for the Reforming Reaction}

This step involves simulation of only the reforming reaction using the influx of oxygen through the simplified thickness of the FOx tube. The influx of oxygen has temperature dependence, as illustrated in Figure 32, and therefore accounts for the variation in partial pressure of oxygen required to transport oxide ions into the FOx tube from the air-side anode. The reforming reaction is simulated alone to quantify the consumption of energy without interactions between combusting species. Figure 35 shows the axial distribution of temperature in the simulation domain due to the reforming reaction only.

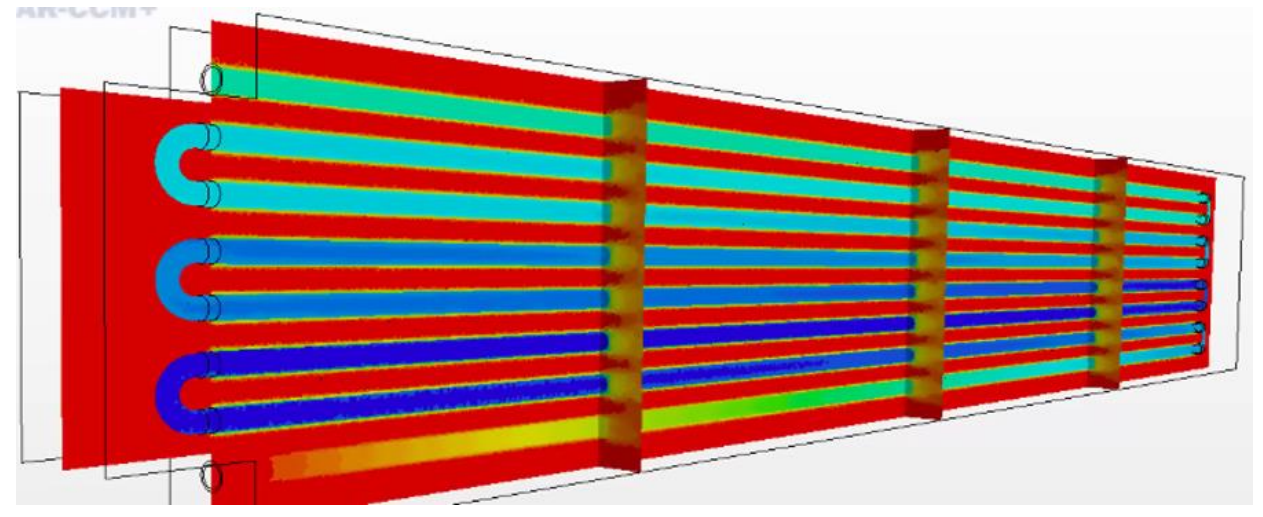

Figure 35. Reforming reaction: axial distribution of temperature in FOx tubes and air (color scale is redacted).

It is evident that the temperature of the fuel mixture varies significantly, first, lowering by approximately $100^{\circ} \mathrm{C}$ in the first four tubes, and then rising approximately $50^{\circ} \mathrm{C}$ due to the warmer ambient air. Figure 36 shows the axial distribution of species in the FOx tubes. The initial reduction in the fuel mixture temperature is attributed to the endothermic progression of the reforming reaction as evidenced by a consistent decrease in the mass fraction of methane and stoichiometrically proportionate increases in the mass fractions of hydrogen and carbon dioxide. It is suggested that in the first four tubes, once the available enthalpy is consumed for reforming, the rate of reaction reduces until sufficient enthalpy is absorbed from the ambient air while flowing downstream of the FOx tube. A progression in the reforming reaction is observed again. The consumed methane is replaced by equivalent moles of carbon dioxide and hydrogen produced by the reforming reaction. 


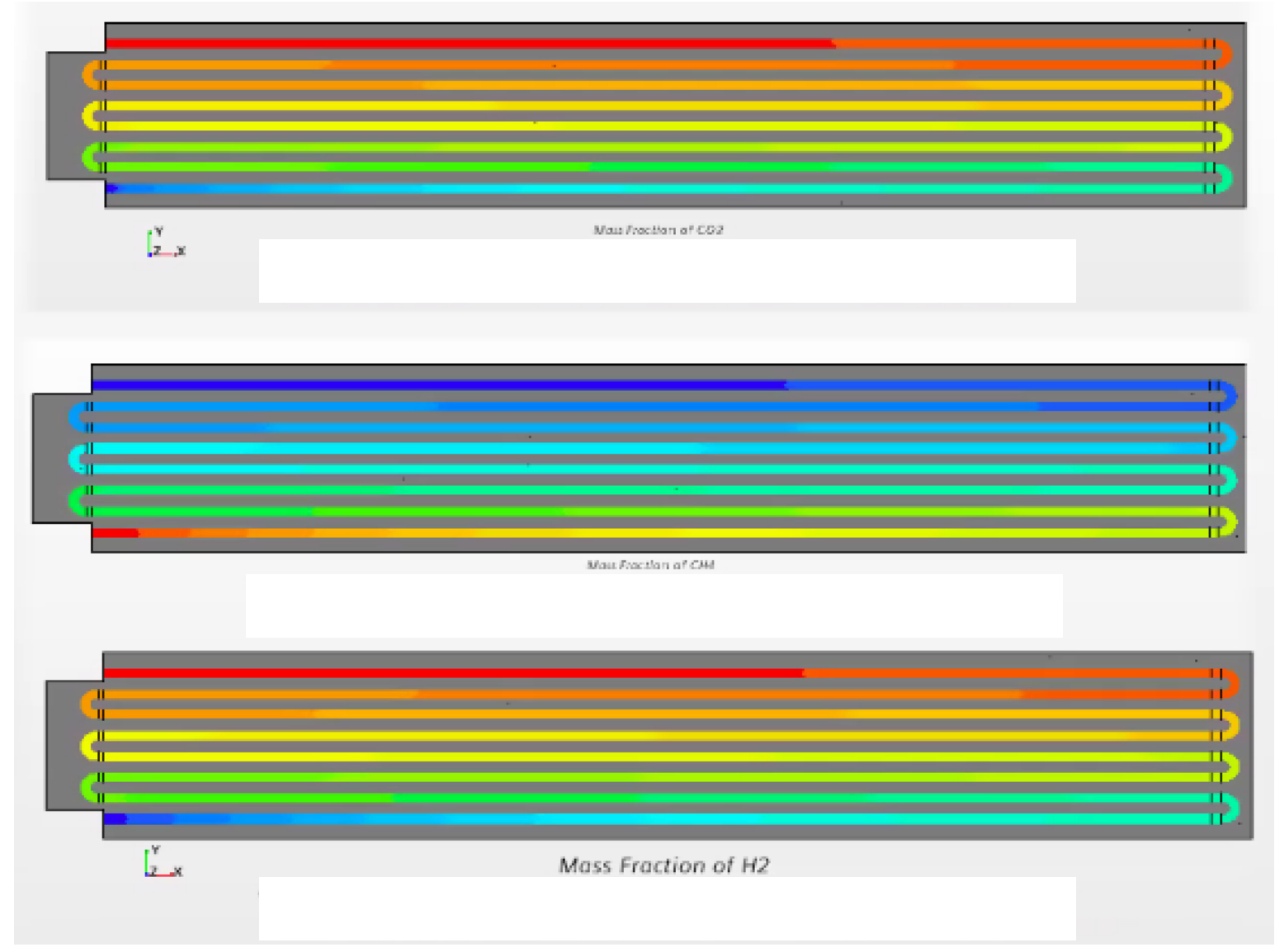

Figure 36. Reforming reaction: axial distribution of gas species (top - carbon dioxide, middle - methane, bottom - hydrogen) in FOx tubes (color scale is redacted).

\subsubsection{StarCCM+ Results: Simulation of Reforming and Combustion Reactions}

This step involves simulation of both, reforming and combustion reactions using the influx of oxygen through the simplified thickness of the FOx tube. The Eddy Break-Up model in STAR-CCM+ was used for this step as well. Figure 37 shows the axial distribution of temperature in the simulation domain due to the reforming and combustion reactions occurring in the FOx tube. The fuel mixture temperature at outflow is significantly higher than the temperature produced by the reforming reaction alone (see Figure 35). It is in good agreement with the initial predictions of reforming and combustion within the FOx tube (see Figure 34). The agreement in thermal profiles (within $100^{\circ} \mathrm{C}$ ) may be attributed to the common representation and chemical transformation of all species involved. In contrast, the difference in thermal profiles suggests that the influx of oxygen can significantly affect the local conversion of methane to syngas and water gas. This is due to the dependence of the influx of oxygen on local temperature, which can create local perturbations in the species profile, thus affecting the stoichiometric availability of oxygen for the oxidative conversion of species in the partially reformed syngas. 


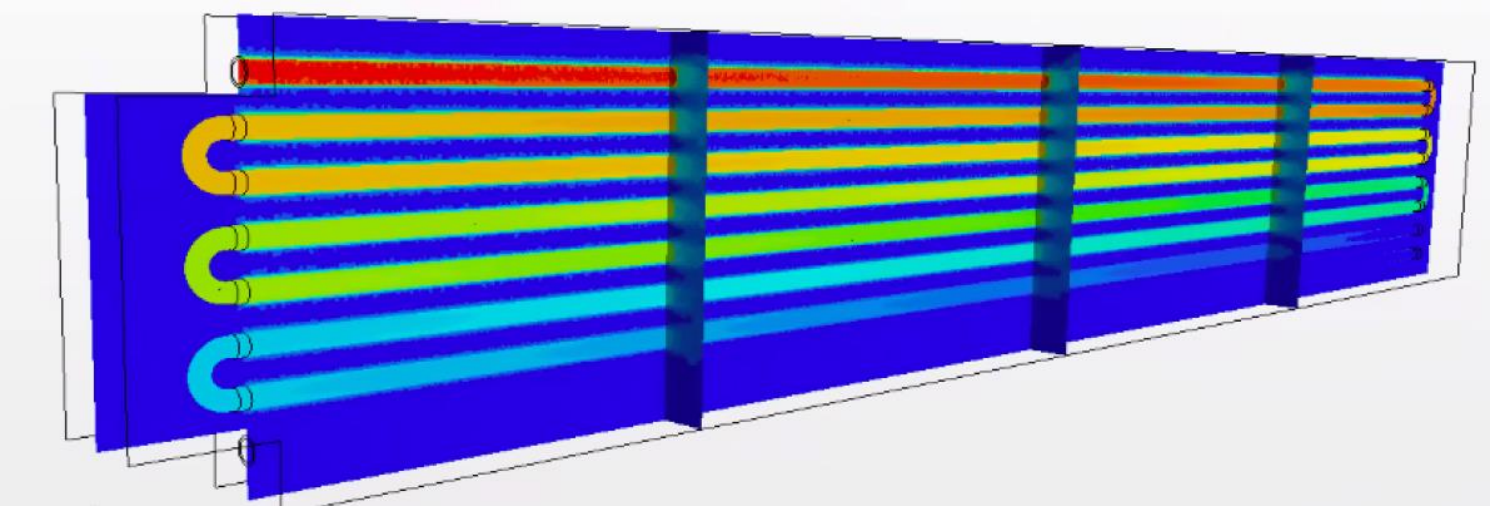

Figure 37. Reforming and combustion reactions: axial distribution of temperature in the FOx tubes and air (color scale is redacted).

Figure 38 shows the importance of oxidation reactions in the complete reforming of methane into syngas and the additional oxidation of species to form water gas. The availability of surplus enthalpy provides the requisite amounts for the rapid conversion of methane into intermediate carbon monoxide and hydrogen products. In contrast, the availability of oxygen provides the necessary species influx to form carbon dioxide and water vapor in the presence of the surplus enthalpy.

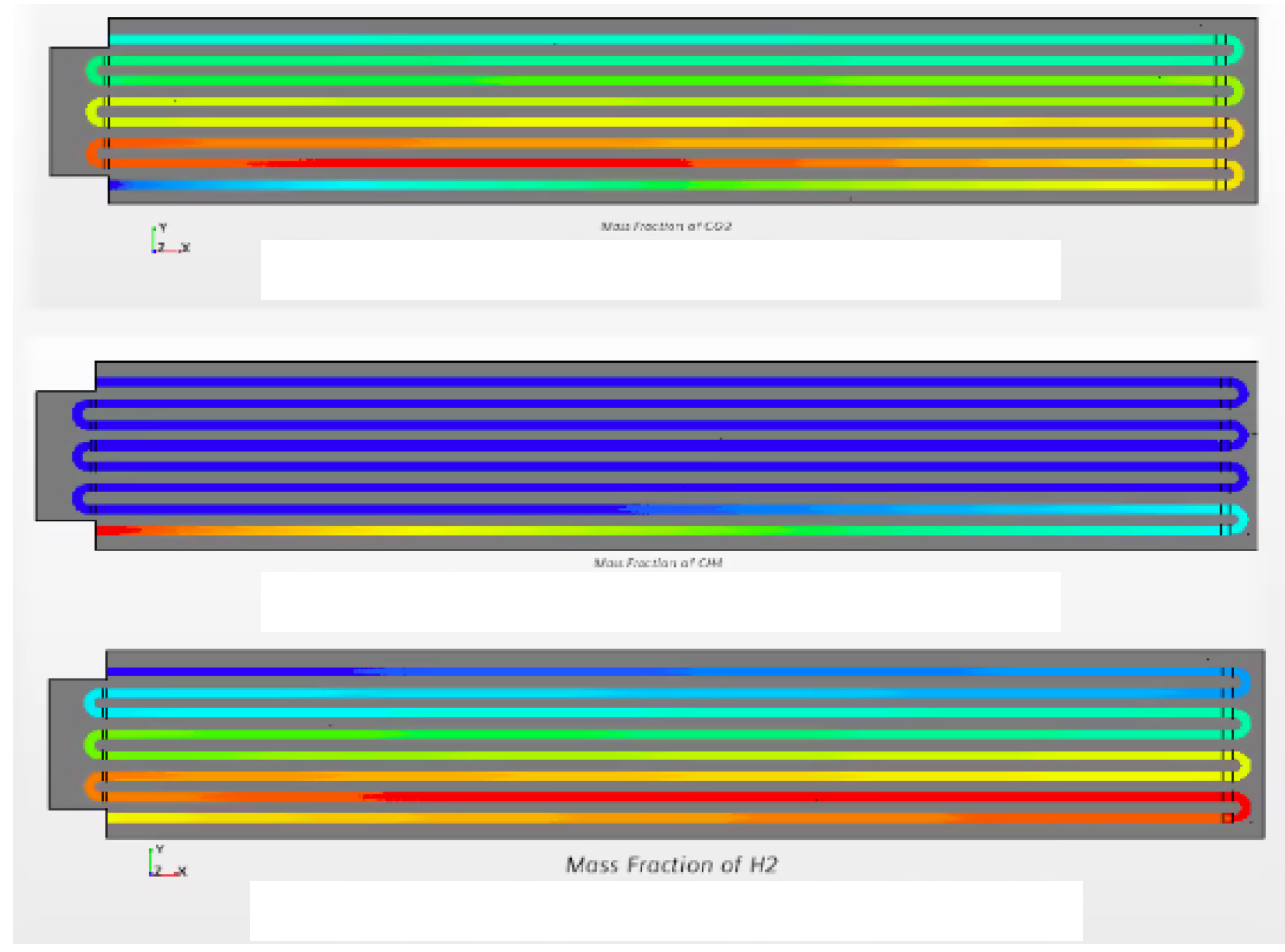

Figure 38. Reforming and combustion reactions: axial distribution of species (top - carbon dioxide, middle methane, bottom - hydrogen) in the FOx tubes (color scale is redacted).

Figure 39 shows the qualitative impact of oxidation reactions in the FOx tube. As the methane is consumed towards reforming and is depleted, the oxygen is now consumed in the vicinity of rich syngas to trigger the formation of combustion products. This is evidenced by the depletion of oxygen and the 
restart in the formation of water vapor in the second tube. Thus, optimizing the range of species influx and range of temperatures is pivotal to ensure efficient thermal conversion of partially reformed syngas into fully converted syngas and water gas.

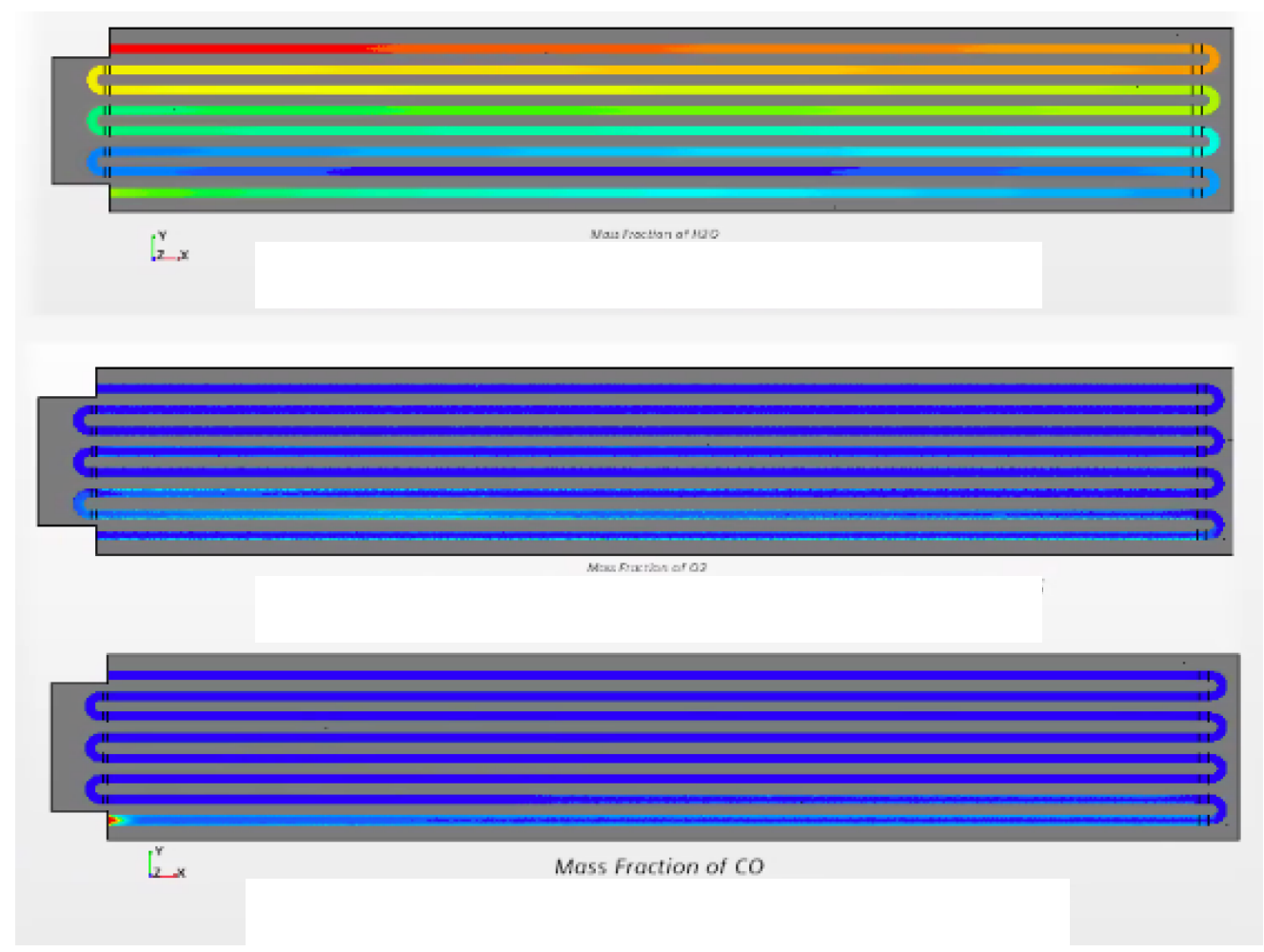

Figure 39. Reforming and combustion reactions: axial distribution of oxidation species (top - carbon dioxide, middle - methane, bottom - hydrogen) in the FOx tubes.

\subsubsection{Process Optimization of FOx Tubes}

Based on the findings from baseline StarCCM+ results, a few parameters were selected to identify the allowable operating ranges for species and temperature, which could reduce thermal penalties in largescale operations with several FOx tube bundles. While the chemistry of conversion is governed by stoichiometry, the simultaneous participation of species in multiple reactions can create a local surplus or deficiency, which can be leveraged by a proportionate availability of enthalpy from ambient air to trigger the onset of endothermic conversions. Therefore, Simcenter HEEDS was used to parameterize the following parameters, which showed the most sensitivity to thermochemistry: (i) inflow mass fraction of methane, (ii) temperature of the air, and (iii) temperature of fuel mixture (partially reformed syngas). These parameters were varied at two set points of oxygen influx through the FOx tube from ambient air to assess the variation and selectivity of species yields in the presence of excessive and deficient amounts of oxygen.

This study's objective was to further optimize the orientation of tube bundles in operating facilities to maximize the local consumption of oxygen while enhancing syngas yield without compromising process efficiency.

Each permutation of parameters was tested for optimum in high-oxygen and low-oxygen values at influx. A yield is defined for each desired product to indicate the mass flow rate ratio for species in outflow to 
the same species in inflow. Values of yield greater than 1 thus reflect any net generation of the species, while values less than 1 indicate a net consumption of the species.

\subsubsection{Process Optimization: FOx Tubes with High Oxygen Content}

The presence of higher than stoichiometric amounts of oxygen can indicate a likelihood favoring the generation of carbon dioxide and water vapor from carbon monoxide and hydrogen, respectively. As summarized in Figure 40, lower values of oxygen influx favor a higher yield of hydrogen while there is no discernible formation of carbon monoxide. The yields of water vapor are not proportionate to the net hydrogen production rate, which can be attributed to the absence of required oxygen to form water vapor. As the values of oxygen influx increase, the yield of hydrogen reduces with a notable increase in the yield of water vapor. Therefore, the impact of increasing oxygen influx is evident at identical process temperatures.

The lowest hydrogen yield concurrently identifies with the highest yield of water vapor. This argument alone does not bear standing for the higher yields of carbon dioxide, as both oxygen and water vapor aid the oxidation of carbon monoxide. Therefore, the trend for the generation of carbon monoxide is not a reliable indicator for the yield of carbon dioxide.

\begin{tabular}{|c|c|c|}
\hline Designa & Name & State \\
\hline 19 & Design 19 & $\checkmark$ \\
\hline 20 & Design 20 & $\checkmark$ \\
\hline 21 & Design 21 & $\checkmark$ \\
\hline 10 & Design 10 & $\checkmark$ \\
\hline 11 & Design 11 & $\checkmark$ \\
\hline 12 & Design 12 & $\checkmark$ \\
\hline 22 & Design 22 & $\checkmark$ \\
\hline 14 & Design 14 & $\checkmark$ \\
\hline 1 & Design 1 & $\checkmark$ \\
\hline 23 & Design 23 & $\checkmark$ \\
\hline 13 & Design 13 & $\checkmark$ \\
\hline 2 & Design 2 & $\checkmark$ \\
\hline 24 & Design 24 & $\checkmark$ \\
\hline 3 & Design 3 & $\checkmark$ \\
\hline 25 & Design 25 & $\checkmark$ \\
\hline 15 & Design 15 & $\checkmark$ \\
\hline 4 & Design 4 & $\checkmark$ \\
\hline 26 & Design 26 & $\checkmark$ \\
\hline 16 & Design 16 & $\checkmark$ \\
\hline 5 & Design 5 & $\checkmark$ \\
\hline 27 & Design 27 & $\checkmark$ \\
\hline 17 & Design 17 & $\checkmark$ \\
\hline 6 & Design 6 & $\checkmark$ \\
\hline 7 & Design 7 & $\checkmark$ \\
\hline 18 & Design 18 & $\checkmark$ \\
\hline 8 & Design 8 & $\checkmark$ \\
\hline 9 & Design 9 & $\checkmark$ \\
\hline & & \\
\hline
\end{tabular}

Figure 40. High-oxygen sweep: yields of species sorted by decreasing yield of hydrogen.

This study favors lower temperature and lower values of oxygen influx to retain hydrogen from oxidation to water vapor. It is suggested that lower values of oxygen influx may be explored to retain the yield of carbon monoxide from converting to carbon dioxide through oxidation by oxygen and water vapor. A graphical summary of this conclusion may be inferred by the trends illustrated in Figure 41 . 


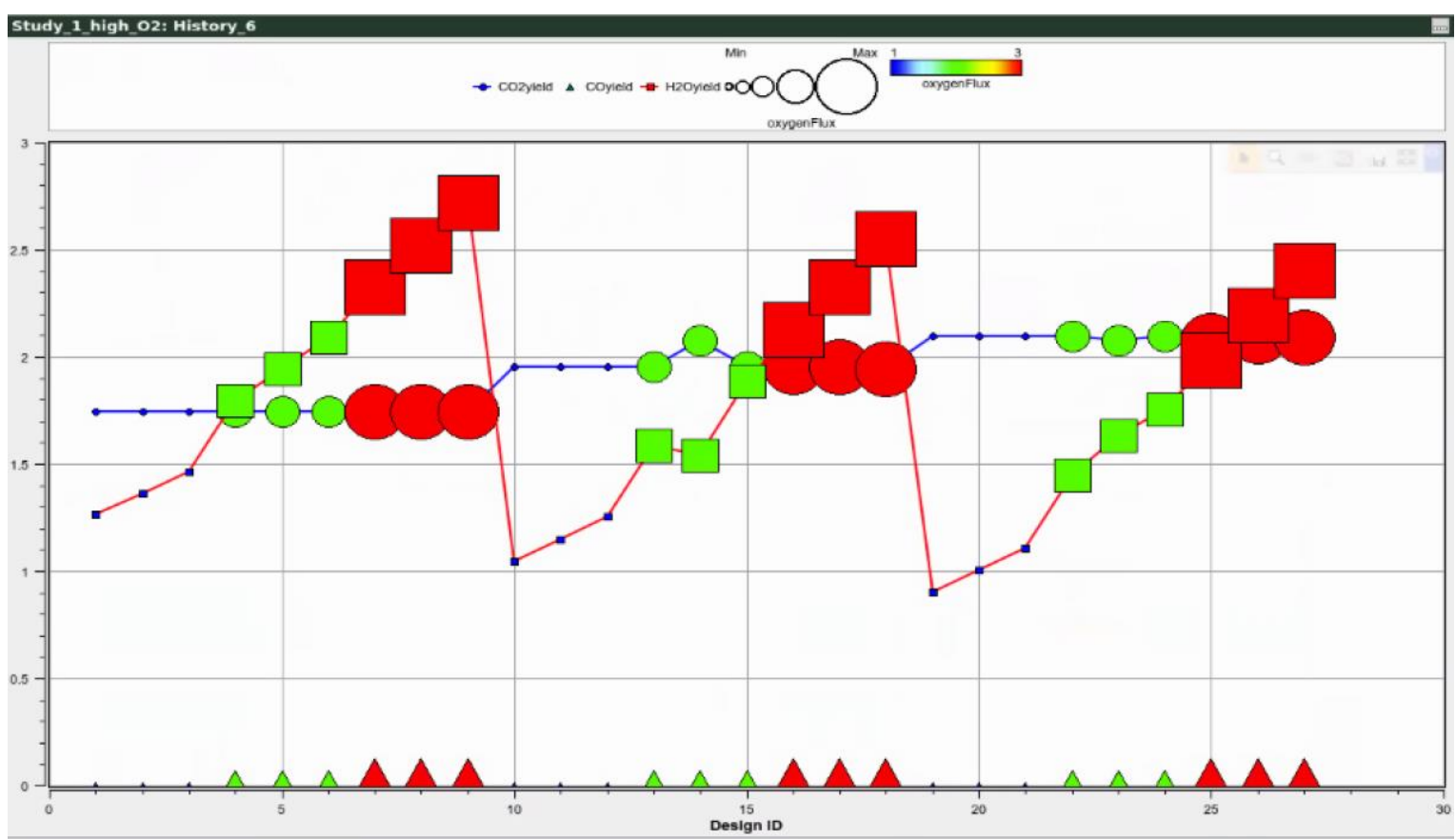

Figure 41. High-oxygen sweep: trends of yield dependency on species.

\subsubsection{Process Optimization: FOx Tubes with Low Oxygen Content}

In this scenario, the influx of oxygen is set to a proportionate factor of 10 lower than the high-oxygen content. Figure 42 summarizes the yield profile for the low-oxygen content sweep. In this case, hydrogen yield is favored at higher temperatures, unlike the high-oxygen content sweep. The lack of stoichiometric oxygen, thus, manifest in yields of water vapor less than 1. Since oxygen is critical to the yield of carbon dioxide and water vapor, oxygen deficiency favors the limited conversion of carbon monoxide to carbon dioxide. Figure 43 further summarizes the trends of dependency for a favorable yield of hydrogen.

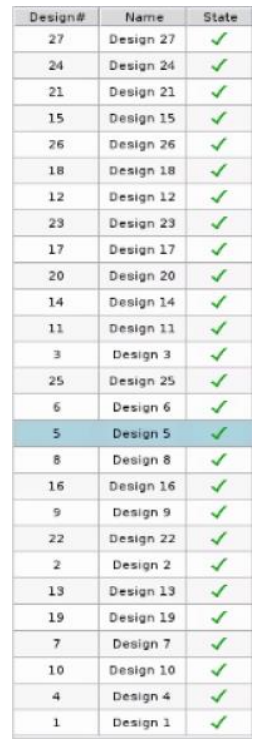

Figure 42. Low-oxygen sweep: yields of species sorted by decreasing yield of hydrogen. 


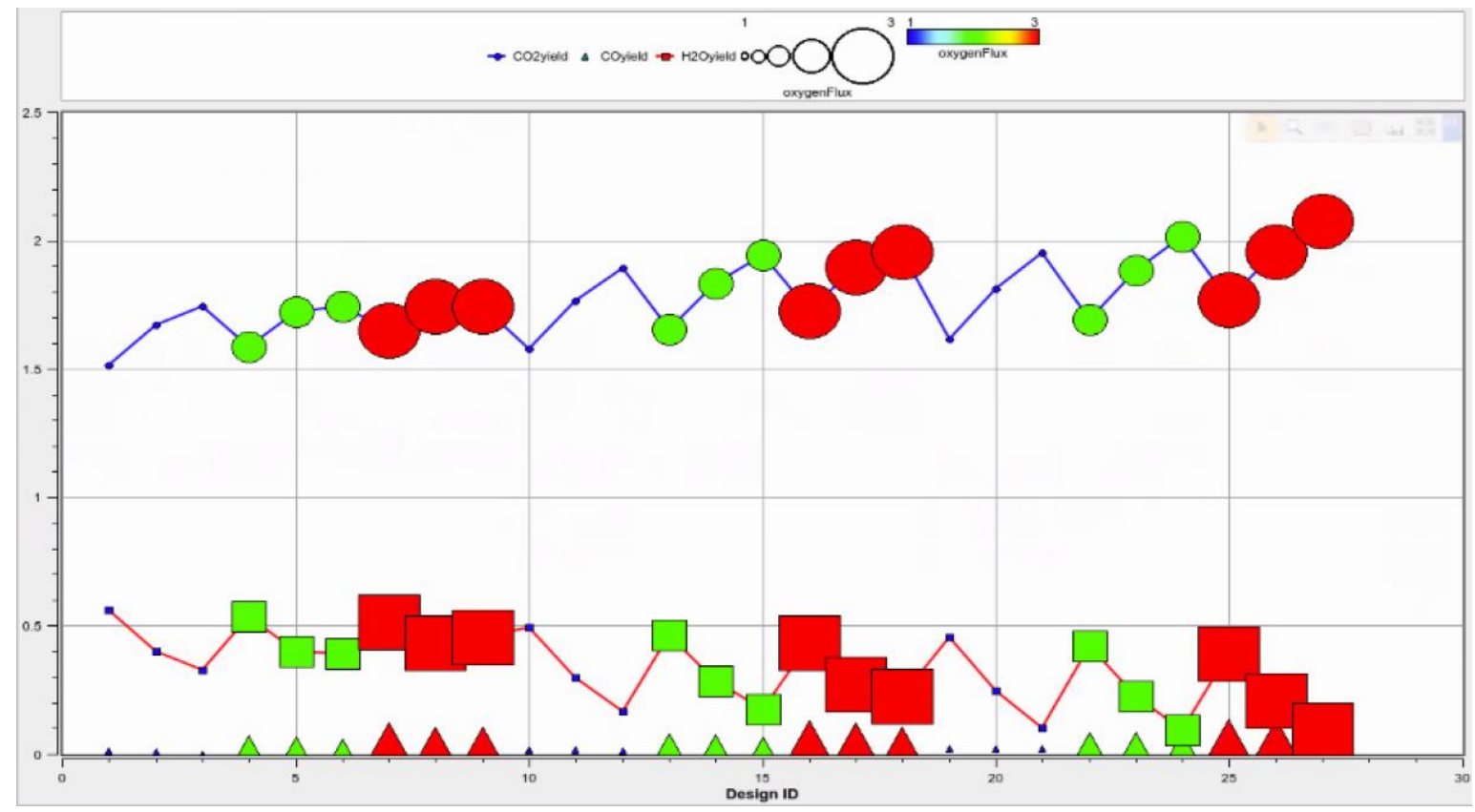

Figure 43. Low-oxygen sweep: trends of yield dependency on species.

\subsubsection{Conclusions}

A summary of all sweep scenarios is plotted in Figure 44. It is recommended that influx values of oxygen be retained at a minimum bounding limit to generate a steady yield for the FOx tube. Additionally, a minimum percentage mass fraction of methane in the partially reformed syngas is recommended for favorable hydrogen yields in achieving the complete conversion of methane to syngas.

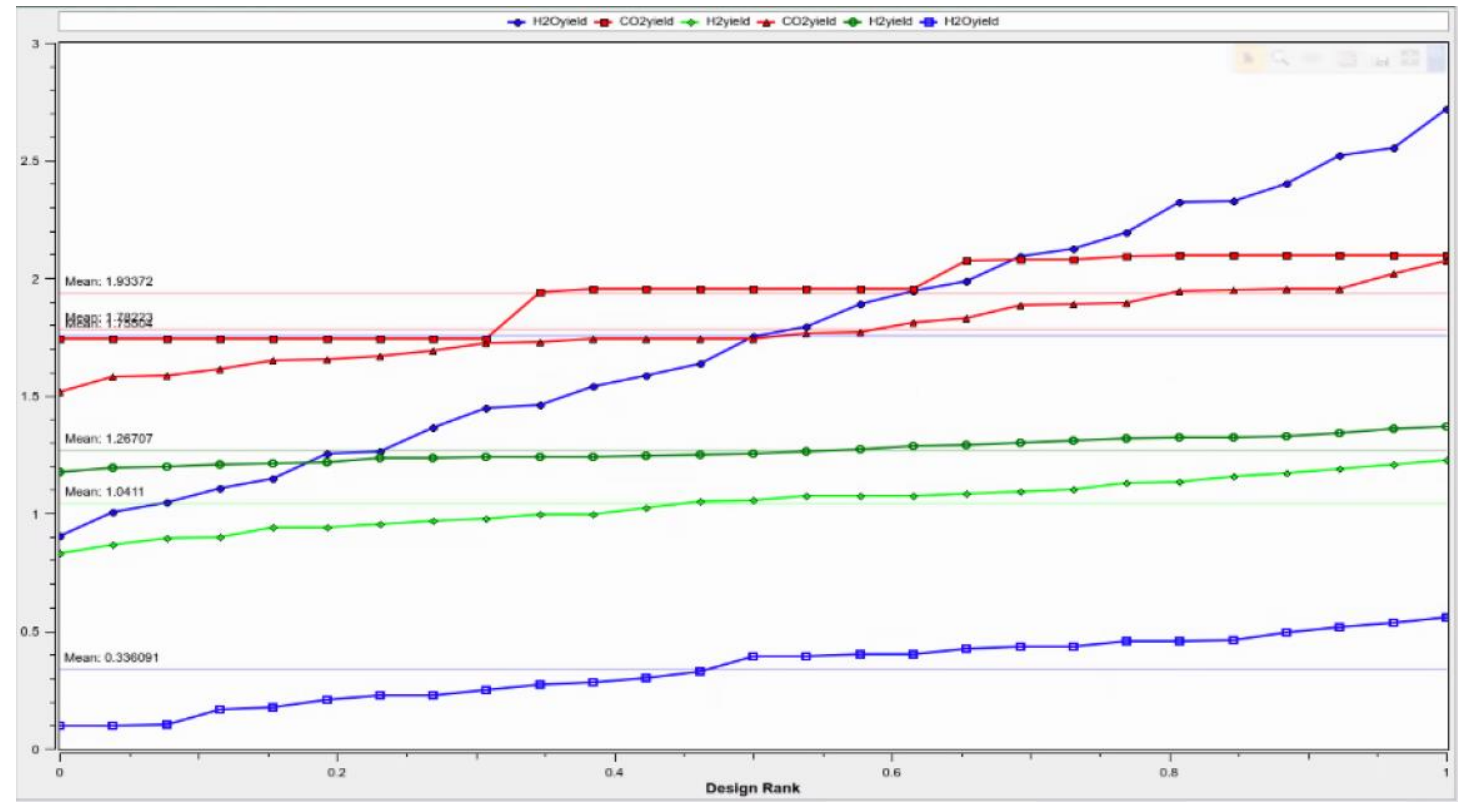

Figure 44. A summary of yield by species for all parametric designs. 
4. SUBJECT INVENTIONS

None. 


\section{COMMERCIALIZATION POSSIBILITIES}

None. 


\section{PLANS FOR FUTURE COLLABORATION}

Throughout this project, several areas of potential collaboration and future research were identified, as follows:

- Device-scale modeling using first-principles, high-fidelity physics on HPC systems

- Evaluate new operating conditions, or process parameters, to reduce the device's carbon footprint,

- Carbon-conscious process optimization,

- Computational screening for various carbon-reduction measures (e.g., new catalysts, sorbents, membranes, etc.),

- Reduce technical risks of deploying innovative retrofittable technologies,

- Accelerate technology maturation, or readiness levels,

- Understand prototype scale up for a real system.

- Multi-scale optimization of complex interacting systems

- Hybrid energy systems,

- Process intensification to increase efficiency and reduce waste.

\subsection{NEEDS AND CHALLENGES}

The priority to minimize carbon and greenhouse gas emissions will require an extension of the current tools with new models and methods to allow systems of extreme efficiency and low emissions. The challenges in developing new computational technologies are to ensure that these tools and methods are tailored to meet the needs of the various industries. This will require effective, close collaboration among those with technology (industry, national laboratories, software vendors, and others) and those with resources (industry and the federal government). Access to cost-effective, high-performance computing systems, software, and database architectures is vital in fulfilling the benefits of parallel and distributed computing.

CFD simulation platforms will need to constantly be updated with emerging advances in physical models and property databases and provide a readily adaptable architecture. For example, in the chemical industry, advancement in CFD will depend on the continuous improvement of tools for more complex systems such as high-temperature gas-phase systems, multiphase mixing, polymer processing, nonNewtonian rheology, dense multiphase turbulent flow (with or without chemical reaction), and crystallization with particle nucleation and growth.

Software tools are needed that bring together a complete modeling environment, or Digital Twin, including simulation, parameter estimation from experimental data, optimization, graphical representation of results, and statistical measures of uncertainty.

Some of the specific requirements that can be met in this area include the development of:

- simulation tools that integrate combinatorial optimization and ways to deal with uncertainty in simulation and optimization, such as sensitivity analysis and deterministic modeling,

- whole-site business production models that move beyond individual plant modeling, and

- more robust fundamental models that are broadly applicable and reduce empiricism.

Large-scale integration of intelligent systems needs to be incorporated into the guidance of operations, with more significant advances in Artificial Intelligence (AI) for scientists and engineers, to move to everincreasing scales and scopes. Accomplishing this will require: 
- an information infrastructure that permits data to be shared regardless of geographical location with sufficient safeguards to protect proprietary information,

- a knowledge representation that is independent of the software system or inference engine that uses that knowledge, and

- cost-effective combinations of heuristic inference, discrete-event simulation, real-time optimization, dynamic simulation, and computational modeling in single, real-time, online advisory systems.

In general, the application of constantly improving computational technologies enables efficiency increases that lead to the reduction of emissions, with:

- shortened product-process development cycles,

- optimization of existing processes to improve energy efficiency, and

- the efficient design of new products and processes.

\subsection{OPPORTUNITIES}

Process modeling and optimization will be an integral part of the development and implementation cycle, from the early stages of research through process operations. CFD tools will be widely used to guide experimental optimization and scale-up. Advisory systems employing AI technologies will play a significant role in integrating and managing the entire enterprise, including business systems, process flow sheets, unit operations, and computational simulations.

Coupling process science and engineering with the basic sciences will ensure the rapid development, design, scale-up, control, and optimization of existing and new processes for safely manufacturing chemicals and the products made from them, as well as their disassembly, recycling, and reuse. A successful accomplishment of these advances will be marked by widely available, user-friendly modeling environments that are comprehensive, cohesive, well supported, and affordable. Such environments will provide tools that couple:

- multi-physics with fluid dynamics,

- modeling with experimentation,

- process models with business models, and

- structures with material properties.

Well-maintained national databases and high-speed networks will make it easy to share results and avoid duplication. Success will be marked by widely available, cost-effective, user-friendly open-source and commercial software for implementing advisory systems that can provide operational support for an entire enterprise, including system/machine/plant operations, supply and distribution chains, and business decisions.

Support and further development are essential for the upcoming GPU-based computing platforms, which require major advances in support tools for system operation and programming; parallel GPU numerical algorithms and template applications; and fully developed, optimized and supported end-user applications. Additionally, an increased support is required for experimental validation of (or challenges to) computational results. The technology would benefit significantly from a large-coordinated program combining theoretical and computational methods with experimental programs designed from the beginning to challenge those methods.

Public-private partnerships should continue to be encouraged to leverage the expertise from the industry, national laboratories, and AI software companies for expanding the role of modeling and simulation in improving our manufacturing, process, energy, and carbon efficiencies. 


\section{REFERENCES}

Abanades, S., Charvin, P., Lemont, F., and Flamant, G. (2008). "Novel Two-Step $\mathrm{SnO}_{2} / \mathrm{SnO}$ WaterSplitting Cycle for Solar Thermochemical Production of Hydrogen," International Journal of Hydrogen Energy 33(21): 6021-6030.

Aiello, R., Fiscus, J. E., Zur Loye, H.-C., and Amiridis, M. D. (2000). "Hydrogen Production via the Direct Cracking of Methane over $\mathrm{Ni} / \mathrm{SiO}_{2}$ : Catalyst Deactivation and Regeneration," Applied Catalysis A: General 192(2): 227-234.

Akikusa, J., and Khan, S. U. (2002). "Photoelectrolysis of Water to Hydrogen in p-SiC/Pt and p-SiC/n$\mathrm{TiO}_{2}$ Cells," International Journal of Hydrogen Energy 27(9): 863-870.

Anderson, L. L., Armstrong, P. A., Broekhuis, R. R., Carolan, M. F., Chen, J., Hutcheon, M. D., Lewinsohn, C. A., Miller, C. F., Repasky, J. M., Taylor, D. M., et al. (2016). "Advances in Ion Transport Membrane Technology for Oxygen and Syngas Production," Solid State Ionics 288: 331337.

Andres, M.-B., Boyd, T., Grace, J. R., Lim, C. J., Gulamhusein, A., Wan, B., Kurokawa, H., and Shirasaki, Y. (2011). "In-situ $\mathrm{CO}_{2}$ Capture in a Pilot-Scale Fluidized-Bed Membrane Reformer for Ultra-Pure Hydrogen Production," International Journal of Hydrogen Energy 36(6): 4038-4055.

Balat, H., and Kirtay, E. (2010). "Hydrogen from Biomass-Present Scenario and Future Prospects," International Journal of Hydrogen Energy 35(14): 7416-7426.

Balat, M., and Balat, M. (2009). "Political, Economic and Environmental Impacts of Biomass-Based Hydrogen,” International Journal of Hydrogen Energy 34(9): 3589-3603.

Bamberger, C., and Richardson, D. (1976). "Hydrogen Production from Water by Thermochemical Cycles," Cryogenics 16(4): 197-208.

Barbosa, M. J., Rocha, J. M., Tramper, J., and Wijffels, R. H. (2001). "Acetate as a Carbon Source for Hydrogen Production by Photosynthetic Bacteria," Journal of Biotechnology 85(1): 25-33.

Barelli, L., Bidini, G., Gallorini, F., and Servili, S. (2008). "Hydrogen Production through SorptionEnhanced Steam Methane Reforming and Membrane Technology: a Review," Energy 33(4): 554570 .

Basile, A., Campanari, S., Manzolini, G., Iulianelli, A., Longo, T., Liguori, S., De Falco, M., and Piemonte, V. (2011). "Methane Steam Reforming in a Pd-Ag Membrane Reformer: an Experimental Study on Reaction Pressure Influence at Middle Temperature," International Journal of Hydrogen Energy 36(2): 1531-1539.

Beebe Jr, T. P., Goodman, D. W., Kay, B. D., and Yates Jr, J. T. (1987). "Kinetics of the Activated Dissociative Adsorption of Methane on the Low Index Planes of Nickel Single Crystal Surfaces," The Journal of Chemical Physics 87(4): 2305-2315.

Berndes, G., Hoogwijk, M., and Van den Broek, R. (2003). "The Contribution of Biomass in the Future Global Energy Supply: a Review of 17 Studies," Biomass and Bioenergy 25(1): 1-28.

Bhavsar, S., and Veser, G. (2014). "Chemical Looping beyond Combustion: Production of Synthesis Gas via Chemical Looping Partial Oxidation of Methane," RSC Advances 4(88): 47254-47267.

Blok, K. (2005). "Enhanced Policies for the Improvement of Electricity Efficiencies," Energy Policy 33(13): 1635-1641.

Boeltken, T., Wunsch, A., Gietzelt, T., Pfeifer, P., and Dittmeyer, R. (2014). "Ultra-Compact Microstructured Methane Steam Reformer with Integrated Palladium Membrane for On-Site 
Production of Pure Hydrogen: Experimental Demonstration," International Journal of Hydrogen Energy 39(31): 18058-18068.

Bonaquist, D., Chen, J., Chen, H., Corpus, J., Drnevich, R., Prasad, R., Raybold, T., Shreiber, E., Sirman, J., Spero, J., et al. (2004). "Oxygen Transport Membranes for Future IGCC Power Plants," Proceedings of 21 st Annual Pittsburgh Coal Conference, September 13-17, 2004, Osaka, Japan, Edited by Badie Morsi. International Pittsburgh Coal Conference, University ..., pp. 1-8.

Brown, L. C., Besenbruch, G. E., Lentsch, R., Schultz, K. R., Funk, J., Pickard, P., Marshall, A., and Showalter, S. (2003). High Efficiency Generation of Hydrogen Fuels Using Nuclear Power, Technical report, GA-A24285, General Atomics (US).

Chen, L., Zhang, Y., Wang, H., Wang, Y., Li, D., and Duan, C. (2018). "Cobalt Layered Double Hydroxides Derived $\mathrm{CoP} / \mathrm{Co}_{2} \mathrm{P}$ Hybrids for Electrocatalytic Overall Water Splitting," Nanoscale 10(45): 21019-21024.

Chen, M.-q., Wang, J., Zhang, M.-x., Chen, M.-g., Zhu, X.-f., Min, F.-f., and Tan, Z.-c. (2008). "Catalytic Effects of Eight Inorganic Additives on Pyrolysis of Pine Wood Sawdust by Microwave Heating," Journal of Analytical and Applied Pyrolysis 82(1): 145-150.

Chen, Z., Grace, J. R., Lim, C. J., and Li, A. (2007). "Experimental Studies of Pure Hydrogen Production in a Commercialized Fluidized-Bed Membrane Reactor with SMR and ATR Catalysts," International Journal of Hydrogen Energy 32(13): 2359-2366.

Chihaia, V., Sohlberg, K., Dan, M., Mihet, M., Biris, A. R., Marginean, P., Almasan, V., Borodi, G., Watanabe, F., Biris, A. S., et al. (2012). "Supported Nickel Catalysts for Low Temperature Methane Steam Reforming: Comparison between Metal Additives and Support Modification," Reaction Kinetics, Mechanisms and Catalysis 105(1): 173-193.

Chikazawa, Y., Nakagiri, T., Konomura, M., Uchida, S., and Tsuchiyama, Y. (2006). “A System Design Study of a Fast Breeder Reactor Hydrogen Production Plant Using Thermochemical and Electrolytic Hybrid Process," Nuclear Technology 155(3): 340-349.

COMSOL Multiphysics, COMSOL User's Guide, Version 5.6, 2021. [Online]. Available: https://doc.comsol.com/5.6/docserver/\#!/com.comsol.help.comsol/helpdesk/helpdesk.html.

Conte, M., Iacobazzi, A., Ronchetti, M., and Vellone, R. (2001). "Hydrogen Economy for a Sustainable Development: State-of-the-Art and Technological Perspectives," Journal of Power Sources 100(1-2): 171-187.

Das, D., and Veziroglu, T. N. (2008). "Advances in Biological Hydrogen Production Processes," International Journal of Hydrogen Energy 33(21): 6046-6057.

Das, D., and Veziroglu, T. N. (2001). "Hydrogen Production by Biological Processes: a Survey of Literature," International Journal of Hydrogen Energy 26(1): 13-28.

De Falco, M., Marrelli, L., and Iaquaniello, G. (2011). Membrane Reactors for Hydrogen Production Processes, Springer, London.

Dell, R. M., and Rand, D. A. J. (2001). "Energy Storage - A Key Technology for Global Energy Sustainability," Journal of Power Sources 100(1-2): 2-17.

Demirbas, A. (2001a). "Biomass Resource Facilities and Biomass Conversion Processing for Fuels and Chemicals," Energy Conversion and Management 42(11): 1357-1378.

Demirbas, A. (2001b). "Yields of Hydrogen-Rich Gaseous Products via Pyrolysis from Selected Biomass Samples," Fuel 80(13): 1885-1891. 
Demirbas, A. (2002). "Gaseous Products from Biomass by Pyrolysis and Gasification: Effects of Catalyst on Hydrogen Yield," Energy Conversion and Management 43(7): 897-909.

Demirbas, A. (2004). "Hydrogen-Rich Gas from Fruit Shells via Supercritical Water Extraction," International Journal of Hydrogen Energy 29(12): 1237-1243.

Demirbas, M. F. (2006). "Technological Options for Producing Hydrogen from Renewable Resources," Energy Sources, Part A: Recovery, Utilization, and Environmental Effects 28(13): 1215-1223.

Dincer, I., and Balta, M. T. (2011). "Potential Thermochemical and Hybrid Cycles for Nuclear-Based Hydrogen Production," International Journal of Energy Research 35(2): 123-137.

Dittmar, B., Behrens, A., Schödel, N., Rüttinger, M., Franco, T., Straczewski, G., and Dittmeyer, R. (2013). "Methane Steam Reforming Operation and Thermal Stability of New Porous Metal Supported Tubular Palladium Composite Membranes," International Journal of Hydrogen Energy 38(21): 8759-8771.

D’Jesús, P., Boukis, N., Kraushaar-Czarnetzki, B., and Dinjus, E. (2006a). "Gasification of Corn and Clover Grass in Supercritical Water," Fuel 85(7-8): 1032-1038.

D’Jesús, P., Boukis, N., Kraushaar-Czarnetzki, B., and Dinjus, E. (2006b). "Influence of Process Variables on Gasification of Corn Silage in Supercritical Water," Industrial \& Engineering Chemistry Research 45(5): 1622-1630.

DOE. (2020). Hydrogen Strategy: Enabling a Low-Carbon Economy, Technical report, Office of Fossil Energy.

Elbadawi, A. H., Ge, L., Li, Z., Liu, S., Wang, S., and Zhu, Z. (2021). "Catalytic Partial Oxidation of Methane to Syngas: Review of Perovskite Catalysts and Membrane Reactors," Catalysis Reviews 63(1): 1-67.

Elder, R. and Allen, R. (2009). Nuclear heat for hydrogen production: Coupling a very high/high temperature reactor to a hydrogen production plant, Progress in Nuclear Energy 51(3): 500-525.

Eroglu, E., Gündüz, U., Yücel, M., Türker, L., and Eroglu, I. (2004). "Photobiological Hydrogen Production by Using Olive Mill Wastewater as a Sole Substrate Source," International Journal of Hydrogen Energy 29(2): 163-171.

Ersöz, A. (2008). "Investigation of Hydrocarbon Reforming Processes for Micro-Cogeneration Systems," International Journal of Hydrogen Energy 33(23): 7084-7094.

Evans, R., Boyd, L., Elam, C., Czernik, S., French, R., Feik, C., Philips, S., Chaornet, E., and Parent, Y. (2003). "Hydrogen from Biomass-Catalytic Reforming of Pyrolysis Vapors," US DOE Hydrogen, Fuel Cells \& Infrastructure Technologies Program-2003 Annual Merit Review Meeting.

Fang, H. H., Liu, H., and Zhang, T. (2005). "Phototrophic Hydrogen Production from Acetate and Butyrate in Wastewater," International Journal of Hydrogen Energy 30(7): 785-793.

Fidalgo, B., and Menéndez, J. (2012). "Study of Energy Consumption in a Laboratory Pilot Plant for the Microwave-Assisted $\mathrm{CO}_{2}$ Reforming of $\mathrm{CH}_{4}$," Fuel Processing Technology 95: 55-61.

Florin, L., Tsokoglou, A., and Happe, T. (2001). "A Novel Type of Iron Hydrogenase in the Green Algascenedesmus Obliquus is Linked to the Photosynthetic Electron Transport Chain," Journal of Biological Chemistry 276(9): 6125-6132.

Forsberg, C. (2005). "Futures for Hydrogen Produced Using Nuclear Energy," Progress in Nuclear Energy 47(1-4): 484-495. 
Forsberg, C. W., Peterson, P. F., and Pickard, P. S. (2003). "Molten-Salt-Cooled Advanced HighTemperature Reactor for Production of Hydrogen and Electricity," Nuclear Technology 144(3): 289302.

Funk, J. E. (2001). "Thermochemical Hydrogen Production: Past and Present," International Journal of Hydrogen Energy 26(3): 185-190.

García-García, F., Rahman, M., Kingsbury, B., and Li, K. (2010). "A Novel Catalytic Membrane Microreactor for COx free $\mathrm{H}_{2}$ Production," Catalysis Communications 12(3): 161-164.

Gaudernack, B., and Lynum, S. (1998). "Hydrogen from Natural Gas without Release of $\mathrm{CO}_{2}$ to the Atmosphere," International Journal of Hydrogen Energy 23(12): 1087-1093.

Gholipour, M. R., Dinh, C.-T., Béland, F., and Do, T.-O. (2015). "Nanocomposite Heterojunctions as Sunlight-Driven Photocatalysts for Hydrogen Production from Water Splitting," Nanoscale 7(18): 8187-8208.

Ghoneim, S. A., El-Salamony, R. A., El-Temtamy, S. A., et al. (2016). "Review on Innovative Catalytic Reforming of Natural Gas to Syngas," World Journal of Engineering and Technology 4(01): 116.

Giaconia, A., Grena, R., Lanchi, M., Liberatore, R., and Tarquini, P. (2007). "Hydrogen/Methanol Production by Sulfur-Iodine Thermochemical Cycle Powered by Combined Solar/Fossil Energy," International Journal of Hydrogen Energy 32(4): 469-481.

Gil, A., Wu, Z., Chadwick, D., and Li, K. (2012). "Novel Catalytic Membrane Micro-Reactors for $\mathrm{CO}_{2}$ Capture via pre-Combustion Decarbonization Route," Procedia Engineering 44: 1315-1316.

Guan, C., Xiao, W., Wu, H., Liu, X., Zang, W., Zhang, H., Ding, J., Feng, Y. P., Pennycook, S. J., and Wang, J. (2018). "Hollow Mo-doped CoP Nanoarrays for Efficient Overall Water Splitting," Nano Energy 48: 73-80.

Guan, Y., Deng, M., Yu, X., and Zhang, W. (2004). Two-Stage Photo-Biological Production of Hydrogen by Marine Green Alga Platymonas Subcordiformis," Biochemical Engineering Journal 19(1): 6973.

Gupta, S., Mahapatra, M. K., and Singh, P. (2015). Lanthanum Chromite Based Perovskites for Oxygen Transport Membrane," Materials Science and Engineering: R: Reports 90: 1-36.

Hadjipaschalis, I., Poullikkas, A., and Efthimiou, V. (2009). "Overview of Current and Future Energy Storage Technologies for Electric Power Applications," Renewable and Sustainable Energy Reviews 13(6-7): 1513-1522.

Hahn, J. J. (2006). Hydrogen Production From Biomass, Ph.D. thesis, University of Missouri-Columbia.

Hall, P. J., and Bain, E. J. (2008). "Energy-Storage Technologies and Electricity Generation," Energy Policy 36(12): 4352-4355.

Hao, X., Guo, L., Mao, X., Zhang, X., and Chen, X. (2003). Hydrogen Production from Glucose Used as a Model Compound of Biomass Gasified in Supercritical Water," International Journal of Hydrogen Energy 28(1): 55-64.

He, D., Bultel, Y., Magnin, J.-P., Roux, C., and Willison, J. C. (2005). "Hydrogen Photosynthesis by Rhodobacter Capsulatus and its Coupling to a PEM Fuel Cell," Journal of Power Sources 141(1): $19-23$.

Holladay, J. D., Hu, J., King, D. L., and Wang, Y. (2009). “An Overview of Hydrogen Production Technologies," Catalysis Today 139(4): 244-260. 
Homsi, D., Aouad, S., Gennequin, C., Aboukaïs, A., and Abi-Aad, E. (2014). "A Highly Reactive and Stable $\mathrm{Ru} / \mathrm{Co}_{6-\mathrm{x}} \mathrm{Mg}_{\mathrm{x}} \mathrm{Al}_{2}$ Catalyst for Hydrogen Production via Methane Steam Reforming," International Journal of Hydrogen Energy 39(19): 10101-10107.

Huang, Z., Ohashi, H, and Inagaki, Y., Thermal and Chemical Analysis of Carbon Dioxide Reforming of Methane Using the Out-of-Pile Test Facility, Japan Atomic Energy Research Institute, Tokyo, 2000.Hwang, K.-R., Lee, C.-B., Ryi, S.-K., Lee, S.-W., and Park, J.-S. (2012). “A Multi-Membrane Reformer for the Direct Production of Hydrogen via a Steam-Reforming Reaction of Methane," International Journal of Hydrogen Energy 37(8): 6601-6607.

Inagaki, Y., Ohashi, H., Inaba, Y., Sato, H., Nishihara, T., Takeda, T., Hayashi, K., and Ogawa, M. (2007). "Research and Development on System Integration Technology for Connection of Hydrogen Production System to an HTGR," Nuclear Technology 157(2): 111-119.

Iulianelli, A., Liguori, S., Wilcox, J., and Basile, A. (2016). "Advances on Methane Steam Reforming to Produce Hydrogen through Membrane Reactors Technology: A Review," Catalysis Reviews 58(1): $1-35$.

Iulianelli, A., Manzolini, G., De Falco, M., Campanari, S., Longo, T., Liguori, S., and Basile, A. (2010). $\mathrm{H}_{2}$ Production by Low Pressure Methane Steam Reforming in a Pd-Ag Membrane Reactor over a Ni-Based Catalyst: Experimental and Modeling," International Journal of Hydrogen Energy 35(20): $11514-11524$.

Kang, D., Lee, M., Lim, H. S., and Lee, J. W. (2018). "Chemical Looping Partial Oxidation of Methane with $\mathrm{CO}_{2}$ Utilization on the Ceria-Enhanced Mesoporous $\mathrm{Fe}_{2} \mathrm{O}_{3}$ Oxygen Carrier," Fuel 215: 787 798.

Kapdan, I. K., and Kargi, F. (2006). "Bio-Hydrogen Production from Waste Materials," Enzyme and Microbial Technology 38(5): 569-582.

Kim, M.-S., Baek, J.-S., and Lee, J. K. (2006). "Comparison of $\mathrm{H}_{2}$ Accumulation by Rhodobacter Sphaeroides KD131 and its Uptake Hydrogenase and PHB Synthase Deficient Mutant," International Journal of Hydrogen Energy 31(1): 121-127.

Kolb, G. J., Diver, R. B., and Siegel, N. (2006). "Central-Station Solar Hydrogen Power Plant,” Journal of Solar Energy Engineering 129(2): 179-183.

Kothari, R., Buddhi, D., and Sawhney, R. (2008). "Comparison of Environmental and Economic Aspects of Various Hydrogen Production Methods," Renewable and Sustainable Energy Reviews 12(2): 553563.

Kubo, S., Kasahara, S., Okuda, H., Terada, A., Tanaka, N., Inaba, Y., Ohashi, H., Inagaki, Y., Onuki, K. and Hino, R. (2004). A pilot test plan of the thermochemical water-splitting iodine-sulfur process, Nuclear Engineering and Design 233(1-3): 355-362.

Lam, S. S., Russell, A. D., Lee, C. L., and Chase, H. A. (2012). "Microwave-Heated Pyrolysis of Waste Automotive Engine Oil: Influence of Operation Parameters on the Yield, Composition, and Fuel Properties of Pyrolysis Oil," Fuel 92(1): 327-339.

Lattner, J. R., and Harold, M. P. (2004). "Comparison of Conventional and Membrane Reactor Fuel Processors for Hydrocarbon-Based PEM Fuel Cell Systems," International Journal of Hydrogen Energy 29(4): 393-417.

Le Duigou, A., Borgard, J.-M., Larousse, B., Doizi, D., Allen, R., Ewan, B. C., Priestman, G. H., Elder, R., Devonshire, R., Ramos, V., et al. (2007). "HYTHEC: an EC Funded Search for a Long Term Massive Hydrogen Production Route Using Solar and Nuclear Technologies," International Journal of Hydrogen Energy 32(10-11): 1516-1529. 
Levene, J. I., Mann, M. K., Margolis, R. M., and Milbrandt, A. (2007). “An Analysis of Hydrogen Production from Renewable Electricity Sources,” Solar Energy 81(6): 773-780.

Li, J. "OTM Combined Reformer for IGCC Power Systems," 10 April 2018. [Online]. Available: https://netl.doe.gov/sites/default/files/netl-file/20180410_1330G_FE0023543_PRAXAIR.pdf. [Accessed 25 October 2021].

Li, J. "Praxair's Oxygen Transport Membrane Technology for Syngas and Power Applications," 10 August 2015. [Online]. Available: https://netl.doe.gov/sites/default/files/2017-11/Gasification-andC-CBTL-Conference-OTM-Presentation-2015.pdf. [Accessed 25 October 2021].

Lin, Y., Pan, Y., Liu, S., Sun, K., Cheng, Y., Liu, M., Wang, Z., Li, X., and Zhang, J. (2019). "Construction of Multi-Dimensional Core/Shell Ni/NiCoP Nano-Heterojunction for Efficient Electrocatalytic Water Splitting,” Applied Catalysis B: Environmental 259: 118039.

Lior, N. (2002). "Thoughts about Future Power Generation Systems and the Role of Exergy Analysis in Their Development," Energy Conversion and Management 43(9-12): 1187-1198.

Liu, H.-1., Nosheen, F., and Wang, X. (2015). "Noble Metal Alloy Complex Nanostructures: Controllable Synthesis and Their Electrochemical Property," Chemical Society Reviews 44(10): 3056-3078.

Liu, S., Zhu, J., Chen, M., Xin, W., Yang, Z., and Kong, L. (2014). "Hydrogen Production via Catalytic Pyrolysis of Biomass in a Two-Stage Fixed Bed Reactor System," International Journal of Hydrogen Energy 39(25): 13128-13135.

Lu, Y., Guo, L., Ji, C., Zhang, X., Hao, X., and Yan, Q. (2006). "Hydrogen Production by Biomass Gasification in Supercritical Water: A Parametric Study," International Journal of Hydrogen Energy 31(7): 822-831.

Lund, H. (2007). "Renewable Energy Strategies for Sustainable Development," Energy 32(6): 912-919.

Maeda, I., Miyasaka, H., Umeda, F., Kawase, M., and Yagi, K. (2003). "Maximization of Hydrogen Production Ability in High-Density Suspension of Rhodovulum Sulfidophilum Cells Using Intracellular Poly (3-Hydroxybutyrate) as Sole Substrate," Biotechnology and Bioengineering 81(4): 474-481.

Mahecha-Botero, A., Boyd, T., Gulamhusein, A., Comyn, N., Lim, C. J., Grace, J. R., Shirasaki, Y., and Yasuda, I. (2008). "Pure Hydrogen Generation in a Fluidized-Bed Membrane Reactor: Experimental Findings," Chemical Engineering Science 63(10): 2752-2762.

Masin, J. G., Lewis, M. A., and Vilim, R. (2006). "Development of the Low Temperature Hybrid Cu-Cl Thermochemical Cycle, AIChE Annual Meeting, Conference Proceedings, Cincinnati, OH, United States, Vol. 30.

Mathias, P. M., Brown, L. C. et al. (2003). Thermodynamics of the sulfur-iodine cycle for thermochemical hydrogen production, 68th Annual Meeting of the Society of Chemical Engineers, Japan, Vol. 23.

Mavroides, J. G. (1978). "Electrode Materials for the Photoelectrolysis of Water," Materials Research Bulletin 13(12): 1379-1388.

Mei, D., Glezakou, V.-A., Lebarbier, V., Kovarik, L., Wan, H., Albrecht, K. O., Gerber, M., Rousseau, R., and Dagle, R. A. (2014). "Highly Active and Stable $\mathrm{MgAl}_{2} \mathrm{O}_{4}-\mathrm{Supported} \mathrm{Rh}$ and Ir Catalysts for Methane Steam Reforming: A Combined Experimental and Theoretical Study," Journal of Catalysis 316: 11-23.

Mejdell, A., Jøndahl, M., Peters, T., Bredesen, R., and Venvik, H. (2009). "Experimental Investigation of a Microchannel Membrane Configuration with a $1.4 \mu \mathrm{m}$ Pd/Ag 23 wt.\% Membrane-Effects of Flow and Pressure," Journal of Membrane Science 327(1-2): 6-10. 
Melis, A. (2002). "Green Alga Hydrogen Production: Progress, Challenges, and Prospects," International Journal of Hydrogen Energy 27(11): 1217-1228.

Momirlan, M., and Veziroglu, T. (2002). "Current Status of Hydrogen Energy," Renewable and Sustainable Energy Reviews 6(1-2): 141-179.

Momirlan, M., and Veziroglu, T. N. (2005). "The Properties of Hydrogen as Fuel Tomorrow in Sustainable Energy System for a Cleaner Planet,” International Journal of Hydrogen Energy 30(7): 795-802.

Muradov, N. (1993). "How to Produce Hydrogen from Fossil Fuels without $\mathrm{CO}_{2}$ Emission," International Journal of Hydrogen Energy 18(3): 211-215.

Muradov, N. (2001). "Hydrogen via Methane Decomposition: an Application for Decarbonization of Fossil Fuels,” International Journal of Hydrogen Energy 26(11): 1165-1175.

Muradov, N., and Veziroglu, T. (2005). "From Hydrocarbon to Hydrogen-Carbon to Hydrogen Economy," International Journal of Hydrogen Energy 30(3): 225-237.

Muradov, N. Z. (1998). " $\mathrm{CO}_{2}$-Free Production of Hydrogen by Catalytic Pyrolysis of Hydrocarbon Fuel," Energy \& Fuels 12(1): 41-48.

Naterer, G., Suppiah, S., Lewis, M., Gabriel, K., Dincer, I., Rosen, M. A., Fowler, M., Rizvi, G., Easton, E., Ikeda, B., et al. (2009). "Recent Canadian Advances in Nuclear-Based Hydrogen Production and the Thermochemical Cu-Cl Cycle," International Journal of Hydrogen Energy 34(7): 2901-2917.

Naterer, G., Suppiah, S., Stolberg, L., Lewis, M., Ferrandon, M., Wang, Z., Dincer, I., Gabriel, K., Rosen, M., Secnik, E., et al. (2011). "Clean Hydrogen Production with the $\mathrm{Cu}-\mathrm{Cl}$ Cycle-Progress of International Consortium, II: Simulations, Thermochemical Data, and Materials," International Journal of Hydrogen Energy 36(24): 15486-15501.

Nelson, P. F., Flores, A., and Francois, J. L. (2007). “A Design-Phase PSA of a Nuclear-Powered Hydrogen Plant," Nuclear Engineering and Design 237(3): 219-229.

Nieva, M. A., Villaverde, M. M., Monzón, A., Garetto, T. F., and Marchi, A. J. (2014). "Steam-Methane Reforming at Low Temperature on Nickel-Based Catalysts," Chemical Engineering Journal 235: $158-166$.

Nikolaidis, P., and Poullikkas, A. (2017). "A Comparative Overview of Hydrogen Production Processes," Renewable and Sustainable Energy Reviews 67: 597-611.

Nipattummakul, N., Ahmed, I. I., Gupta, A. K., and Kerdsuwan, S. (2011). "Hydrogen and Syngas Yield from Residual Branches of Oil Palm Tree Using Steam Gasification," International Journal of Hydrogen Energy 36(6): 3835-3843.

Nishihara, T., and Inagaki, Y. (2006). "Development of Control Technology for the HTTR Hydrogen Production System," Nuclear Technology 153(1): 100-106.

Onuki, K., Inagaki, Y., Hino, R., and Tachibana, Y. (2005). "Research and Development on Nuclear Hydrogen Production Using HTGR at JAERI," Progress in Nuclear Energy 47(1-4): 496-503.

Orhan, M. F., Dincer, I., and Rosen, M. A. (2008). "Energy and Exergy Assessments of the Hydrogen Production Step of a Copper-Chlorine Thermochemical Water Splitting Cycle Driven by NuclearBased Heat," International Journal of Hydrogen Energy 33(22): 6456-6466.

Pen, M., Gomez, J., Fierro, J. G., et al. (1996). "New Catalytic Routes for Syngas and Hydrogen Production," Applied Catalysis A: General 144(1-2): 7-57.

Pickard, P., Gelbard, F., Andazola, J. and Naranjo, G. (2008). Sulfur-iodine thermochemical cycle, 


\section{Technical report.}

Poirier, M., and Sapundzhiev, C. (1997). "Catalytic Decomposition of Natural Gas to Hydrogen for Fuel Cell Applications,” International Journal of Hydrogen Energy 22(4): 429-433.

Ponomarev-Stepnoi, N. (2004). "Nuclear-Hydrogen Power," Atomic Energy 96(6): 375-385.

Praxair, "Praxair's Modular Syngas Generator,” 21-23 October 2014. [Online]. Available: http://www.energyfrontiers.org/EFI/files/ccLibraryFiles/Filename/000000001646/EFI_2014-

3_Praxair_Chakravarti.pdf. [Accessed 25 October 2021].

Ratlamwala, T., and Dincer, I. (2015). "Comparative Energy and Exergy Analyses of Two Solar-Based Integrated Hydrogen Production Systems," International Journal of Hydrogen Energy 40(24): 75687578 .

Rennard, D. C., Kruger, J. S., and Schmidt, L. D. (2009). "Autothermal Catalytic Partial Oxidation of Glycerol to Syngas and to Non-Equilibrium Products," ChemSusChem: Chemistry \& Sustainability Energy \& Materials 2(1): 89-98.

Rossmeisl, J., Logadottir, A., and Nørskov, J. K. (2005). "Electrolysis of Water on (Oxidized) Metal Surfaces," Chemical Physics 319(1-3): 178-184.

Roy, P. S., Park, N.-K., and Kim, K. (2014). "Metal Foam-Supported Pd-Rh Catalyst for Steam Methane Reforming and Its Application to SOFC Fuel Processing," International Journal of Hydrogen Energy 39(9): 4299-4310.

Saric, M., van Delft, Y. C., Sumbharaju, R., Meyer, D. F., and de Groot, A. (2012). "Steam Reforming of Methane in a Bench-Scale Membrane Reactor at Realistic Working Conditions," Catalysis Today 193(1): 74-80.

Schicks, J., Neumann, D., Specht, U., and Veser, G. (2003). "Nanoengineered Catalysts for HighTemperature Methane Partial Oxidation," Catalysis Today 81(2): 287-296.

Schultz, K. R. (2003). Use of the Modular Helium Reactor for Hydrogen Production, Technical report, GENERAL ATOMICS (US).

Schwartz, J., Lim, H., and Drnevich, R. (2010). Integrated Ceramic Membrane System for Hydrogen Production, Technical report, Praxair, Inc., Tonawanda, NY.

Shi, X.-Y., and Yu, H.-Q. (2005). "Response Surface Analysis on the Effect of Cell Concentration and Light Intensity on Hydrogen Production by Rhodopseudomonas Capsulata," Process Biochemistry 40(7): 2475-2481.

Siemens 2021. STAR-CCM+ User Guide.

Steinberg, M. (1999). "Fossil Fuel Decarbonization Technology for Mitigating Global Warming," International Journal of Hydrogen Energy 24(8): 771-777.

Steinberg, M., and Cheng, H. C. (1989). "Modern and Prospective Technologies for Hydrogen Production from Fossil Fuels," International Journal of Hydrogen Energy 14(11): 797-820.

Steinfeld, A. (2005). "Solar Thermochemical Production of Hydrogen - a Review," Solar Energy 78(5): 603-615.

Sun, H., Min, Y., Yang, W., Lian, Y., Lin, L., Feng, K., Deng, Z., Chen, M., Zhong, J., Xu, L., et al., (2019). "Morphological and Electronic Tuning of $\mathrm{Ni}_{2} \mathrm{P}$ through Iron Doping toward Highly Efficient Water Splitting," ACS Catalysis 9(10): 8882-8892. 
Sundkvist, S. G., Julsrud, S., Vigeland, B., Naas, T., Budd, M., Leistner, H., and Winkler, D. (2007). "Development and Testing of AZEP Reactor Components," International Journal of Greenhouse Gas Control 1(2): 180-187.

Trimm, D. L. (1997). “Coke Formation and Minimisation during Steam Reforming Reactions," Catalysis Today 37(3): 233-238.

Ueno, Y., Kurano, N., and Miyachi, S. (1999). "Purification and Characterization of Hydrogenase from the Marine Green Alga, Chlorococcum Littorale," FEBS letters 443(2): 144-148.

Wang, Z., He, T., Qin, J., Wu, J., Li, J., Zi, Z., Liu, G., Wu, J., and Sun, L. (2015). "Gasification of Biomass with Oxygen-Enriched Air in a Pilot Scale Two-Stage Gasifier," Fuel 150: 386-393.

Wang, Z., Li, Z., Cui, Y., Chen, T., Hu, J., and Kawi, S. (2019). "Highly Efficient No Decomposition via Dual-Functional Catalytic Perovskite Hollow Fiber Membrane Reactor Coupled with Partial Oxidation of Methane at Medium-Low Temperature," Environmental Science \& Technology 53(16): 9937-9946.

Williams, P. T., and Onwudili, J. (2006). "Subcritical and Supercritical Water Gasification of Cellulose, Starch, Glucose, and Biomass Waste,” Energy \& Fuels 20(3): 1259-1265.

Winkler, M., Heil, B., Heil, B., and Happe, T. (2002). "Isolation and Molecular Characterization of the [Fe]-Hydrogenase from the Unicellular Green Alga Chlorella Fusca," Biochimica et Biophysica Acta (BBA)-Gene Structure and Expression 1576(3): 330-334.

Wood, R. (2010). Sensitivity of Hydrogen Production via Steam Methane Reforming to High Temperature Gas-Cooled Reactor Outlet Temperature Process Analysis, Technical report, INL/TEV-961.

Wu, X., and Onuki, K. (2005). “Thermochemical Water Splitting for Hydrogen Production Utilizing Nuclear Heat from an HTGR," Tsinghua Science and Technology 10(2): 270-276.

Xu, X., and Antal Jr, M. J. (1998). "Gasification of Sewage Sludge and other Biomass for Hydrogen Production in Supercritical Water," Environmental Progress 17(4): 215-220.

Yang, N.-T., Kathiraser, Y., and Kawi, S. (2013). " $\mathrm{La}_{0.6} \mathrm{Sr}_{0.4} \mathrm{Co}_{08} \mathrm{Ni}_{02} \mathrm{O}_{3-\delta}$ Hollow Fiber Membrane Reactor: Integrated Oxygen Separation- $\mathrm{CO}_{2}$ Reforming of Methane Reaction for Hydrogen Production," International Journal of Hydrogen Energy 38(11): 4483-4491.

Yang, W., Wang, H., Zhu, X., and Lin, L. (2005). "Development and Application of Oxygen Permeable Membrane in Selective Oxidation of Light Alkanes," Topics in Catalysis 35(1-2): 155-167.

Yao, Y., Jin, Z., Chen, Y., Gao, Z., Yan, J., Liu, H., Wang, J., Li, Y., and Liu, S. F. (2018). "Graphdiyne$\mathrm{WS}_{2}$ 2D-Nanohybrid Electrocatalysts for High-Performance Hydrogen Evolution Reaction," Carbon 129: 228-235.

Yin, C. 2011. Advanced Modeling of Oxy-Fuel Combustion of Natural Gas. ForskEL 2009-1-0256. Department of Energy Technology, Aalborg University.

You, B., and Sun, Y. (2018). "Innovative Strategies for Electrocatalytic Water Splitting," Accounts of Chemical Research 51(7): 1571-1580.

Yu, H., Xue, Y., Hui, L., Zhang, C., Zhao, Y., Li, Z., and Li, Y. (2018). "Controlled Growth of $\mathrm{MoS}_{2}$ Nanosheets on 2D N-Doped Graphdiyne Nanolayers for Highly Associated Effects on Water Reduction," Advanced Functional Materials 28(19): 1707564.

Zamfirescu, C., Dincer, I., and Naterer, G. (2010). "Thermophysical Properties of Copper Compounds in Copper-Chlorine Thermochemical Water Splitting Cycles," International Journal of Hydrogen Energy 35(10): 4839-4852. 
Zhang, J., He, T., Wang, Z., Zhu, M., Zhang, K., Li, B., and Wu, J. (2017). "The Search of Proper Oxygen Carriers for Chemical Looping Partial Oxidation of Carbon," Applied Energy 190: 11191125.

Zhang, L., Xu, C. C., and Champagne, P. (2010). "Overview of Recent Advances in Thermo-Chemical Conversion of Biomass," Energy Conversion and Management 51(5): 969-982.

Zhao, B., Zhang, X., Sun, L., Meng, G., Chen, L., and Xiaolu, Y. (2010). "Hydrogen Production from Biomass Combining Pyrolysis and the Secondary Decomposition," International Journal of Hydrogen Energy 35(7): 2606-2611.

Zheng, J., Wu, K., Lyu, C., Pan, X., Zhang, X., Zhu, Y., Wang, A., Lau, W.-M., and Wang, N. (2020). "Electrocatalyst of Two-Dimensional Cop Nanosheets Embedded by Carbon Nanoparticles for Hydrogen Generation and Urea Oxidation in Alkaline Solution," Applied Surface Science 506: 144977.

Zhou, H., Liang, W., Liang, F., and Jiang, H. (2019). "Simultaneous Production of Synthesis Gases $\mathrm{H}_{2} / \mathrm{N}_{2}$ and $\mathrm{H}_{2} / \mathrm{CO}$ in a Dual-Phase Mixed Conducting Membrane Reactor," Catalysis Today 331: 2-6. 